This report was prepared as an accoumt of

A. Makes any warranty, nor any person acting on behalf of racy, completeness, or usy or representation, expressed or implied, wission:

pet a liformation, apparatus me

B. owned rights; or or or press disclosed in this repor, or that the use

B. Assumes any liablitios with report may not infringe

As any information, apparatus, method, to the use of, or for damages resulting irom

As used in the above. "person acting on behalf disclosed in thises report.

ployee or contractor of the commissiong on behalf of the comralssion" includes any

disch employee or contractor of the cion, or employee of such contractor, to the exty em-

with the Cos, or provides access to, ans intolon, or employee of such contractor prent that

with the Commission, or his employment with such pursuant to his employment prepares,

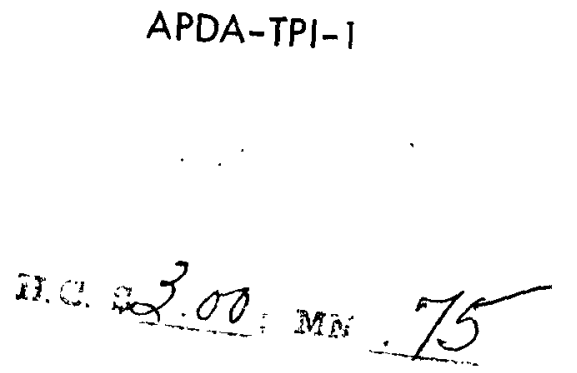

\title{
FACILITIES, CAPABILITIES, AND EXPERIENCE IN LIQUID METALS AND FAST REACTOR RESEARCH AND DEVELOPMENT
}

Division of Reactor Development and Technology AEC Contract No. AT (11-1) -865, Project Agreement No. 16 \section{FIRST STREET, DETROIT, MICHIGAN 48226}


IIST OF ILIUSTRATIONS. .............. v. vii

INTRODUCTION ....................... ix

HISTORICAI BACKGROUND. ............ ix

ORGANIZATION .................

PERSONNEL ................... $\mathrm{x}$

I. REACTOR PHYSICS, SAFETY, AND SHIELDING. . . . . I. 1

A. GENERAI ................... I. 1

B. PHYSICS ...................... I. 1

1. Fast Reactor Projects ............ I. 1

a. Enrico Fermi Atomic Power Plant. ...... . I. 1

b. Mixed Oxide Fuel Studics. . . . . . . . I. 2

c. Piped Particulate Fuel Systems for Fast . . . . . . . . . I. 2

d. Fast Reactor Core Design Parameter Study. . I. 3

e. 1000-Mwe Fast Reactor Study ........ I. 3

f. Fast Reactor Fuel Testing ......... I. 3

2. Computer Facilities and Programs ....... I. 4

a. Facilities............. I. 4

b. Programs. ............. I. 4

3. Publications ................. I. 6

4. Over-all Physics Capabilities ......... I. 8

a. Conceptual Design Studies - Fast Reactors . . I. 8

b. Code Development........... I. I.

c. Experimental Capability ......... I. 9

5. Critical Assembly Facilities. . . . . . . I I. 9

6. Facilities for Evaluation of Dynamic Nuclear Characteristics. ............ I. 9

7. Nuclear Tests Performed in the Enrico Fermi Atomic Power Plant ............ I. 9 
C. REACTOR SAFETY. ............. I. . 11

1. Fast Reactor Projects............. I. 11

a. Enrico Fermi Atomic Power Plant........ I. 11

b. Other Safety Studies............ I. 11

2. Thermal Reactor Safety. ........... I. 12

3. Reactor Safeguards Reports ........... I. 12

4. Computer Programs............. I. 13

5. Summary of Capabilities ............ I. 14

D. REACTOR SHIEI DING. .............. I. 14

1. Enrico Fermi Atomic Power Plant........ I. 14

a. Materials and Design ........... I. 14

b. Shield Test Program ........... I. 15

2. Other Shielding Work ............ I. 16

3. Computer Programs............. I. 16

4. Publications ................ I. 17

5. Over-All Shielding Capabilities......... I. 17

II. REACTOR COMPONENTS ................ II. 1

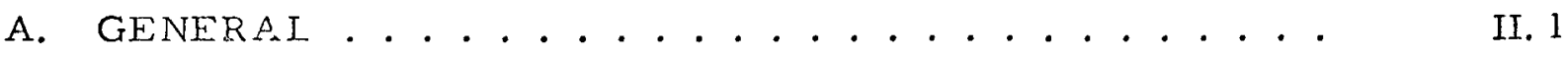

B. REACTOR COMPONENTS............ II. 2

1. Valves................. II. 2

2. Seals and Joints.............. II. 2

a. Materials for Gas Seals. . . . . . . . II. 2

b. Mechanical Seal for Rotating Shield Plug. . . . . II. 2

c. Bellows Seals .............. II. 3

d. Buffered Seals. . . . . . . . . . . II. 3

e. Floating Ring Seals ............ II. 3

f. Oil Seals................. II. 3

g. Metallic O-Rings ............. II. 3

h. Proprietary Seals and Joints . . . . . . . II. 4

i. Freeze Seal Plugs. . . . . . . . . . II. 4

3. Fuel Exit Port (Reactor Tube Nozzles). . . . . . II. 4

4. Piping ................. Ir. 5 
5. Vessel and Piping Heaters. . . . . . . . II. 5

6. Insulation. . . . . . . . . . . . . II. 5

7. Submerged Drives and Guides . . . . . . . . II. 5

a. Offset Handling Mechanism ......... II. 6

b. Rotating Shield Plug. . . . . . . . . II. 6

c. Hold-Down Mechanism ......... II. 6

d. Safetgr and Control Rod Drives. . . . . . II. 6

e. Sweep Mechanism ............ II. 7

f. Oscillator Rod and Drive. . . . . . . . II. 7

g. Transfer Rotor Mechanism . . ..... II. 8

h. Special Equipment............. II. 8

8. Pumps................. I. . . 9

a. General ............... II. 9

b. Seals................. II. 10

c. Bearings............... II. 11

9. Intermediate Heat Exchangers. . . . . . . . II. 11

10. Steam Generators ............... II. 11

c. PUblications ................... II. 12

III. INSTRUMENTATION . . . . . . . . . . . . . . . III. 1

A. FACIIITIES. . . . . . . . . . . . . . III. 1

1. The APDA Sodium Technology Loop. . . . . . . III. 1

2. Hydraulics - Water Systems . . . . . . . III. 1

3. Under Sodium Scanner Test Apparatus . . . . . III. 1

B. ACHIEVEMENTS ................ III. 1

1. Under Sodium Scanner. . . . . . . . . . III. 1

2. Sodium Level Detectors . . . . . . . . . III. 2

C. SPECIAL CAPABILITIES. . . . . . . . . . . III. 2

1. Fission Product Monitoring......... III. 2 


\section{TABIE OF CONTENTS (CONT'D)}

2. Pressure and Vibration Monitoring. . . . . . . . .

3. Reactor Control Room Instrumentation . . . . . . . .

III. 3

4. Nondestructive Testing . . . . . . . . . . . III. 4

D. RESEARCH AND DEVELOPMENT PROGRAMS . . . . III. 5

1. Under Sodium Scanner, AEC Contract No. AT(1 l-1)-865, Project Agreement No. 14 . . . . . III. 5

2. Sodium Technology Loop, AEC Contract No. AT(11-1)-865, Project Agreement No. 11....... III. 5

E. PUBIICATIONS . . . . . . . . . . . . . . . III. 6

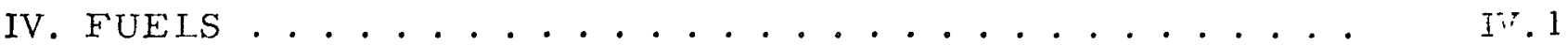

A. FUEL PROGRAMS. ............... IV. 1

1. Core A. ..................... IV. 1

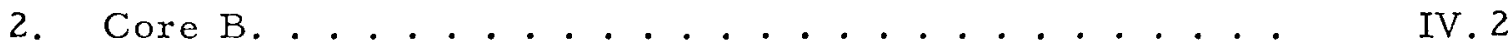

3. Plutonium Fuel Studies............. IV. 2

4. Fuel Cycle Studies .............. IV. 3

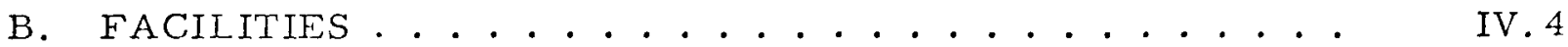

1. Hydraulic-Water Systems. . . . . . . . . . IV. 4

a. Four-Inch Hydraulic Test Ioop . . . . . . . IV. 4

b. Simulant Mobile Fucl Loops . . . . . . . . . IV. 5

2. High-Temperature Sodium Ioop ......... IV. 5

3. Sodium Endurance Loop. . . . . . . . . . IV. 5

4. Fuel Pin Meltdown Equipment . . . . . . . . IV.6

C. MAJOR CONTRIBUTIONS AND PUBIICATIONS . . . . . IV. 6

V. IIQUID METALS . . . . . . . . . . . . . . V. I

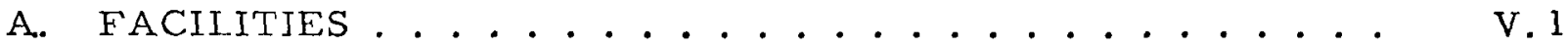

1. Hydraulic-Water Systems. . . . . . . . . . . . V. 1

2. High-Temperature Sodium Loop .......... V. I

3. Sodium Endurance Loop. ............. . . . 2 


\section{TABIE OF CONTENTS (CONT'D)}

Page

4. Fuel Pin Meltdown Equipment. ............

5. Sodium Technology Loop ............. . V. 2

6. Sodium-Water Reaction Test, Rig-10........ V. 2

7. Sodium-Water Reaction Test, Rig-33......... . V. 3

8. Under Sodium Scanner Test Apparatus ......... V. 4

9. Hydrogen Detector Test Loop. ........... V.4

10. Oil-Fired Heater ................ V. 4

11. NaK Heater-Cooler Unit ............. V. 5

12. Chemistry Iaboratory. ............. V. 5

13. Radiochemistry Laboratory............. . V.7

B. GENERAI EXPER IENCE . . . . . . . . . . . . V V.7

C. PROGRAMS AND ACCOMPIISHMENTS. . . . . . . V.8

1. Endurance and Hydraulic Testing. . . . . . . . . V.8

2. Paste Concept for Fast Reactor Blanket Application, AEC Contract No. AT(11-1)-865, Project Agreement No. 8...................

3. Fast Reactor Fuel Meltdown Studies, AEC Contract

No. AT(11-1)-865, Project Agreement No. 5, Task 1. .

4. Sodium Technology Loop Program, AEC Contract Nc. AT(11-1)-865, Project Agreement No. 11.....

5. Small Ieak Sodium-Water Reaction, AEC Contract No. AT(1 -1)-865, Project Agreement No. 10. .... V. 10

6. Under Sodium Scanner, AEC Contract No. AT(11-1)865, Project Agreement No. 14........... V. 10

7. Sodium-Heated Steam Generator Development . . . . . V.11

8. APDA Reactor Components Test........... V.11

9. Sodium Ioss Test................. V. 11

10. Safety Analysis Capability and Experience ....... V. 12

D. PUBLICATIONS ................... . . . . . 12 


\section{LIST OF ILLUSTRATIONS}

Figure

Page

II-1 APDA Seal Test Fixture for Fermi Reactor Plug Seal . .

II. 14

II-2 External View of APDA Bearing Test Rig . . . . . . . .

II. 15

II-3 APDA Prototype Shaft Seal Tester for Fermi 12, $000 \mathrm{gpm}$

Liquid-Metal Pump . . . . . . . . . . . . . . .

II-4 External View of the Prototype Shaft Seal Tester for

Fermi 12,000 gpm Liquid-Metal Pump . . . . . . . .

II-5 Preliminary Shaft Seal Test................

II-6 Steam Generator. Test . . . . . . . . . . . .

II-7 Sodium-Water Reaction Test Pit . . . . . . . . . .

II. 20

III-1 Under Sodium Scanner ..................

III-2 Fission Product Monitor . . . . . . . . . . . . .

\section{7}

III-3 Fission Product Detector Monitoring System . . . . . .

III-4 Schematic of Probe Installation for Checking Sodium

Pressure and Pressure Surges . . . . . . . . . . III. 10

IV $-1 \quad$ Nonfissionable Materials Subassembly . . . . . . . . . IV.7

IV-2 Standard Fuel Test Subassembly . . . . . . . . . IV.8

IV -3 Close-up of 4-Inch Hydraulic Test Loops . . . . . . . IV.9

IV-4 Switching Panel for Hydraulic Test Loop . . . . . . . . IV. 10

V-1 Plot Plan of Facilities at APDA Test Site . ........ V.14

V-2 Sodium Technology Building .............. V. 15

V-3 High-Bay Building ................. . . V.16

V-4 Chemistry and Radioactive Laboratory . . . . . . . . V. 17 


\section{LIST OF ILLUSTRATIONS (Continued)}

V-5 High-Temperature Sodium Loop.............. . V.18

V-6 Sodium Endurance Loop ............... . . V. 19

V-7 Sodium Technology Loop ............... V.20

V-8 Schematic of Sodium Technology Loop. . . . . . . . . V.21

V-9 101-Foot Support Structure for Sodium-Water Reaction

Test, Rig-10.................... V. 22

V-10 Reactor Vessel, Rig 10............... . . . . 23

V-11 Schematic of Sodium-Water Reaction Test, Rig-10.... . V.24

V-12 Sodium-Water Reaction Test, Rig-33.......... . V. 25

V-13 Schematic of Sodium-Water Reaction Test, Rig-33.... . V.26 


\section{INTRODUCTION}

HISTORICAI BACKGROUND

Atomic Power Development Associates, Inc. (APDA), a nonprofit membership corporation organized in 1955 under New York law, operates exclusively for scientific and educational purposes. The membership is made up of a group of United States industries having the primary objective of developing atomic power into a commercially practicable means of electric power generation.

APDA is the successor to the Dow Chemical-Detroit Edison Study Group, which was formed in 1950 as a part of the United States Atomic Energy Commission's Industrial Participation Program to study the practicability of using atomic power for industrial purposes. This early study indicated that a liquid metal-cooled fast breeder reactor had the most attractive potential for industrial purposes. Subsequently, APDA evolved a conceptual design of such a reactor-electric plant having an output of $100 \mathrm{Mw}$ of electricity, the heat being obtained from the fast breeder reactor rated at $300 \mathrm{Mv}$ of heat. This conceptual design was the bas is for a proposal for the development of a fast breeder reactor under the USAEC's " Power Demonstration Reactor Program, submitted on March 31, 1955, to the Commission by The Detroit Edison Company on behalf of a group of investor-owned electric systems, all of which were members of APDA.

With the acceptance of this proposal by the AEC on August 8, 1955, APDA concentrated on the development of the plant, which was named the Enrico Fermi Atomic Power Plant. A second company, Power Reactor Development Company (PRDC), was formed to construct and operate the plant, while APDA assumed the primary responsibility for designing and developing the reactor-steam portion of the plant.

The research, design, and developmental work performed by APDA was broad and comprehensive, including (1) reactor physics and related calculations; (2) development of fuel, shielding, and reactor materials; (3) design of fuel elements; (4) development and design of the reactor, heat transport system, and other related system components.

These activities were followed by extensive nonnuclear preoperational testing of the reactor, associated mechanisms, and heat transport system of the Fermi plant. More recently, APDA has been responsible for the lowpower nuclear testing of the reactor and is now guiding the approach to fullpower operation. 


\section{ORGANIZATION}

APDA is managed by a Board of Directors and by an Executive Committee that is empowered to act for the Board under specified conditions. Members of the Board and the Executive Committee are, in general, officers of the member companies. Reporting to them are the Economics, Finance, Technical and Engineering, and Nominating Committees, all of which are similarly composed of executives from the member companies. A Patent Review Committee, which also reports to the Executive Committee, is composed primarily of APDA staff personnel and former APDA staff personnel. The responsibility for day-to-day management of the Project is vested in the Vice President and General Manager.

Although they are not considered to be a part of the APDA staff, members of the Technical and Engineering Committee continually contribute significantly to all phases of APDA technical programs. The varied skills of these engineers, who are key personnel in their home companies, are called on liberally by APDA. In a similar manner, the skills of the members of the Economics Committee are used in various economic studies and analyses.

APDA is organized on a functional basis. Direct responsibility for major portions of the work is delegated to personnel within the various groups so that each person participates of the fullest extent of his abilities in. important segments of the work done in his group.

\section{PERSONNEI}

APDA's staff of scientists and engineers is experienced in all phases of nuclear power development. The capabilities of the staff range from those needed for the development of conceptual designs and performance of economic studies to those required for rescarch and development work leading to the design and fabrication of components and to those necessary for the erection, testing, and operation of a nuclear power plant.

Many scientific and engineering disciplines are represented at APDA by personnel with bachelors and advanced degrees in physics, mathematics, and chemistry; civil, mechanical, metallurgical, nuclear, industrial, aeronautical, chemical, and electrical engineering; engineering administration; and industrial management.

A recent survey showed that APDA's technical personnel have an average of approximately 14 years of experience in nuclear power development or closely related fields, and an average of more than 5 years of experience with APDA in the development of the Enrico Fermi reactor, and in the conceptual design and research and development of advanced solidand mobile-fueled reactor concepts. 


\section{REACTOR PHYSICS, SAFETY, AND SHIE LDING}

\section{A. GENERAI}

APDA physicists have had extensive experience in all phases of fast reactor physics, including steady-state reactor design, reactor transient analysis, fast reactor safety, and basic methods development. This experience includes, also, shielding design and analysis, health physics, and reactor system control design and analysis. APDA physicists have planned, helped to carry out, and analyzed the results of Core $A^{*}$ critical experiment in the Zero Power Reactor III (ZPR-III). Further, they have planned and assisted in the conducting of the Core $B^{* *}$ critical experiment, have planned Transient Test Reactor Facility (TREAT) experiments for evaluation of Core A safety, and are highly competent in making complex calculations with digital and analog computers. In addition, they have planned, conducted, and evaluated the low-power nuclear testing of Core $A$ and are currently conducting and evaluating the high-power nuclear testing of Core A, also planned by them. Specific areas of A.PDA experience are covered below.

\section{B. PHYSICS}

\section{Fast Reactor Projects}

\section{a. Enrico Fermi Atomic Power Plant}

APDA physicists have been responsible for determining the nuclear characteristics of Core A and Core B for the Enrico Fermi reactor. This work has involved many analyses and studies including calculations of critical mass, breeding ratio, neutron balance, and power distribution; estimations of the effect of changes in geometry and composition on these characteristics; conceptual design of the control system; evaluation of temperature and power coefficients; analysis of kinetic reactor behavior; evaluations of the effects of burnup on reactivity and on power distribution; and determinalions of control and safety rod worths.

APDA physicists also designed, carried out, and analyzed the results of the critical experiments for Core A and Core B. In addition, reactor physicists have designed, supervised, and evaluated the results of the low-pover ( $1 \mathrm{Mwt}$ ) nuclear test carried out after the reactor reached criticality; they also prepared the nuclear test procedures for approach to full-power operation and are supervising and evaluating the results of these

\footnotetext{
${ }^{*}$ Core A consisting of U-10 w/o Mo pin-type fuel elements with U-3 w/o axial blanket rods for the initial core loading of the Fermi reactor.

${ }^{* *}$ A proposed Core $\mathrm{B}$ consisting of $\mathrm{UO}_{2}$-SS cermet plate-type fuel elements with $\mathrm{UO}_{2}$ axial blanket rods for the Fermi reactor.
} 
tests. Test results obtained in Fermi reactor operations have been quite successful in confirming the predicted nuclear characteristics of the reactor. The test procedures developed in this effort are listed in Item 7 below.

Of great theoretical and practical interest to those concerned with fast reactor physics and safety is the natural phenomenon called the Doppler effect, on which APDA and its consultants did much of the pioneering analyses. A study by two of our consultants in 1954 was one of the first to estimate the magnitude and significance of this effect in fast reactors. The fact that this phenomenon may be useful as an ultimate safety feature in some types of large fast reactors with a high proportion of fertile material was evolved from work done by APDA in the late 1950's. This appreciation of the Doppler effect in cores of this type is having an important influence on several major AEC-supported programs. Another interesting item (which is having a substantial effect on the Commission's programs) resulting from physics studies is the prediction of the possibility of a positive sodium temperature coefficient in large fast reactor cores.

Basic reactor kinetic and safety studies have been made in depth; the dynamic safety and stability of the fast reactor have been investigated by analog simulation, digital techniques and by analytical methods. This work has resulted in the development of several studies in reactor kinetics that have acquired world-wide recognition: (1) fast reactor stability criteria, (2) dynamic temperature representation, and (3) a method of representing fission product decay heat during shutdown transients.

\section{b. Mixed-Oside Fuel Studies}

In 1958-60, APDA and five member companies undertook an evaluation of the performance capabilities and economics of a $150-$ Mwe and a 300 -Mwe sccond-generation plutonium-fueled fast brceder reactor employing a $\mathrm{PuO}_{2}-\mathrm{UO}_{2}$ core. Again, APDA physicists determined the nuclear char acteristics of these concepts. APDA is working on the development of mixedoxide fuels in a continuation of work over the years and in 1965 developed a program for the design and development of a $\mathrm{PuO}_{2}-\mathrm{UO}_{2}$ core for demonstration in a large fast reactor. Basic physics characteristics of both a uniform core and a zoned core were evaluated in comparison to each other and to Fermi Core A.

\section{c. Piped Particulate Fuel Systems for Fast Reactors}

Since 1963, APDA has been performing, at the request of the AEC, studies of a settled-bed, mobile (paste)concept for fast reactor blanket application, a concept on which APDA had worked as early as 1955. In connection with this program, APDA physicists performed several evaluations of the nuclear characteristics of such reactors. In this connection, the 
effect of the thickness and composition of the blanket on the breeding ratio and the blanket power density was analyzed. Similarly, the effect of the type of fertile material (uranium carbide paste, uranium metal paste, and uranium carbide pins) was also evaluated.

APDA physicists also contributed materially to an APDA study of mobile blanket concepts conducted for the AEC. This study took into account the engineering, physics, and economics of two concepts, clad spheres and paste, with the consideration of three fuel materials, $\mathrm{U}-3 \mathrm{w} / \mathrm{O} \mathrm{Mo}, \mathrm{UO}_{2}$ and $\mathrm{UC}$.

\section{d. East Reactor Core Design Parameier Study}

Early in 1960, APDA and personnel from five other companies made parametric studies of 11 fast reactor fucl systems at the request of the AEC. The objective of these studies was to determine with respect to a number of core designs the important physics and economic factors on which the cost of producing power depends and to determine the effect of changes in these factors on the power costs. The nuclear characteristics considered in thise studies included critical mass, breeding ratio, enrichment, is otopic fission rates, the fraction of reactor fissions that occurs in rarious regions, power distribution, core and blanket average lifetime, and burnup of primary fissionable is otopes.

\section{e. 1000-Mwe Fast Reacior Study}

APDA was a member of one of the four groups selected by the AEC to carry out the Commission-sponsored sludies of a 1000 -Mive sodiumcooled fast breeder reacior. The study group was made up of Allis-Chalners Manufacturing Company, APDA, and The Babcock\& Wilcox Company. APDA was responsible for the physics and safety analyses of the reactor design developed by the group--an annular core fueled by stainless steel-clad $\mathrm{PuO}_{2}{ }^{-}$ $\mathrm{UO}_{2}$.

\section{f. Fast Reactor Fuel Testing}

A.PDA has conducted a number of studies on fast reactor fuel testing for the Commission. Although most of these studies are related to demonstrating fuel performance, it was necessary to review the capabilities of existing facilities, as to their suitability for fast reactor fuel testing. The object here was to determine the best way to design irradiation experiments to be conducted in a thermal reactor that are still meaningful for fast reactors. Physics work involved determining (1) power levels and flux depressions in the fuel test elements, (2) effectiveness of spectrum hardening in the driver core, and (3) effectiveness of using thermal neutron filters. 
One such study involved possible modifications to the Experimental Organic Cooled Reactor (EOCR) for testing fast reactor fuels. Still another was a conceptual design study adapting the Pratt \& Whitney in-pile package loop for use as a fast reactor fuel test facility in the Advanced Test Reactor (ATR). A similar study was also made of an in-pile package loop for sodium-cooled thermal reactor fuel testing in ATR.

\section{Computer Facilities and Programs}

\section{a. Facilities}

Currently, APDA uses, on a rental basis, the computer facilities at the Research Laboratories, General Motors Corporation, Warren, Michigan. These facilities include two IBM-7094 Model 1 computers, equipped with CRT plotters, and, as peripheral computer equipment, two IBM-1460 computers; over-all control of the system is by the General Motors monitor, which has an extensive subroutine library. The programming languages used are FORTRAN II and FORTRAN IV, and include FAP and MAP, the symbolic programming systems for FORTRAN II \& IV. Additional future cquipment and their projected dates of installation include (1) an IBM-360, Model 50, 256 K memory computer (6-15-66), (2) an IBM-360, Model 50, $512 \mathrm{~K}$ memory computer (7-15-66), and (3) an IBM-360, Model 67 computer.

In addition to the GM facilities, APDA uses or has available for use the following backup and extension facilities:

(1) Service Bureau Corp. (SBC), New York IBM-7094, Mode1 1

(2) CEIR, Washington, D. C. IBM -7090

(3) Control Data Corp. (CDC), Minneapolis, Minn. CDC 3600 (131 K memory)

(4) The Detroit Edison Company, Detroit, Michigan IBM-1620, w/ disc IBM-360, Model 50

IBM -705

\section{b. Programs}

The following general and fast reactor analysis programs have been developed, modified, and/or made operational by APDA: 
DEKA Fits least squares of the form $N=N_{O C}-\lambda t$ to foil decay data and calculates the root mean square deviation between observed and calculated values.

MATX A general-purpose program to solve the matrix equation $\mathrm{AX}=\mathrm{B}$ for $\mathrm{X}$, where $\mathrm{A} \leq 8 \times 8$.

FERMI A program designed to keep track of (1) U-235

BURNUP destruction in the Fermi reactor for accountability purposes, and (2) individual subassembly burnup for timing fuel exchanges.

DTF A one-dimensional multigroup transport code.

TFC Calculates the reactor transfer function, taking into account.feedback, for an axially-sectioned model of the core.

DDK A two-dimensional multigroup transport code

ECON A series of economic programs giving profit, heat revenue, $\mathrm{Pu}$ credit, average reprocessing and fabrication costs, and average $U$ and $P u$ inventory. changes.

ELMOE Treats elastic scattering resonances in fast reactors.

GAM Computes a 68 -group fundamental mode flux and adjoint spectra and average cross sections over the calculated spectra to oblain multigroup cross sections.

FAIM A one-dimensional multigroup diffusion code.

RAPTURE A program for resonance integral calculations.

IDIOT A program for the calculation of effective resonance cross sections and their temperature derivatives.

GRBN A series of programs for the evaluation of various numerical integration schemes used in resonance. integral calculation.

INDOORS A matrix inversion program.

RECORE A burnup program.

RESPA A series of programs to calculate resonance parameters for fissionable isotopes by fitting the known values of fission and capture cross sections. 
NILS

A generalized least squares curve fitting program. $\mathrm{MC}^{2}$

A code for generation of multigroup cross sections from fundamental data, including resonance and inelastic scattering cross-section calculations and averaging of cross sections over a calculated energy spectrum.

\section{Publications}

Initial Loading to Criticality of the Enrico Fermi Reactor (APDA-NTS-1).

Determination of Control Rod Float in the Enrico Fermi Reactor (APDA-NTS-2).

Determination of the Safety Rod Drop Time in the Enrico Fermi Reactor (APDA-NTS-3).

Investigation of Core Reproducibility of the Enrico Fermi Reactor (APDA-NTS-4).

Measurement of the Is othermal Temperature Coefficient of Reactivity of the Enrico Fermi Reactor (APDA-NTS-5)

Worth Measurements of Core and Blanket Subassembly Materials in the Enrico Fermi Reactor (APDA-NTS-6)

Measurement of Sodjum Worth in the Enrico Fermi Reactor (APDA-NTS-7).

On the Doppler Effect in Fast Reactors (APDA-119)

Temperature Response to Power, Inlet Coolant Temperature, and Flow Transients in Solid Fuel Reactors (APDA-132)

Preliminary Report on Sodium Temperature Coefficients in Large Fast Reactors (APDA-135)

Fast Reactor Core Design Parameter Study (APDA-133)

$150-\mathrm{Mw}$ Plutonium-Fueled FastBreeder Atomic Power Plant (APDA-136) 
Study of Requirements and Suitability of Available Reactors for Fast Fuel Tests (APDA-153)

Fast Reactor Fuel Cycle Costs and Temperature Coefficients of Reactivity for $\mathrm{PuO}_{2}-\mathrm{SS}$ and $\mathrm{PuO}_{2}-\mathrm{UO}_{2}$ (APDA-154).

Calculation of the Doppler Coefficient for Plutonium-OxideFueled Fast Reactors (APDA-157)

Core B Critical Experiment Program, Second Revision, March 1961

Group Cross Sections for Fast Reactors (Seminar on the Physics of Fast and Intermediate Reactors, Vienna, Austria, August 1961)

The Physics of the Enrico Fermi Reactor (Seminar on the Physics of Fast Reactors, Vienna, Austria, August 1961)

Localized Source Multiplication and Reactor Startup (ANS)

Fission Neutron Importance in a Fast Reactor Spectrum (ANS)

Critical Studies with ZPR-III for the Enrico Fermi Fast

Reactor Core B (ANS)

Preoperational Test Procedure XIV-D. 1, "Calibration Procedures--Temperature Instrumentation"

Phase B Preoperational Shield Test Program for the Enrico Fermi Atomic Power Plant

Physics of Fast Reactors (Geneva)

Measured and Calculated Fission Distribution in the Fermi Reactor (ANS)

Improved Calculations of Sodium Worth in the Enrico Fermi Fast Reactor (ANS)

Fermi Approach to Criticality (ANS)

Result of Is othermal Temperature Coefficient Measurements for the Enrico Fermi Fast Breeder Reactor (ANS)

Sodium Worth Measurements and Calculations on the Enrico Fermi Fast Reactor (ANS) 
The Design of a $1000-$ Mwe Fast Breeder (ANS)

4. Over-all Physics Capabilities

a. Conceptual Design Studies - Fast Reactors

APDA has approximately 10 physicists with statics physics experience and approximately 3 physicists with dynamics physics experience in fast reactor design. A summary of APDA's experience and capabilities in these areas is presented below.

Statics Physics

(1) Criticality studies. Both Fermi and numerous advanced designs, including uranium and plutonium alloy, oxide, paste, and cermet designs up to 1000 Mwe have been studied, using $1-D$ and 2-D diffusion and transport theory.

(2) Control rod design and oscillator rod design

(3) Neutron source design

(4) Reactivity worths of materials, especially sodium void cocfficient

(5) Temperature coefficients

(6) Burnup effects and fuel cycling

(7) Plutonium production in core and blanket

(8) Nuclear heating in core components and blanket heating

(9) Flux distributions in core and blanket and flux spectrum studies

(10) Doppler effect

(11) Cross-section studies

(12) Neutron balance breakdowns

(13) Reflector studies for fast reactor application

Dynamics Physics

(1) Delayed neutron fraction, lifetime studies, etc.

(2) Power coefficient studies 
(4) Control system studies

\section{b. Code Development}

There are approximately four mathematicians with code development experience. APDA's mathematicians are capable of applying numerical analysis to general scientific studies pertaining to fast reactors. They have had experience in making codes operational and in developing subroutines for existing codes. Codes written by APDA personnel include cross-section, meltdown, Doppler, and burnup codes.

\section{c. Experimental Capability}

APDA personnel have participated in planning, conducting, and analyzing two fast critical experiments: Fermi Core $\mathrm{A}$ and a $\mathrm{UO}_{2}$-SS cermet critical experiment in ZPR-III. APDA physicists have also planned, conducted, and analyzed low-power and high-power physics tests on the Fermi reactor. In addition, they have worked on preliminary physics design studies for fast test reactors.

APDA's staff of approximately three experimental physicists are also capable in the following in-core experiment areas:

(1) In-core loop design for fast reactors

(2) Fuel irradiation capsule physics designs

(3) Fuel irradiation test subassembly physics designs, including reactivity, flux perturbation, burnup, and safety studies

(4) Materials surveillance subassembly physics design

(5) Foil design and sodium worth subassembly design.

5. Critical Assembly Facilities

APDA has conducted the critical experiments on Core A and Core B of the Fermi reactor in cooperation with ANI in ANI facilities.

\section{Facilities for Evaluation of Dynamic Nuclear Characteristics}

The Enrico Fermi Atomic Power Plant is available to APDA for such evaluations; however, the reactor is not immediately available for general use.

7. Nuclear Tests Performed in the Enrico Fermi Atomic Power Plant Initial Load to Criticality 
Absolute Power Calibration

Source Power Calibration

Control Rod Float

Flow Dependence of Reactivity

Control Rod Calibration (Preliminary)

Safety Rod Drop

Pressure Coefficient

Is othermal Temperature Coefficient

Flux Mapping Instrument Tubes (Preliminary)

Reload for Retractable Source

General Reactivity Measurements

Full Is othermal Temperature Coefficient

Shin Subassembly Worth

Edge Fuel Worth

Blanket Worth

Sodium Worth

Oscillator Rod Wave Shape

Power Coefficient of Reactivity

Flow Coefficient

Power Demand Transients

Single-Circuit Shutdown

Scram Transients

Reactivity Worth of Antimony Section

Reactivity Changes Caused by Raising and I-owering the Holdiswn Mechanism

Reactivity Pulse and Noise Analysis

Calibration of Shim and Regulating Rods

Safety Rod Calibration

Flux Mapping of Neutron Detector Guide Tubes

Foil Irradiation Procedure

Reload for Uscillator Rod

Power Coefficient of Reactivity at Reduced Primary Sodium Flows. 
Power Setback Transients

Scram Transients

Approach to Power on Automatic Control

Reload for Temporary Instrument Thimble

\section{REACTOR SAFETY}

\section{Fast Reactor Projects}

a. Enrico Fermi Atomic Power Plant

APDA's work in fast reactor safety has been concentrated largely on the Enrico Fermi reactor. However, much of the effort has been of value to the development of fast brecder reactors in general. One such contribution by APDA physicists has been the development of basic techniques for analyzing maximum hypothetical accidents. Because the Enrico Fermi reactor is the first large fast reactor to be located anywhere near a center of population, it has been necessary to make an exhaustive investigation and analysis of the safety aspects of the plant. This work included an unprecedented effort to determine the energy releasc of nuclear accidents, methods of dissipating this energy, and ultimate containment of any fission products released.

In addition, APDA's work on the Doppler effect and the prediction of the possibility of a positive sodium temperature coefficient in large fast reactor cores has influenced fast reactor development in this country and abroad.

In connection with the analysis of the maximum hypothetical accident in the Fermi reactor, all basic analyses were formulated and directed by APDA. Some of these, such as studies of the containment of the rotating shield plug, were carried out in other installations under direct guidance.

Throughout the entire licensing procedure, from obtaining a construction permit to obtaining the license to operate the reactor at full power, APDA physicists provided full technical support to Power Reactor Development Company, the owner-operator of the Fermi plant. In addition, APDA physicists are now engaged in preparing material for hazards analyses for operating the Fermi reactor as a testbed for testing fast reactor fuels.

\section{b. Other Safety Studies}

As mentioned in Section B, APDA has performed several studies of fast reactor fuel testing facilities for the AEC. In addition, APDA also has investigated for the $\mathrm{AEC}$ certain aspects of fast reactor fuel meltdown 
One investigation consisted of an experimental and analytical effort designed to produce a setter understanding of meltdown accidents, and the conditions that could cause them, in a sodium-cooled fast reactor fueled with uranium alloy pin-type elements. To that end, dynamic mockup tests were performed using lead and water as simulants for uranium alloy and sodium, respectively, and electrical resistance heating to simulate fission heating.

Another investigation made at the request of the $A E C$ involved determining the feasibility of experimentally detcrmining fuel reassembly rates and pressure-time histories in fast reactor excursions. The experimental approach involved two reactor facilities designated FAst Reactor Meltdown Experiment $A$ and B (FARME-A and - B). One facility, FARME-A, would be used for parametric partial meltdown studies; FARME-B would be used for mockups of fuel configurations and reactivity insertion rates deduced from the experiments carried out in FARME-A.

To provide a basis for the evaluation of existing or proposed reactor facilities for fast reactor meltclown testing. APDA made another AEC-sponsored study with the objective of establishing the nuclear characteristics and supporling auxiliaxies required of a test reactor facility to enable it to make a significant contribution to existing data on meltdown phenomena for fast reactor safety studies. This work was subsequently expanded to investigate (1) the extent of the possible application of the Power Burst Facility (PBF) to fast reactor fuel meltclown tests, and (2) the feasibility of a second core for PBF to improve the capability of this facility in performance of fast reactor fuel meltdown tests of interest.

2. Thermal Reactor Safety

APDA's work in reactor safety has been devoted almost exclusively to fast reactors.

\section{Reactor Safeguards Reports}

APDA physicists wrote all the reactor physics and safety evaluations contained in the Hazards Summary Report for the Enrico Fermi Atomic Power Plant, which was published by Power Reactor Development Company. In addition, APDA physicists prorided technical support to PRDC in meetings with the Advisory Committee on Reactor Safety and have written the following reports and papers on reactor safety:

Reactor Safety and Oscillator Tests (APDA-117)

Inherent Design and Safety Features of The APDA Fast Breeder Reactor

Studies of the Cause of Reactor Accidents for the APDA Fast Breeder Reactor 
Survey of the Radiation Levels in the Containment Vessel of the Enrico Fermi Atomic Power Plant (TM-16, Part V-A)

Methods for Determining the Energy Release in Hypothetical Reactor Meltdown Accidents (APDA-150)

Two-Facility Approach to Investigations of Fast Reactor Meltdowns (APDA-151)

Study of Fast Reactor Meltdown Accidents Using Simulant Materials (APDA-155)

Safety Considerations in the Enrico Fermi Reactor Design (IAEA/Rome)

Fast Reactor Meltdown Experiments (ANI/AEC) Materials Problems and Selections in the Enrico Fermi Fast Brecder Reactor (AIME/ANS)

Fast Reactor Safety Research (Geneva)

Fast Reactor Safety Rescarch (ASME)

\section{Computer Programs}

The following APDA computer programs which can be employed in fast reactor safety studies have been developed, modified, and/or made operational by APDA:
- CRAMF
A one-or two-dimensional multigroup diffusion code
MATX
A general purpose program to solve the matrix equation $A X=B$ for $X$, where $A=8 \times 8$
DTF
A one-dimensional multigroup transport code
TFC
Calculates the reactor transfer function for an axially sectioned model of the core, taking into account feedback.
DDK
A two-dimensional multigroup transport code
HAPT
Harmonic analysis of pulse test data
IAPT
Laplace transform analysis of transfer function data
AXI
$A$ one-dimensional meltdown accident code
WEAK
A meltdown accident code which includes Doppler effect and allows for ramp insertion rate
REACTOR
A two-region, two-dimensional meltdown accident EXP code with no Doppler step insertion 


\begin{tabular}{|c|c|}
\hline AIREK & A reactor kinetic code \\
\hline CASEY & $\begin{array}{l}\text { A reactor kinetic code with temperature dependent } \\
\text { feedback }\end{array}$ \\
\hline FORE & $\begin{array}{l}\text { A neutron kinetics program for the analysis of } \\
\text { fast reactor excursions }\end{array}$ \\
\hline $\begin{array}{l}\text { TRAFUS } \\
\text { ZAMAN } \\
\text { TFII }\end{array}$ & Transfer function programs \\
\hline INDOORS & A matrix inversion program \\
\hline FIT & A least squares fitting program for certain curves \\
\hline NIIS & A generalized lcast squares curve fitting program \\
\hline
\end{tabular}

\section{Summary of Capabilities}

APDA's capabilities in fast reactor safety analys is are commensurate with its wide experience in this field. APDA's staff can analyze fast reactor core designs to determine their behavior under various credible accident conditions and can ascertain the necessary protective design criteria, such as desired signals, trip level settings, and response times, required for adequate protection. In addition, APDA can perform analyses of hypothetical accident situations to determine the magnitude of excursions in terms of energy release, peak pressures, and subsequent consequences to confining structures. APDA can also (1) analyze the effect of transient conditions in test loops to determine the possibility of fuel element failure, coolant boiling, and interaction with other test specimens and driver core; (2) design, specify, and evaluale meltdown experiments in TREAT or other facilities to investigate the effect of fuel element failure in test loops; and (3) evaluate the stability characteristics of a specific reactor system.

\section{REACTOR SHIE IDING}

\section{Enrico Fermi Atomic Pover Plant}

a. Materials and Design

APDA's work in reactor shielding has been devoted extensively to the design, development, and testing of the shielding system for the Enrico Fermi reactor. The design of the Fermi shield system included the shield design of fuel transport casks and shipping containers for fuel and hardware; the design of primary, secondary, and biological shields; the shield designs for auxiliary reactor systems and buildings; the design of waste gas systems; and reactor shield system calculations.

APDA also pioneered the use of two new shielding materials, serpentine and calcium borate, and conducted a major effort in the procurement 
and testing of suitable existing materials. In addition APDA devised new methods to improve shielding design and to facilitate the installation of shielding material.

\section{b. Shield Test Program}

The shield test program is designed to evaluate the shielding in the Fermi plant from a safety standpoint and to obtain basic performance data. The evaluation program covers all the shields in the Fermi plant and

is separated into two phases: Phase A - Test program for shields within the reactor building; Phase B - Test program for shields for the service buildings and equipment. Each phase of the program is in turn subdivided according to the operational condtions of the reactor or system.

Preoperational Tests - The tests performed with the Reactor Building, before reactor operation began, investigated the shielding effectiveness and uniformity of the secondary shield wall. The preoperational tests performed within the service buildings included gross checks of the shielding integrity of all shields within these buildings, and also tests of various penetrations of these shields.

Operational Tests - After the reactor had achieved criticality, a number of tests were made at powers up to 1 Mwt. Measurements of neutron levels were made at various points inside the reactor vessel, in the primary graphite shield, and in the reactor compartment. Both neutron and gamma-ray streaming through the exit port and the rotating plug penetrations were measured, and measurements vere made of both sodium and argon activities.

The remaining experiments on the reactor are scheduled to occur between power levels of $1 \mathrm{Mwt}$ and $200 \mathrm{Mwt}$. These tests include the following:

Phase B Tests - The shield adequacy of all outbuildings, i.e., all buildings except the reactor building, are to be measured.

Sodium Sampling - The primary sodium system is to be sampled for radioactivity in order to measure the magnitude of $\mathrm{Na}-24, \mathrm{Na}-22$, and various fission products and metallic impurities.

Reactor Building Radiation Surveys - These include the neutron measurements below the operating floor, and neutron and gamma measurements above the operating floor.

Shield Foil Program - The remainder of the shield foil program to be completed covers foils in areas where neutron levels are low, e.g., at the top of the reactor vessel, near the rotating shield plug. 
Fuel and Repair Building Shield Test - This test is to be done after the $200 \mathrm{Mwt}$ power level has been demonstrated, when the first spent fuel elements are transferred. The fuel itself will be the source of radiation for the test.

Cover Gas Measurements - Measurements of cover gas activity will be made. Argon activity will be measured and fission products in the gas will be checked.

\section{Other Shielding Work}

In addition to its shielding work on the Enrico Fermi reactor, APDA has worked on two additional shielding design projects: (1) the shielding for the conceptual design of a $775-\mathrm{Mwt}$ second-generation plutonium fueled fast breeder atomic power plant (reported in APDA-129) and (2) preliminary design shielding studies for the alternate conceptual designs of an FFTF reactor. The first study proposed a shielding design similar to that of the Fermi reactor, taking into account the increascd power level; the major departure is the method used for shielding against neutron streaming penetrations of the primary shield wall. Preliminary design studies for an FFTF reactor have so far pertained to an alternate loop design concept.

\section{Computer Programs}

The following APDA programs for reactor shielding analyses have been developed, modified, and/or made operational by APDA:

$\begin{array}{ll}\text { CRAMF } & \begin{array}{l}\text { A one-or two-dimensional multigroup diffusion } \\ \text { code }\end{array} \\ \text { MATX } & \begin{array}{l}\text { A general purpose program to solve the matrix } \\ \text { equation } \mathrm{AX}=\mathrm{B} \text { for } \mathrm{X} \text {, where } \mathrm{A}<8 \times 8\end{array} \\ \text { DTF } & \text { A one-dimensional multigrcup transport code } \\ \text { DDK } & \text { A two-dimensional multigroup transport code } \\ \text { EIMOE } & \begin{array}{l}\text { Treats elastic scattering resonances in fast } \\ \text { reactors }\end{array} \\ \text { GAM } & \begin{array}{l}\text { Computes a } 68 \text {-group fundamental mode flux and } \\ \text { adjoint spectra and avcrage cross sections over }\end{array} \\ & \begin{array}{l}\text { the calculated spectra to obtain multigroup cross } \\ \text { sections }\end{array} \\ \text { FAIM } & \text { A one-dimensional multigroup diffusion code } \\ \text { IDIOT } & \text { A program for the calculation of effective resonance } \\ & \text { cross sections and their temperature derivatives }\end{array}$


INDOORS A matrix inversion program

FIT

NILS

$M C^{2}$

A leàst squares fitting program for certain curves

A generalized least squares curve fitting program

A code for generation of multigroup cross sections from fundamental data including resonance and inelastic scattering cross-section calculations and averaging of cross sections over a calculated energy spectrum

FORD A code for the computation of induced radioactivity.

4. Publications

APDA has written the following reports on reactor shielding:

New Shielding Materials for High Temperature Application

Shielding on 30-Inch Pipe (TM-10)

Shielding the Enrico Fermi Fast Brceder Reactor - (Nucleonics, November 1958)

New Shielding Materials for High Temperature Applications (Nuclear Science and Engincering)

Introduction to Shielding (Lecture Notes)

Detailed Conceptual Design of the Graphite Primary Shield for the Enrico Fermi Fast Breeder Reactor (TM-23)

An Analysis of the Preoperational Sheld Iest Program for the Enrico Fermi Atomic Power Plant (TM-38)

Phase A Preoperational Shield Test Program for the Enrico Fermi Atomic Power Plant (P-63-6)

5. Over-all Shielding Capabilities

APDA's over-all capabilities in reactor shielding include the design, analysis, and testing of shield systems. Design capabilities include the shield design of fuel transport casks and shipping containers for fuel hardware; the design of primary, secondary, and biological shields; the shield designs for auxiliary reactor systems and buildings; and the design of waste gas systems. Other capabilities include planning and developing shield test programs and conducting and analyzing the results of shield tests.

Calculations can be made of radiation damage, nuclear heating of materials and shielding, radioactivation of materials, coolants, etc., and fission product buildup, decay, and heating in fuel elements. APDA capabilities also include conducting radiological analyses of accidents. 


\section{REACTOR COMPONENTS}

\section{A. GENERAL}

The work done by APDA has contributed substantially to the technology now available for the liquid metal-cooled fast breeder reactor. APDA effort has been devoted to this type of reactor, either in support of the Enrico Fermi Atomic Power Plant or in special as signments for the AEC and others.

One major contribution to the development of fast reactor technology was the development, construction, and testing, between 1955 and 1961, of the world's largest sodium system for nuclear purposes-the APDA Reactor Components Test at the Enrico Fermi Atomic Power Plant, now an integral part of the Fermi plant. For this test, APDA assembled all major components for the reactor: reactor vessel, rotating shield plug, primary shield tank, dummy fuel and blanket elements, fuel-handling mechanisms, control rod drives, liquid-metal pumps, sodium purification equipment, liquid-metal heat exchangers, piping, and instrumentation. The reactor, associated mechanisms, and one primary pump were then operated in sodium at operating temperatures as high as $1000 \mathrm{~F}$. This work is described fully in APDA-147, "APDA Reactor Components Test."

These and other sodium programs were supported by laboratory and sodium test facilities in which a wide range of tests were conducted in sodium enviromments. The work done ranged from determining the suitability of protective clothing to the development of highly sensitive methods for analyzing impurities in sodium and includer bearing tests, scal tests, compatibility determinations, flow and heat transfer experiments, corrosion, erosion, seizing and galling tests, and chemical and physical analyses. The results of this work provided a basis for many specifications and other key decisions made in the design of the Enrico Fermi plant.

In addition to the development work on the Enrico Fermi plant APDA. has participated in a number of $\mathrm{AEC}$-sponsored programs and other studies related to fast breeder reactor developments. Several of these for the AEC have been directly related to the operation of reactor components in sodium. For example, in 1959 APDA furnished a design concept for a sodium components test facility as part of the overall Commission program for the development and testing of components for use in liquid-metal systems. The results of this study were published in Report APDA-134, "Sodium Components Test Facility."

Specific items related to reactor components are discussed below. 


\section{B. REACTOR COMPONENTS}

\section{Valves}

APDA investigated the availability of large-diameter stop valves that could be used in a sodium-cooled fast reactor plant. Such valves were not used in the Fermi plant, however. Instead removable check valves were specified for the primary system. Several designs were investigated with the final decision to use a vertical swing-check. A thorough study was made of possible hammer effects which could occur with this valve and led to modifications including the use of a dash-pot and a spring-loaded disc. APDA also specified a throttle valve for reactor blanket flow. Unusual features included 5 per cent flow at the closed position, double bellows stem seal, leak detectors, seal-welded flange, and remote operation. Valves for cover gas and service systems have been specified for the Fermi plant and for many experimental research liquid-metal loops.

\section{Seals and Joints}

\section{a. Materials for Gas Seals}

To determine the acceptability of flexible materials as inert gas-filled container bags for removal of sodium-covered equipment from the Fermi plant, APDA conducted a series of tests on various materials suggested for this use. The object of the tests was to determine the compatibility of these materials with sodium and sodium vapor.

\section{b. Mechanical Seal for Rotating Shield Plug}

One extensive effort on the part of APDA was the development of bearings and seals for the Fermi rotating shicld plug, which measures 10 feet in diameter and weighs 250,000 pounds. The experimental work was done at the Franklin Institute under the direction of APDA. Extensive testing of a special double-race ball bearing was carried out in quarter-scale model at ambient temperature as high as $250 \mathrm{~F}$ in a dry argon environment with sodium vapor present.

The bearing test device utilized in the above program was subsequently moved to the APDA Test Site, where it was modified and converted to a seal tester used in developing the seal for the rotating shield plug of the Fermi reactor. APDA worked closely with Detroit Silicone Rubber Company testing many configurations of seals both in the one-quarter and in the fullscale test device (Figure II-1) under ambient conditions. The success of these programs is evidenced by the present rotating plug bearings and seals in the Fermi reactor, which have been in service without maintenance since 1960 . 


\section{c. Bellows Seals}

APDA has demonstrated a capability for design specification and testing of bellows seals, using contemporary theory and calculational methods.

Bellows seals are used both in gas and in sodium environments. Fabricated to APDA specifications, they are used in the Fermi reactor on mechanisms such as the offset handling mechanism (OHM or fuel handling mechanism) control rod drives, hold-down actuator, oscillator rod extension, pipe expansion joints, valve stem seals, and in sealing the check valve to the pump tank. Experience with these seals has been good. Bellows seals have been used as reciprocating seals for various mechanisms at the APDA Test Site.

\section{d. Buffered Seals}

Specifications for these seals were evolved by APDA and used successfully on Fermi mechanisms such as the OHM, rotating plug, oscillator rod extension, and transfer rotor drive. Buffered seals are defined here as twin seals with slightly pressurized clean (uncontaminated) gas supplied to the space between the seals in order to limit leakage across the pair to less than the leakage of either seal.

\section{e. Floating Ring Seals}

APDA has had experience in designing and testing floating ring scals for small, high-speed rotating shaft scals with good results. Recently work is being done on the conceptual design of a high-speed centrifuge for processing sodium on a continuous flow basis. As a part of this effort, the applicability of a floating ring gas seal to sodium service is being evaluated and the expected leak rate and the effects of such a leak rate are being studied.

\section{f. Oil Seals}

APDA has had a great deal of experience in developing, evaluating, and specifying oil seals, especially for use on the Fermi sodium pumps and on the pumps in the sodium loops at the APDA Test Site.

\section{g. Metallic O-Rings}

Experience with several versions of metallic O-rings for gas and sodium service is extensive and has been derived from work done at the Fermi plant and at the APDA Test Site. This experience has resulted in a good understanding of the performance limitations and appropriate applications for metallic O-rings. 


\section{h. Proprietary Seals and Joints}

APDA has had wide experience in the designing and use of Conoseal joints in standard and special applications, including high-temperature and high-vacuum applications. These joints have been used at the APDA Test Site on the sodium endurance loop, the sodium distillation unit, sodium centrifuge, and in the Fermi reactor exit pipeline. Similarly, Graylok pipe connections have been used at the Test Site on the sodium technology loop, in the sodium-water reaction test apparatus, and in the paste loop. Detailed descriptions of this equipment can be found in Section V, Liquid Metals.

\section{i. Freeze Seal Plugs}

Experience in the use and performance evaluation of freeze seal plugs has been gained through their use in the drains of the Fermi intermediate heat exhcangers, as vacuum seals for the distillation cleaning test specimen section of the sodium endurance loop, and as "valves" for doing line maintenance or modifications.

\section{Fuel Exit Port (Reactor Tube Nozzles)}

The exit port is the egress point for inserting or removing subas semblies in or out of the reactor. During reactor operation, the exit port is sealed by a biological shield plug in which silicone lip seals were used originally to separate the reactor enviromment from the containment building. These seals did not allow the smooth withdrawal of the shield plug, and on one occasion they seized against one another. APDA was responsible for the redesign of the exit port plug and for the selection of a compatible sealing material.

The present method for transferring subassemblies between the reactor building and the fuel and repair building involves the use of a motorized cask car. APDA has been directly or indirectly responsible for many design improvements which have been made to the cask car. The uranium ball value replating operation, the redesign of the finned pot storage latching mechanism, and the structural analysis of the cask and shielding materials are some of the problems that were solved which led to the successful operation of the cask car.

The future method for transferring subassemblies between the reactor building and the fuel and repair building will involve the use of a shielded cask that will handle one subassembly at a time. Atomics International in Canoga Park, California, is performing the engineering design and fabrication of this equipment in accordance with a specification prepared by APDA. In the role of technical adviser to PRDC, APDA is reviewing the new design for suitability and compliance with the specification. 


\section{Piping}

A large number of piping arrangements were investigated before the final Fermi plant layout was selected. This investigation included a complete study of the flexibility and shielding requirements for sodium-cooled plants where the reactor is closely coupled with the primary system components. APDA sponsored pioneer stress analysis work on large diameter, thin-walled piping by Mr. W. S. Spielvogel and the M. W. Kellogg Company, wherein it was found that ovality in elbows could provide as much flexibility as 20 feet of pipe. Special problems that occurred during erection of the Fermi plant were responsible for the establishment of new industry standards on cleanliness, mass spectrometer testing, and on tolerance for field fit-up. This APDA experience has an important application in the design of future sodium-cooled plants and in the design of experimental research loops.

\section{Vessel and Piping Heaters}

APDA used the early experience of Argonne National Laboratory in induction heating of liquid-metal piping, and adapted this type of heating to the large-diameter piping and tanks of the Fermi plant. Where critical inaccessible tanks requircd heating readout, conventional resistance heating was specified and detailed. All heating systems have operated successfully at the Fermi plant. Thus, this Fermi plant experience was used in prescribing heating arrangements for piping, tanks, and valves for the many liquid-metal loops at the APDA Test Site.

\section{Insulation}

All a vailable types of insulation have been explored by APDA for temperatures as high as $1200 \mathrm{~F}$. Information was obtained on the conventional properties as well as reaction with sodium and radiation damage. This information is available for specifying insulation requirements both for power plants and for research liquid-metal loops. Original work was performed by APDA in providing both insulation and neutron-streaming prevention in piping penetrations of the shield wall at Fermi.

\section{Submerged Drives and Guides}

APDA's experience in developing concepts, designs, and specifications for the in-reactor fuel handling and control mechanisms for the Fermi reactor, together with the experience gained by APDA in the assembling, installing, testing, and operation of these mechanisms has given APDA unique competence and capability in the field of design and materials selection for under-sodium drives and guides. Typical examples of submerged mechanism elements in the Fermi plant are listed below. 


\section{a. Offset Handling Mechanism}

Submerged components of the OHM include journal-type bearings to accommodate sliding and rotating motions and gripper components which are also subject to sliding motion. Various tests were run in sodium test pots to determine the compatibility and effectiveness of the above-mentioned guide materials under varying test conditions, such as sodium environment, thermal shock, high temperature, and rotating and/or sliding motions. These tests could be duplicated or expanded with existing equipment available at the APDA Test Site.

\section{b. Rotating Shield Plug}

The shield plug rotates in a stepped, close-clearance annulus in the reactor. During operation the annulus is partially below the sodium surface. This mechanism has operated successfully throughout nonnuclear testing and the initial stages of the approach to full-power operation. During a nonnuclear test at $1000 \mathrm{~F}$, the plug became inoperative because of crud accumulation in the annulus. Although this problem was solved by raising and lowering the sodium level while concurrently raising the reactor sodium temperature to dissolve the sodium crud, it prompted tests by APDA to determine the shear strength of sodium and sodium crud of various compositions and sources. This shear strength data has subsequently been used by APDA as a design criterion for mechanisms susceptible to sodium crud formation.

\section{c. Hold-Down Mechanism}

The hold-down mechanism is accurately positioned over the top of the subassembly by a ball-and-socket type of engagement between three spider arms on the hold-down and three support columns located on the perimeter of the reactor. Some developmental work and testing was done by APDA in order to obtain a configuration and material pair satisfactory for this highly loaded sliding engagement. The hold-down has individual fingers which hold down individual subassemblies, normally exerting a force of about 450 pounds. Experience showed that the original configuration and material pair was susceptible to adhesion or self-welding. APDA conducted exhaustive tests in sodium which led to understanding of the phenomenon and to an improved design of the hold-down fingers.

\section{d. Safety and Control Rod Drives}

Each of the safety and control rod drives in the Fermi plant incorporates a submerged gripper, sliding contact within a guide tube, and a latch rod which operates the gripper.

During the control and safety rod drive mechanism commissioning program, operational difficulties with the grippers required design 
modifications to these mechanisms. To develop the information necessary to accomplish such modifications, APDA performed in-depth analyses of the effects of such parameters as operating clearances, camming angles, surface finish, and friction coefficients; these were supplemented by extensive prooftesting of the revised designs in high-temperature sodium. APDA participated actively in the planning and execution of this test program, thereby gaining valuable experience and insight into some of the less obvious factors in the design of such mechanisms for use in high-temperature sodium. To determine the drop times of the control rods as affected by radial clearance between the rod and structural materials, initial acceleration, counter flow of coolant, and temperature changes, a series of drops were made with a simulated control rod at the APDA Test Sile. At the same time, the braking characteristics of the dashpot were determined, as was the effect of distorting the control rod guide tubes.

During preoperational testing of the reactor, the testing of the operating control rods, safety rods, and low-power oscillator rod involved extensive APDA participation. APDA designed a sodium-filled rig for testing a complete safety rod and drive assembly and assisted with its erection in the fuel building at the Fermi site. The test rig was a full-length container, which mocked up a reactor safety rod channel in detail including support plates and guide tubes. Provision was made for adjusting guide tube alignment and performing other experiments to simulate reactor operation of a drive and extension.

An extensive test program, including a life test of a safety rod drive, extension, and rod, was performed in this setup in sodium at reactor operating temperatures. The machine under test successfully completed 3566 operating cycles including scrams, thus verifying that the design solutions to operational problems were satisfactory for reactor operation.

\section{e. Sweep Mechanism}

The sweep mechanism consists of an arm mounted on the lower end of a rotatable column installed through the rotating plug. Prior to fuelhandling operations, the arm is lowered to a horizontal position and the column is rotated, thus indicating that nothing is protruding upward above the top of the core subassemblies. This unit, which was completely designed by APDA, incorporates hardened inserts and overlays to provide under-sodium guidance, and a proven design of a pin joint for the arm.

\section{f. Oscillator Rod and Drive}

During the design and development of the Fermi oscillator drive mechanisms, extensive testing was performed to develop satisfactory bearings for the mechanism. 
The bearings are required to provide low-friction, lowradial-load capability for stabilizing the dynamic operation of the long, slender drive shaft, approximately 30 feet long and 1 inch in diameter for the upper half of its length. The lower half is approximately $1-3 / 4$ inches in diameter. Operating speeds range from 0.06 to $600 \mathrm{rpm}$. An extensive program was undertaken to establish (1) proper combinations of bearing materials and (2) suitable clearances to eliminate dynamic instability of the shaft and surface damage to the bearings. Initially the machine was tested for several hundred hours in air and water and then for about 200 hours in sodium in the safety rod drive test rig. The sodium tests were conducted at speeds from 300 to $600 \mathrm{rpm}$ at sodium temperatures of 500 and $750 \mathrm{~F}$. Several combinations of bearing materials, clearances, and surface finishes were tested to determine the most reliable combinations of these parameters.

APDA participated extensively in the planning, analysis, experimental work, and evaluation of the test results. Extensive experience was gained in the test program with bearings operating in sodium vapor and argon gas, as well as with bearings operating in liquid sodium. Based on this work, APDA made final recommendations on the bearing design for this machine, which has now operated successfully in the Fermi reactor during low-power nuclear testing.

\section{g. Transfer Rotor Mechanism}

The transfer rotor mechanism consists of a rotary drive unit, a 30-foot-long vertical actuator shaft extending into the sodium to provide rotary motion, and a large disk at the bottom of the long shaft in which finned pots containing fuel subassemblics are hung. The tail bearing is submerged in sodium and operales against a hard-faced journal bearing on the acturator shaft. During nonnuclear testing, the journal bearing seized on the ring bearing. Material compatibility analysis, clearance studies, and full-sized models were used to resolve this problem and the mechanism has since operated successfully.

\section{h. Special Equipment}

APDA has also designed and used a variety of special equipment for the Fermi plant involving submerged drives and guides. Several types of grippers have been provided for use on subassemblies and gaging equipment; a special tool utilizes a bayonet engagement for installing or removing lower guide tubes for control rods; and an under-sodium alignment gage, incorporating a magnetic clamp, is used for calibrating the fuel handling mechanisms.

In the course of developing mechanisms for the Fermi plant, APDA recognized the necessity for versatile apparatus capable of testing 
small bearings under various environmental conditions. Consequently, APDA constructed a bearing test rig (Figure II-2) in which the friction and wear characteristics of various bearings and materials can be tested at temperatures up to $1200 \mathrm{~F}$ and pressures up to $100 \mathrm{psig.} \mathrm{Both} \mathrm{radial} \mathrm{and} \mathrm{thrust}$ loads up to 2000 pounds can be applied in this device. This apparatus, a vertically loaded, Type 347 stainless steel chamber, has a test area diameter of $6-1 / 4$ inches and a test area height of 60 inches. A variable-speed, $d-c$ drive unit incorporated in the test device can be governed within 0.1 per cent and can be operated over a speed range of 1 to $600 \mathrm{rpm}$. A magnetic speed scnsor and pulse counter are used for measuring speed. A strain gage device for measuring torque is also included in this apparatus.

The sodium level can be adjusted so that bearings may be tested either in liquid sodium or in an atmosphere of sodium-vapor-laden cover gas. Provision is made for controlling the degree of contamination of both the sodium and the cover gas as a test parameters.

Most recently this rig has been used in the testing of the high-power oscillator rod mentioned previously. In these tests, two radial bearings and one thrust bearing were endurance tested in sodium at $600 \mathrm{~F}$ in a series of starts and stops with speed variations of 6 to $600 \mathrm{rpm}$.

The drive mechanism. for the bearing test rig is adaptable to the APDA water loops and, in fact, was so used in the test of the high-power oscillator rod under conditions of flow.

8. Pumps

a. General

APDA engineers worked very closely with the manufacturer of the Fermi pumps for both the primary and secondary sodium systems throughout design, manfacture, and shop testing. APDA also supervised the installation and the testing of the pumps at the Fermi site.

The three primary sodium pumps are electric-motor-driven, vertical-shaft, centrifugal, sump-type pumps having an oil-lubricated mechanical shaft seal. Each pump is designed to deliver 11,800 gpm at 310 feet of head. The three secondary sodium pumps are electric-motor-driven, vertically mounied, centrifugal, double volute circulating pumps having oillubricated mechanical seals.

Early in the development of these large mechanical sodium pumps, it was recognized that bearings and seals constituted the principle problem areas in this effort. These problems were handled as described below. 


\section{b. Seals}

As part of the seal development program sponsored a test program $c$ nducted at the Allis-Chalmers Manufacturing Company to evaluate both labyrinth and face-type seals for pump application. Figures II-3 and II-4 show the testing device used in this program, which was conducted in two phases:

(1). A determination was made of the leakage of several gases (helium, air, nitrogen, and argon) through a labyrinth seal and a nonlubricated face-seal on a stationary shaft without sodium in the test apparatus. These tests were conducted with the various gases at different seal temperatures and pressure differentials across the seal.

(2). A similar decontamination was on a rotating shaft with sodium in the sump. In addition, a quantitative ineasurement was made of the amount of sodium vapor that had diffused through the gas stream as it left the upper labyrinth seal. A determination was also made of the effect of accumulated sodium on the lower labyrinth seal. In both parts of the program, the gas was admitted to the seal at ambient temperature.

At the same time, tests were conducted in our facilities of a liquid-interface type of seal, Cerro-bend.

Figure II- 5 shows the equipment that simulated the shaft and shaft seal of a main sodium pump. This equipment was used to determine shaft clearances and inert gas flow requirements to prevent galling or seizure of the shaft because of sodium or sodium oxide formations.

These programs were conducted in parallel with a similar program underway at the pump manufacturer, Byron Jackson, and were terminated upon development by Byron Jackson of a lubricated type of face-seal, which has since become the principal seal used today in large sodium pumps.

The experience with these seals has not been entirely successful in that maintenance free operation of the seals has varied from 3 months to 1 year. Since limited seal life would constitute a serious economic penalty, APDA is presently engaged with Bryon Jackson and Power Reactor Development Company in an effort to improve the service life of these seals. 


\section{c. Bearings}

In 1955 the critical nature of the bearing problem prompted APDA to initiate a series of tests to investigate the galling and self-welding characteristics of bearing surfaces. The test program, which was developed and closely supervised by APDA, consisted of a group of laboratory and prototype components tests conducted by the Allis-Chalmers Manufacturing Company, The Detroit Edison Company, and the Argonne National Laboratory to determine the degree of adhesion and self-welding of various bearingcoupling materials in liquid sodium at temperatures from $500 \mathrm{~F}$ to $1000 \mathrm{~F}$. The results of these programs permitted APDA to furnish the pump manufacturer with a choice of several matcrials suitable for bearings for sodium service.

Bearing development work was carried out in water in the Byron Jackson shops. Here a series of experiments was conducted to optimize bearing supply and orifices. This effort culminated in four tests of a completely assembled pump in the Byron Jackson water pit. Throughout this program APDA engineers worked in conjunction with the manufacturer so that the end product not only met hy-draulic requirements but also the requirements peculiar to sodium. The sources of this developmental endeavor is evident in the absence of bearing difficulties with the Fermi primary pumps.

\section{Intermediate Heat Exchangers}

APDA was responsible for the intermediate heat exchangers at the Fermi plant. Each of these units is capable of transfering $4.89 \times 10^{8}$ $\mathrm{Btu} / \mathrm{hr}$. In arriving at the design, APDA studicd many designs and configurations, becoming well versed in heat exchanger design.

In addition to the large Fermi units, APDA has designed and built many smaller sodium-to-sodium heat exchangers for service from low temperature up to $1200 \mathrm{~F}$. These have all provided valuable background and capability in the design of liquid-metal heat exchangers.

\section{Steam Generators}

Another aspect of liquid-metal technology in which APDA has pioneered is the development of sodium-heated, single-walled, once-through steam generators. Early in the steam-generator development program, an engineering evaluation of the reaction of $\mathrm{NaK}$ with water was carried out. Equipment for the NaK-water reaction test was erected in 1955 and was operated until late 1957 to obtain basic reaction data and to obtain an indication of the condition that would prevail should a tube in a NaK-heated steam generator fail. Shock waves, peak pressures, reaction times, and methods for controlling the reaction were studied. 
Shortly after completion of this study, a pilot-plant steam generator test facility was erected (Figure II-6). Both shell-and-tube and bayonettube types of steam generators were tested in this facility, with $\mathrm{NaK}$ as a heat source, to demonstrate the feasibility of such units. The testing program included evaluations of (1) over-all heat transfer performance, (2). watersteam side circuit stability, (3) stress and scale deposition, (4) leak detection and relief control methods, and (5) control characteristics. From operating experience and results of the tests, it appeared that both types of steam generator would be readily adaptable for use in a nuclear power plant.

Another part of APDA's steam generator development program, the sodium-water reaction test (Figure II-7), was designed and erected in 1958 to provide design data for the Enrico Fermi plant steam generators. The over-all results demonstrated that equipment can be designed to accommodate a sodium-water reaction, a conclusion borne out in late 1963 when such a reaction occurred in one of the Fermi steam generators without damage to equipment or injury to personnel. A tangible result of this program was the consiclerable cost savings in the procurement of the steam generators for the Enrico Fermi plant.

AEC-sponsored steam gencrator development projects undertaken by APDA have included a compilation of design information on steam generators, published as TID-18072, and a brief study of economically optimum steam conditions and cycles for large sodium-cooled nuclear power plants. Currently APDA is scrving as consultant to Babcock \& Wilcox Company on an AEC contract to desigr a 1000-Mwt steam generator and to design and build a 30-Mwt prototype. In addition, work is continuing on an AEC-sponsored project involving a series of sodium-water reaction tests in support of steam generator development (Section V). The purpose of this work is (1) to establish a means of estimating the extent of tube wastage during a small leak of water into sodium in a sodium-heated steam generator and (2) to determine the dominant parameters of tube wastage during a small water leak so that these parameters may be taken into account in the design of such a full-sized unit.

\section{PUBLICATIONS}

APDA publications in the area of reactor component development and testing include the following:

NaK Water Reaction Experiments in Closed Heat Transfer Systems

Fuel Handling System for a Fast Breeder Reactor System (ASME-57NESC-123)

Enrico Fermi Reactor Control and Fuel Reloading Cycle (ANS) 
Designing and Fabricating the APDA Reactor Vessel (ANS)

APDA Fast Reactor Vessel (ASME)

Thermal Stresses in Nuclear Reactor Vessel Nozzles, Nuclear

Science and Engineering, February 1960

Analytical Study of Heat Transfer Rates for Parallel Flow of Liquid Metals through Tubes Bundles, AIChE Journal, March 1961

Formal Heat Transfer Solutions, Nuclear Science and Engineering, March 1961

Damage and Abnormal Conditions found on Components Removed from the Enrico Fermi Reactor (MD-751)

Sodium Heated Steam Generator Summary

Reactor Heat-up and Sodium Refiling Procedure, November 15, 1962

APDA Reactor Components Test, (APDA-147)

Analysis of the B\&W Prototype Steam Generator for a Sodium-Water Reaction, (APDA-175)

Analysis of the B\&W Full-Size Steam Generator for a Sodium-Water Reaction, (APDA-176) 


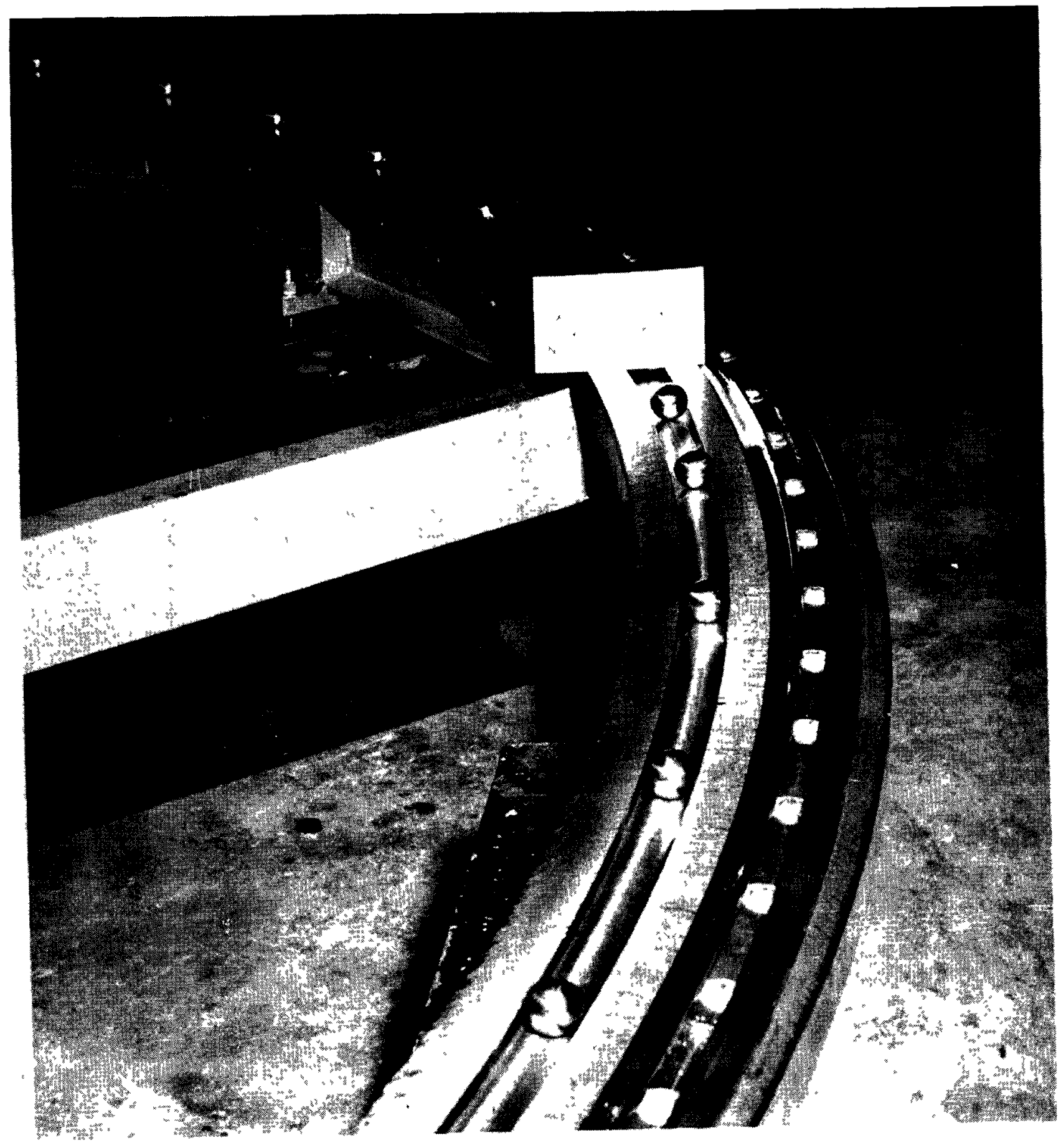

FIG. II- I APDA SEAL TEST FIXTURE FOR FERMI REACTOR PLUG SEAL 


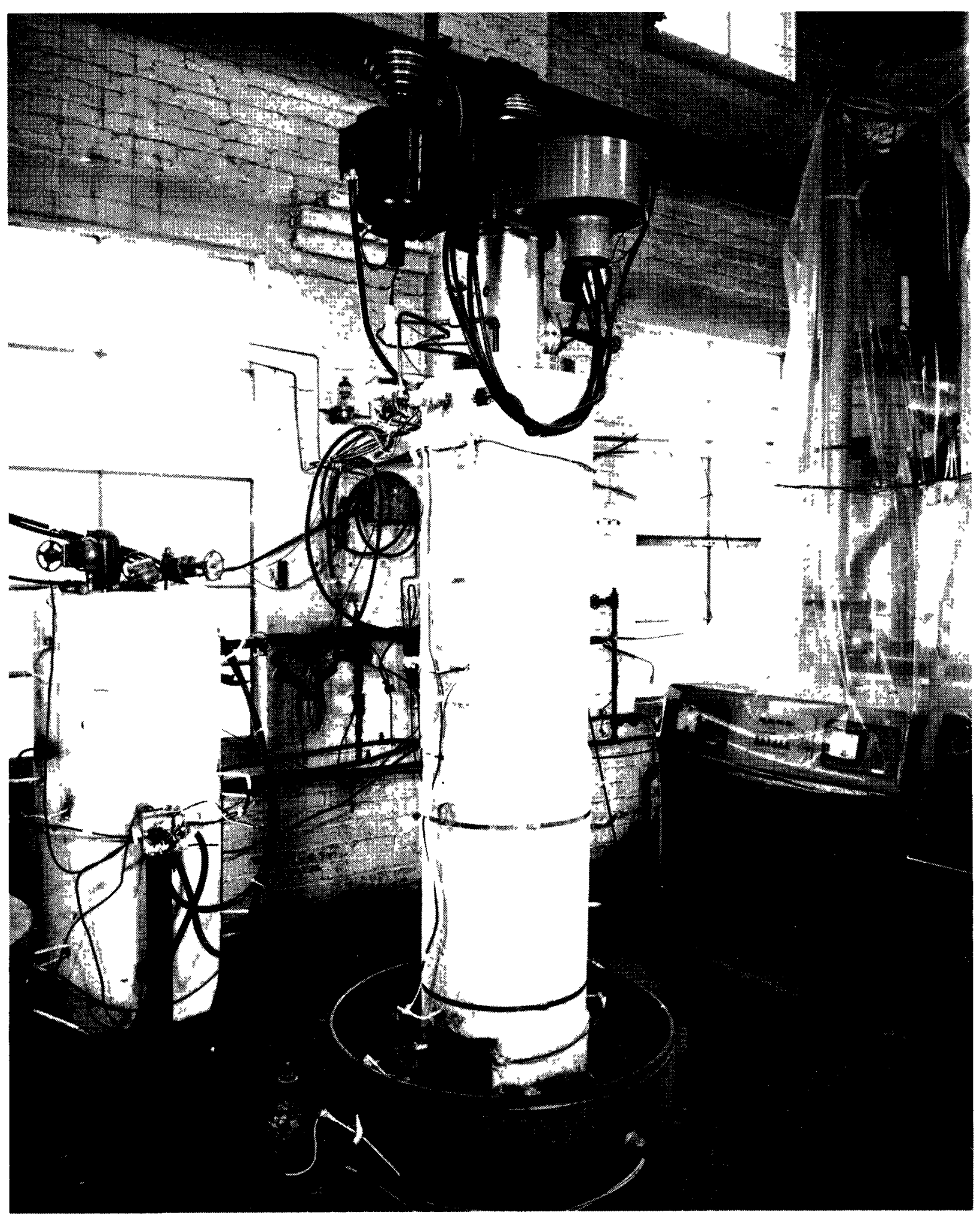

FIG. II-2 EXTERNAL VIEW OF APDA BEARING TEST RIG 


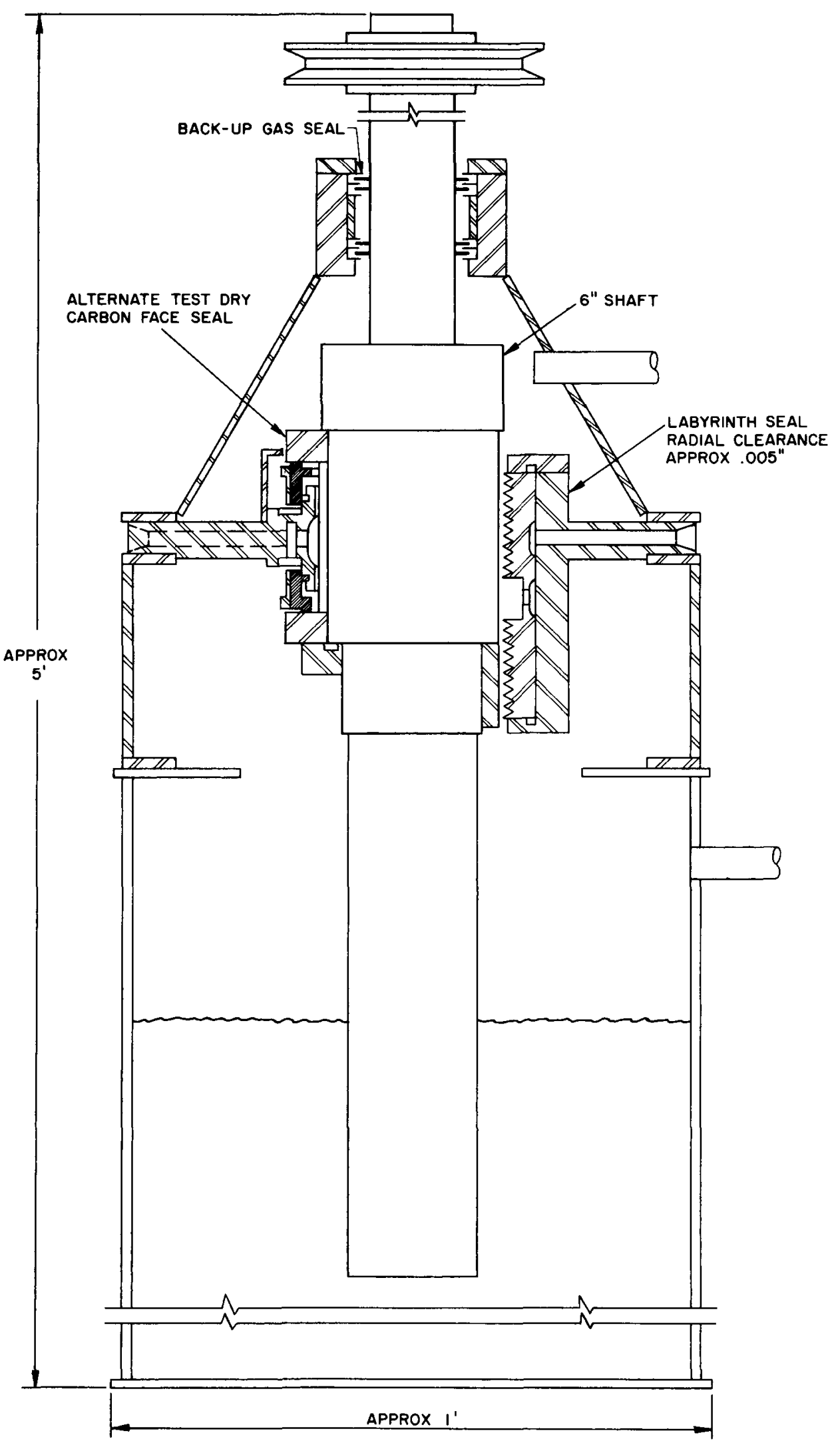

FIG. II-3 APDA PROTOTYPE SHAFT SEAL TESTER FOR FERMI 12.000-GPM LIQUID-METAL PUMP 


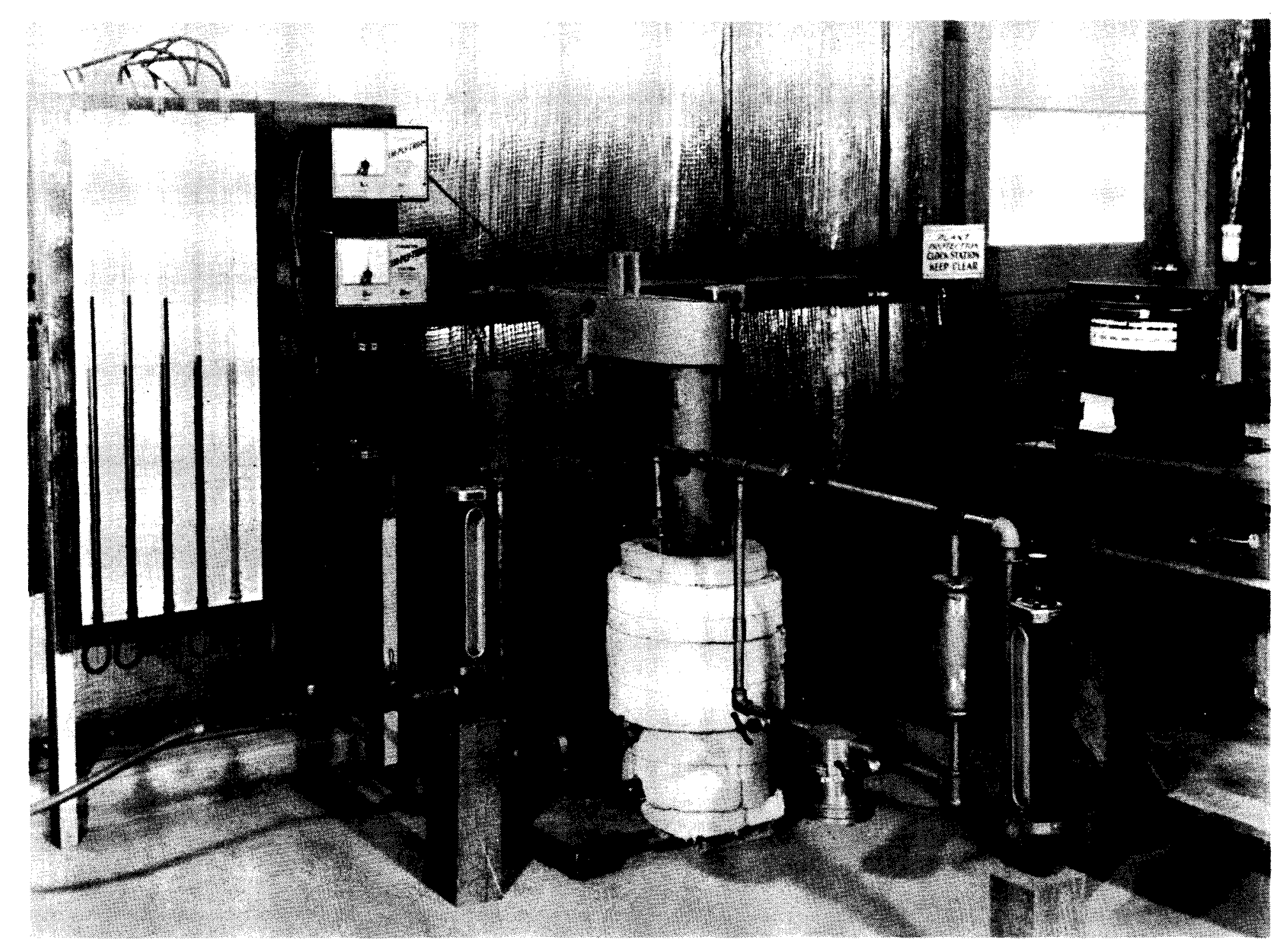

FIG. II-4 EXTERNAL VIEW OF THE PROTOTYPE SHAFT SEAL TESTER FOR FERMI 12,000-GPM LIQUID-METAL PUMP 


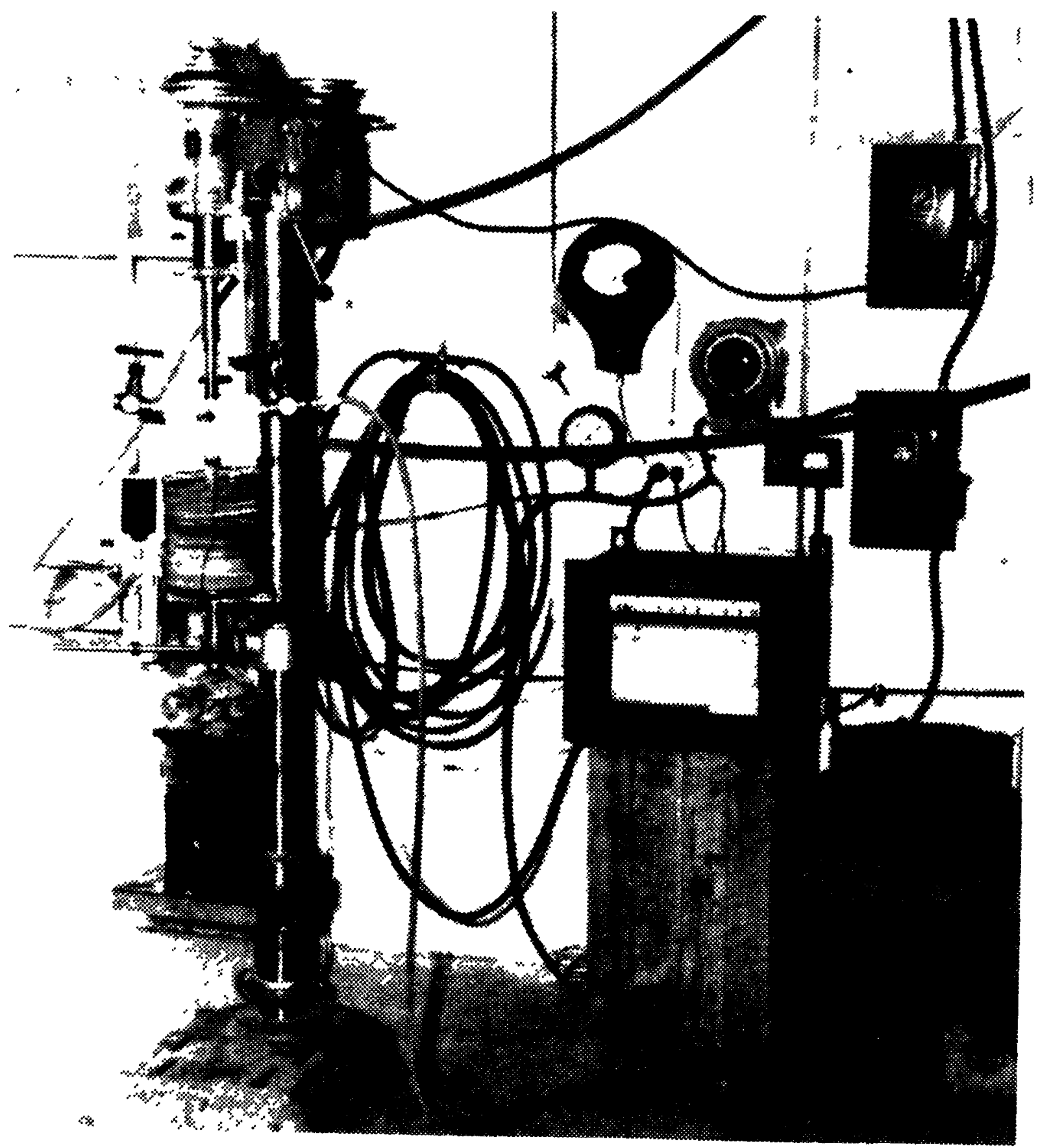

FIG. II-5 PRELIMINARY SHAFT SEAL TEST 


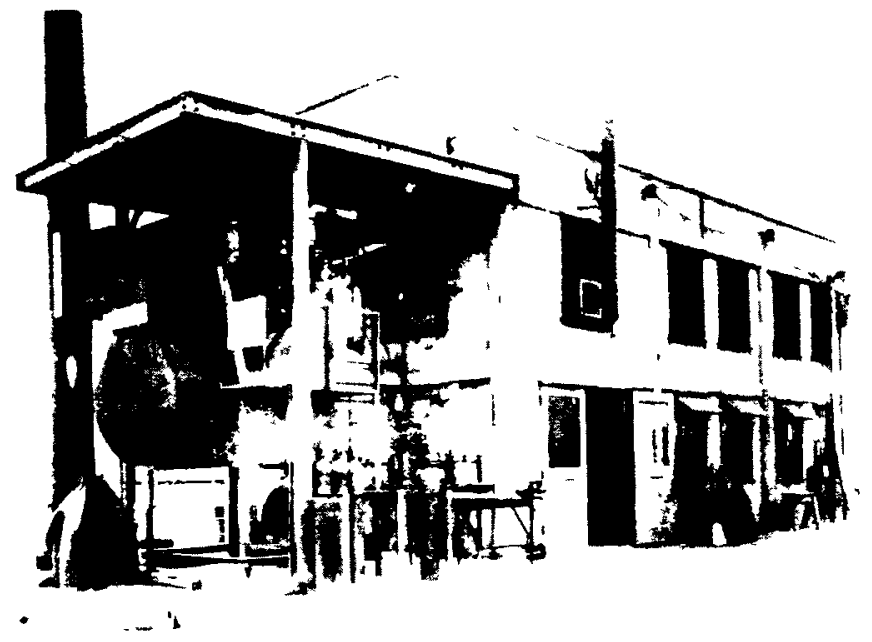

Front of buildıng containing the Steam Generator Test. The oil-fired NaK heater is shown on the left.

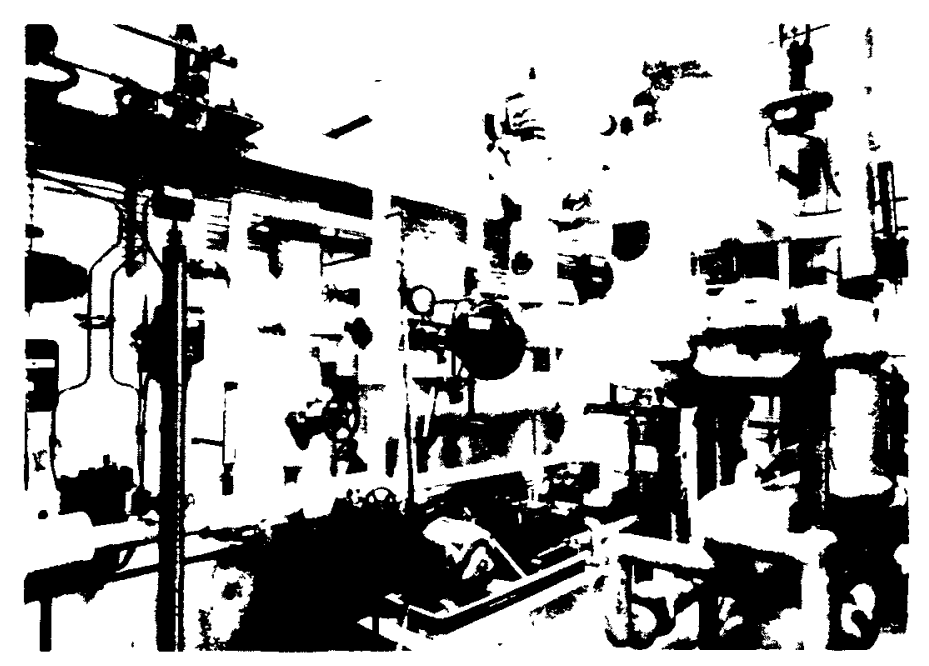

View of room contanner the feedwater system, includini the hoiler feed nump, feedwater and associated pipine.

FIG. II-6 STEAM GENERATOR TEST

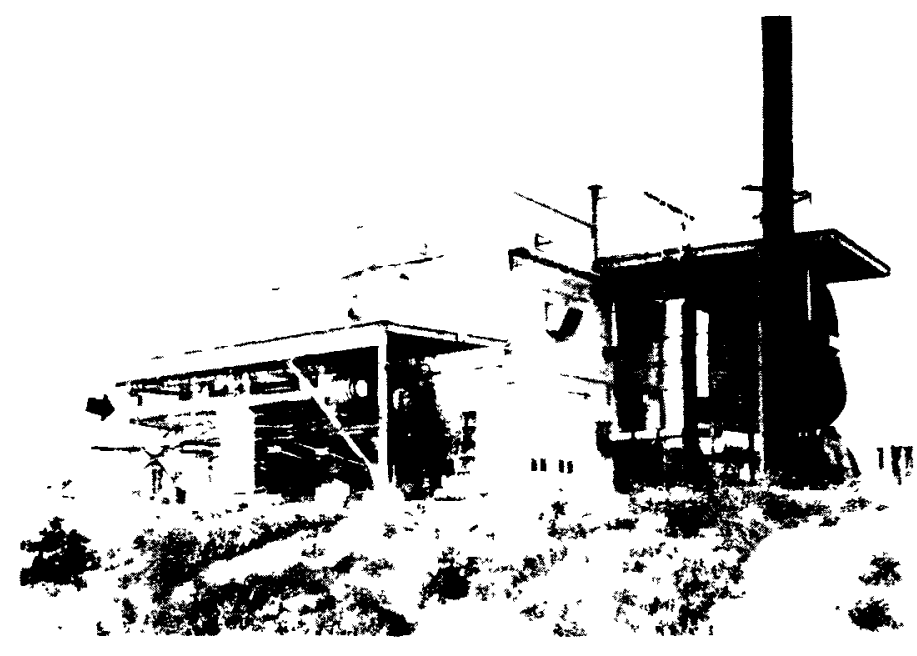

Rear of Steam Generator Test.

The arrow points to the U-shaped steam generator.

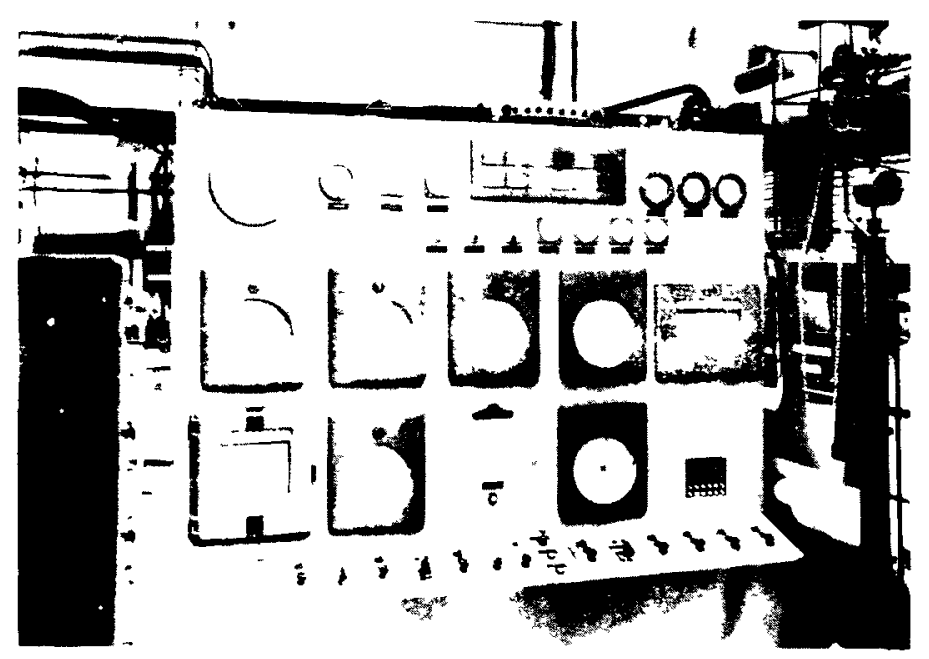

Main control panel for the Steam Generator Test. 


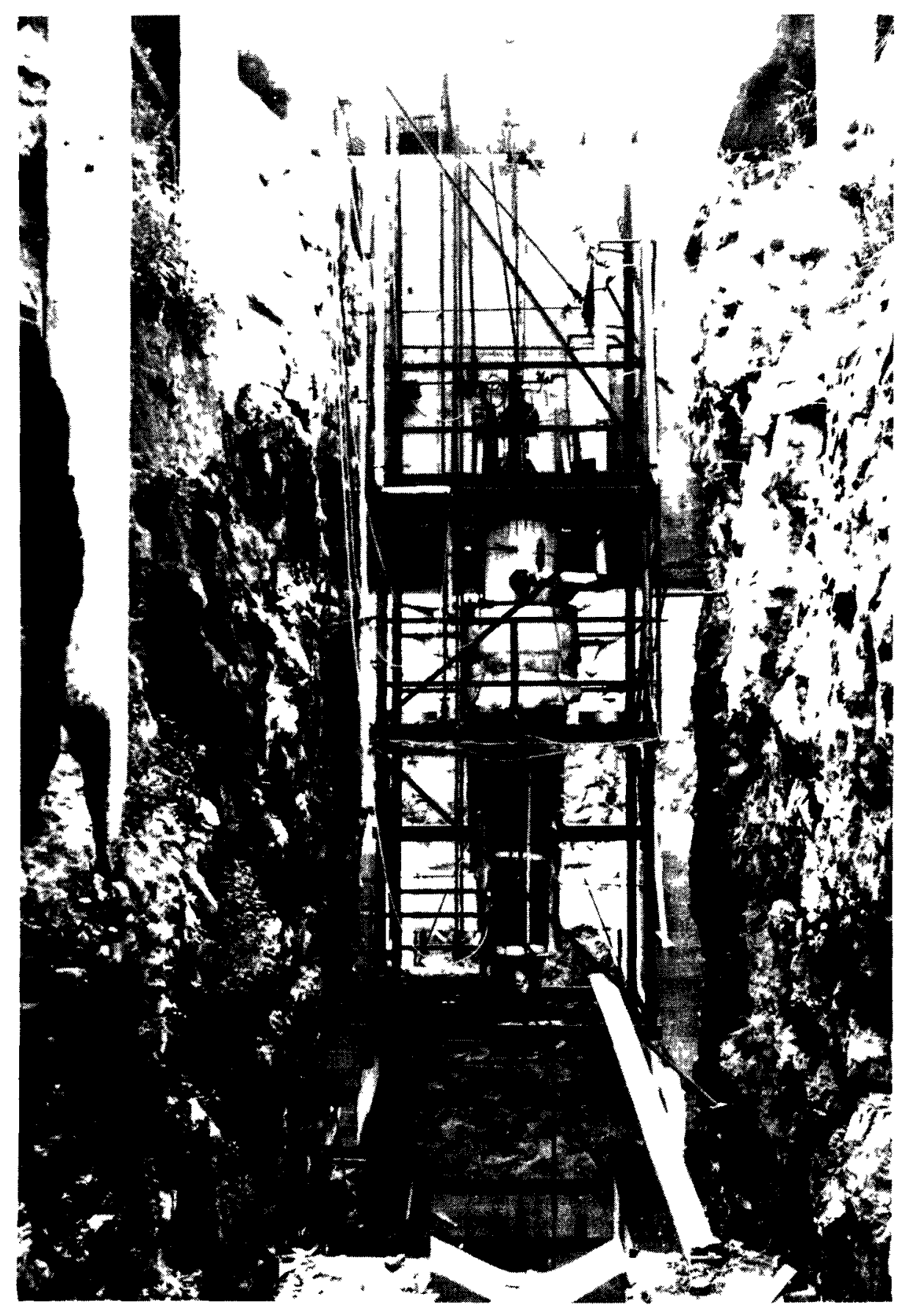

FIG. II-7 SODIUM - WATER REACTION TEST PIT 


\section{INSTRUMENTATION}

\section{A. FACIIITIES}

APDA's facilities for conducting research and development work in the area of instrumentation include:

\section{The APDA Sodium Technology Loop}

Designed for the investigation of sodium systems, this facility and its capabilities are discussed in detail in Section V - Liquid Metals.

\section{Hydraulics - Water Systems}

This facility and its capabilities are discussed in detail in Section V - Iiquid Metals.

\section{Under Sodium Scanner Test Apparatus}

Existing apparatus (Figure III-1) includes a soclium facility with cover gas purification system and the necessary transducer and electronic equipment for conducting attenuation tests in sodium and for the development and evaluation of narrow beam transducers.

The construction of an apparatus for testing of under sodium, single-transducer scanner systems is undervay; the fabrication of a sodium facility is near completion; the scanning mechanism and ultrasonic transducers are being fabricated; and the major part of the elcctronic design will be completed soon, so that assembly of the electronic system can be starled.

In addition to these facilities, APDA's work with the Enrico Fermi reactor makes it possjble to obtain a first-hand evaluation of process measurement techniques and equipment used or proposed for the Fermi reactor.

\section{B. ACHIEVEMENTS}

\section{Under Sodium Scanner}

APDA is engaged in a developmental program for an ultrasonic scanning device which will locate objects in high-temperature liquid sodium and transform the reflected sound waves into images. In this connection, an ultrasonic beam orientation has been found to be feasible by work done by APDA in determining the attenuation of sound waves in liquid sodium and in developing a transducer which operates at the high temperatures of interest. This work is reported in APDA-180, "Attenuation Measurements of Sound and Performance of Ultrasonic Transducers in 600 F. Liquid Sodium". 
Conceptual designs of two practical methods for viewing objects immersed in liquid sodium have been advanced by APDA: the single-transducer scanner and the electronic acoustic image conversion system. APDA179, "Concepts for General Purpose Under Sodium Scanning System, " is a presentation and discussion of the conceptual designs proposed by APDA.

\section{Sodium Level Detectors}

During the period of the conceptual design of the Fermi plant, all known level detectors for high-temperature operation in liquid metals were evaluated. Moore Special Model "15" detectors were selected from those available as most nearly fulfilling the rigid specifications that had been previously established by APDA. Several years later, the Taylor $\mathrm{NaK}$-filled detectors were evaluated and also were installed in the Fermi plant.

The Moore Special Model "l 5 " detectors will measure levels with accuracies of approximately \pm 3 inches of reading. An advantage is that the detectors are capable of mcasuring levels with a cover gas pressure below atmospheric and, with the properly observed precautions, down to a full vacuum.

The Taylor NaK-filled detector has operated satisfactorily with a high degree of accuracy, small temperature shift, good linearity and reproducibility, and with a minimum of maintenance required. APDA's work in this area is reported in APDA-300, "Sodium Ievel Detectors in the Enrico Fermi Atomic Power Plant."

\section{SPECIAI CAPABILITIES}

\section{Fission Product Monitoring}

APDA conducted an investigation of various methods of detection of a fuel failure in the Fermi reactor. As a result of this investigation a precipitation-type fission products detector was selected for further study. This device employs a method of detection which measures the beta decay of fission-product gases evolved in the leak. Specifically, the precipitationtype detector measures the activity of the decay products from krypton and xenon, preferentially in an argon-4l atmosphere. The investigation of this method of detection involved the determination of the feasibility of the precipitation-type detector and the determination and solution of problems associated with such a detector. A description of the equipment is given in Figure IFI-2. Figure III-3 is a schematic diagram of the precipitationtype fission products system that was eventually employed in the Fermi reactor.

\section{Pressure and Vibration Monitoring}

As part of an investigation of the effects of the pressure pulses created in the primary sodium system by operation of the pump check valves, 
three instrumented probes were designed by APDA for insertion in the Enrico Fermi reactor to monitor sodium pressure and pressure surges in the plenums under the support plate and to detect any motion of the support plate which might be induced by pressure pulses in the sodium. These probes were placed in position and the instrument readings were recorded during a test program in which check valves were caused to slam shut either by starting only one or two of the three pumps, or by shutting down one pump while the other two pumps remain operating at various pump speeds.

One probe was installed through the access hole located in the center of the rotating shield plug and extended down to the level of the bottom of the lower support plate in the low-pressure (blanket) plenum. This probe was equipped with both a static and a transient pressure sensing instrument and an accelerometer mounted to measure vertical vibrations.

The second probe was installed in a safety rod position using the lower guide tube safety rod dashpot as a rigid connection between the probe end and the core support plate structure. This probe was equipped with three accelerometers mounted to measure vibrations or motions along each axis. The lower part of the probe containing the instruments was isolated from the remainder by a spring to keep the vibration mass small and increase the sensitivity.

The third probe was installed in a control rod position. This probe consisted of an outer casing which rested on the control rod pedestal and an inner tube conlaining a static and a transient pressure sensing instrument which rested on a shoulder on the inside of the casing near the lower end. As the pedesial rests directly on the lower support plate, there was a direct solid column connection between the top of the instrument probe and the support plate. A dial indicator was installed so that it would show vertical displacement of the probe upper end in relation to the top of the rotating plug. Figure III-4 is a schematic of the three probe installations.

\section{Reactor Control Room Instrumentation}

The control room instrumentation of the Enrico Fermi reactor is the product of APDA design and engineering effort. As such, it represents a wealth of reactor control system experience. The design of the Enrico Fermi control system is predicated uponthree basic conditions: (1) power changes will be initiated at the reactor, (2) sodium flows in the primary and secondary loops will be constant from startup to 1000 per cent of specified power levels, and (3) the normal rate of change of power will be present in the control system. The system programs the reactor outlet temperature from a temperature setpoint and maintains a programmed reactor temperature regardless of the action of other variables, such as actual power or sodium flows. With constant sodium flows and a scheduled reactor inlet 
temperature, reactor power is a function of the reactor outlet temperature. The reactor outlet temperature signal is used to position the regulating rod.

Prior to the final design of the Fermi control system, under the direction and guidance of APDA, an analog simulator with specially designed electromechanical equipment was developed to simulate one of the three circuils of the Fermi reactor. With the support of a steady-state digital analys is of the plant, a philosophy of plant control was evolved. Although an actual control system was not built, conceptual designs were tested on the simulator and an optimum design was selected and tuned. A report on this work was published by the Holley Carburetor Company as Report No. 59-12, "Analysis and Simulation Study of the Operation Control System for the Enrico Fermi Atomic Power Plant."

In addition to this study, a second study was conducted under APDA supervision to sjmulate on an analog computer the power limiting systems of the Fermi reactor. In this siudy, the transients resulting from failures in the electrical and mechanical equipment associated with the reactor were considered. The results of this study are presented in Bendix Report No. 1317, "Supplcmentary Analysis of the Power Iimiting System for the Enrico Fermi Atomic Power Plant, " and an earlier report, Bendix No. 1052 .

The control and jnstrumentation systems are designed for. centralized control of the reactor plant and auxiliary systems. The design of the control systems and the layout of the central control room permit opcration of the plant by the plant operator and one assistant, both stationed in the central control room, and a roring operator. Centralized control of the reactor and plai: auxiliaries provides control of the plant with a small operating shift and, in addition, allows remote control of certain systems even though the local areas become contaminated.

\section{Nondestructive Testing}

When no proven off-the-shelf nondestructive tests could be found for testing the Core A fuel element and element components for the Fermi reactor, APDA assisted in the development of testing techniques. This included the responsibility for dereloping special tests, enginecring and fabricating reliable production test equipment, establishing test standards, correlating instrument and destructive test data, and training the fabricator's quality control personnel in the operation and interpretation of the tests.

APDA has also designed and built a prototype device for testing the nitride thickness on fuel subassemblies. Using the principle that eddy currents are induced by a varying ferromagnetic field, rings with thickness probes were used to slip over the nitrided end of the subassembly. It was found that thickness variations in the nitride casing as small as 1 to 2 mils could be detected by the induced eddy current. 


\section{RESEARCH AND DEVELOPMENT PROGRAMS}

1. Under Sodium Scanner, AEC Contract No. AT(11-1)-865, Project Agreement No. 14

The scope of the under sodium scanner test program is to develop and evaluate devices for locating and discerning objects in liquid sodium. The supporting test facility and the current achievements in this program are described elsewhere in this section. Plans for the program include: (1) the development and evaluation of narrow beam transducers operating in $600 \mathrm{~F}$ sodium which will be used as search units for scanning systems, and (2) the engineering, design, fabrication, and initiation of testing of under sodium, single-transducer scanner systems which will provide locations and images of objects in sodium.

\section{Sodium Technology Loop, AEC Contract No. AT(11-1) -865,} Project Agreement No. 11

The over-all objectives of the sodium technology loop project are to investigate and evaluate in-line detection and purification devices for sodium systems. The testing facilities consist of a pilot-plant scale recirculating sodium system, designated as the sodium technology loop (described in Section V), together with a supporting chemistry laboratory. Two types of impurity monitoring devices are being evaluated at present-the Rhometer and the oxygen meter. At this time, a temperature compensator is being developed for the Rhometer that will automatically correct for temperature variations. In addition to the Rhometer and oxygen meter, a detector is being developed for the monitoring of hydrogen in sodium. The principle of operation is the diffusion of hydrogen through a metallic barricr, the calalytic oxidation of the hydrogen as it emerges from the metallic surface and detection of the water produced with a precision moisture monitor.

Three Rhometers and four of the United Nuclear Corporation oxygen meters are being evaluated for their response to conditions of steady-state impurity level and of increasing and decreasing impurity level. In addition, the Rhometer's response to various types of impurities is being evaluated. The oxygen meters are being evaluated for their response to conditions of increasing and decreasing temperature level. Concurrent with the evaluation of these two monitoring devices, purification devices are being evaluated which include a supercentrifuge, hot trap, cold trap, filters, and hydroclones. Development and evaluation of additional in-line instrumentation is also planned for the detection of carbon in sodium, along with research and development of pressure instrumentation and flowmeter evaluation.

III. 5 
E. PUBIICATIONS

APDA publications on liquid metal and fast reactor instrumentalion include the following:

Over-all Instrumentation of a Nucleax Power Plant (ISA)

A Device for the In-Pile Monitoring of Swelling of an Irradiation Specimen (Proc. AEC Irradiation Capsule Meeting, September 1959)

Evaluation of High-Temperature Strain Gages for the Enrico Fermi Reactor Vessel (Soc. for Experimental Stress Analysis, October 1960)

Design Concept and Proposed Development Program for a Iiquid Level Measuring Device (T-26)

Investigation of Instrumentation for a Fission Products Detector for the Enrico Fermi Reactor ( $T-36)$

Resistivity Meter for High Temperature Iiquid Metals (T-37)

Application of Ultrasonics to Core Surface Scanning in the Fermi Reactor (E\&I, T-3I)

Preoperational Test Report VII-F, Neutron Detectors and Startup Instrumentation

Analysis of the Results Obtained from the Instrumental Probes During the Check Valve Testing Program (MD-63-312)

Sodium Technology Loop Evaluation of In-Iine Instrumentation and Purificalion Devices (AEC-CONE. 650620). 

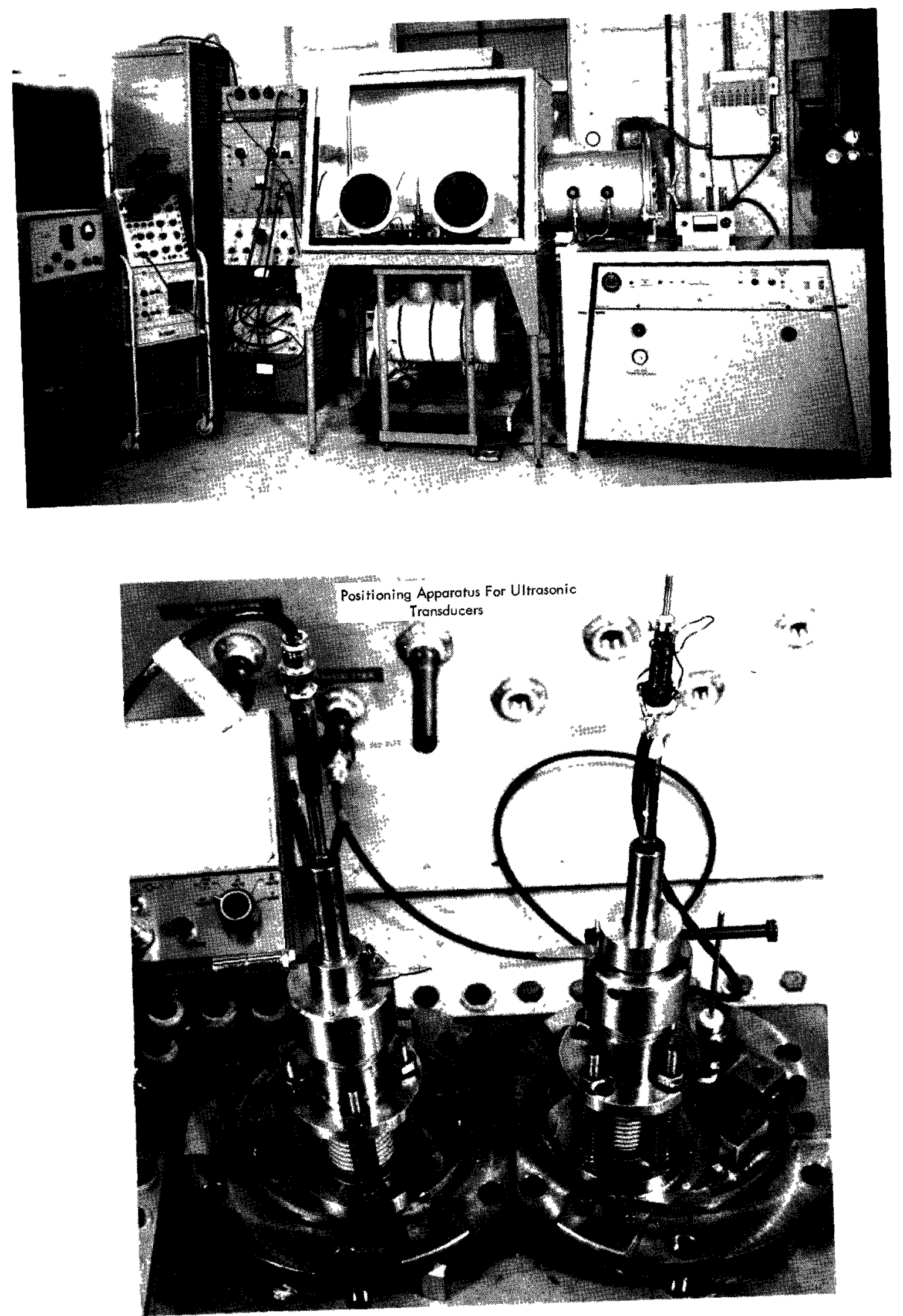

FIG. III-I UNDER SODIUM SCANNER 


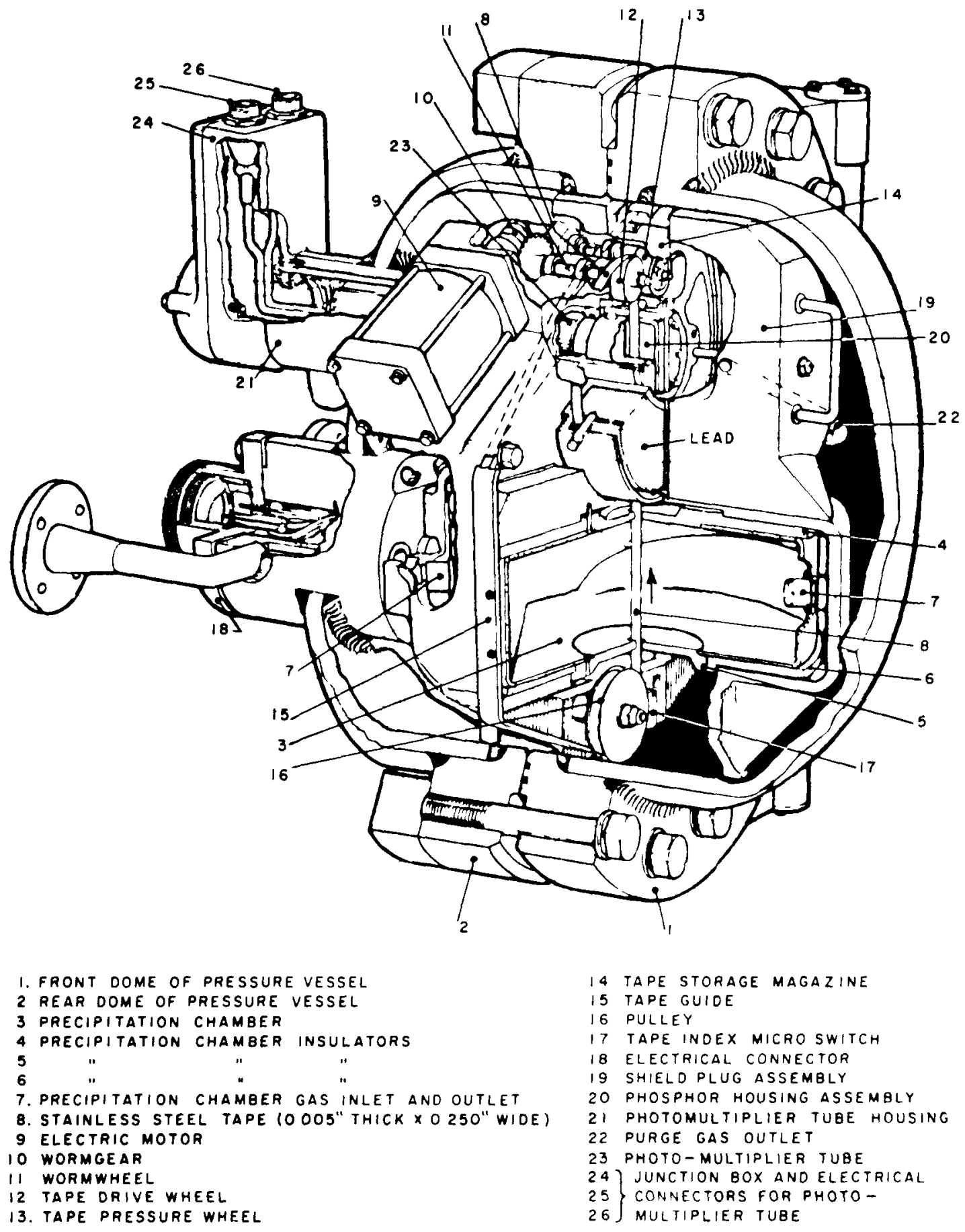

FIG. III-2 FISSION PRODUCT MONITOR (HSR) 


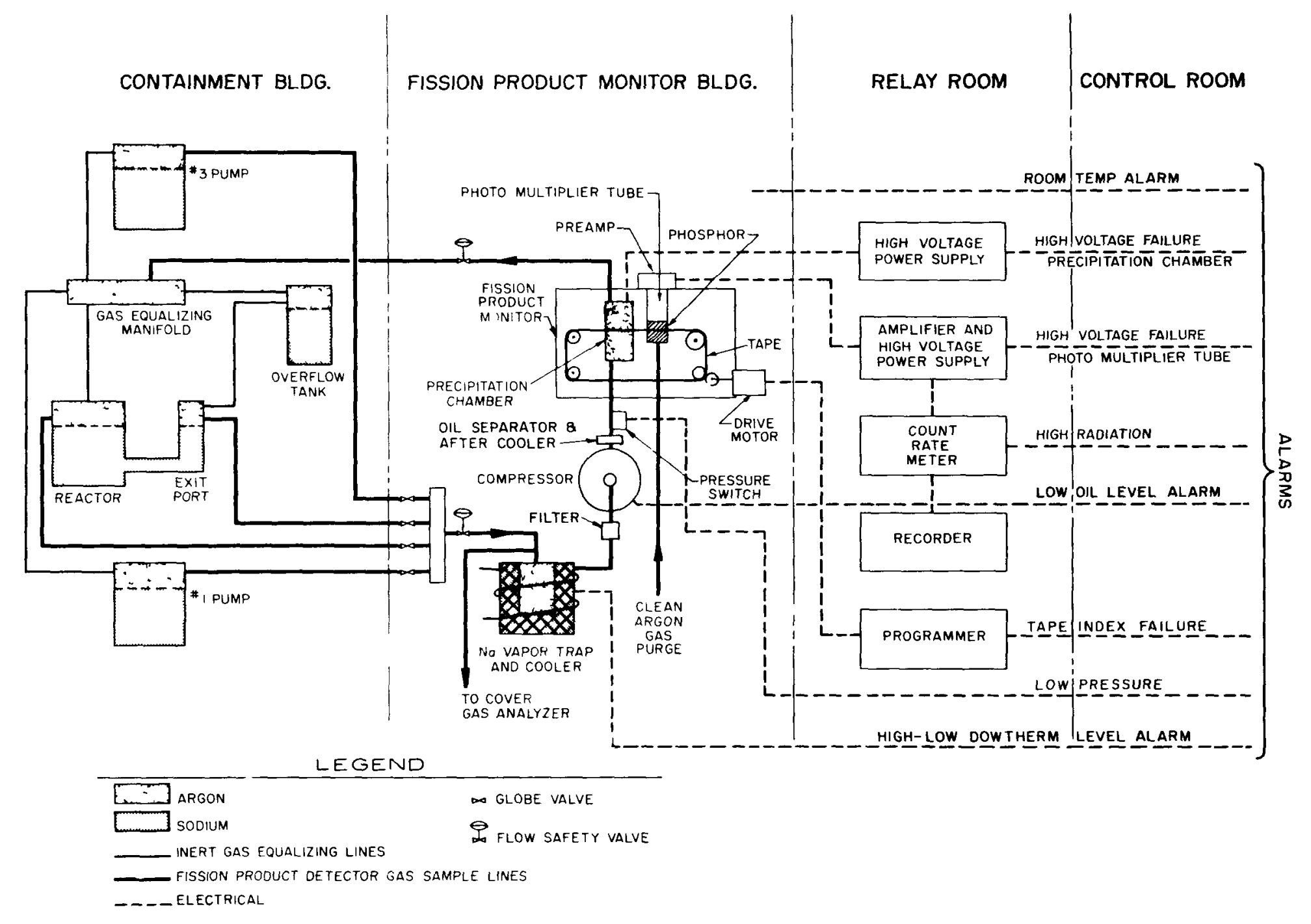

FIG. III-3 FISSION PRODUCT DETECTOR MONITORING SYSTEM (HSR) 


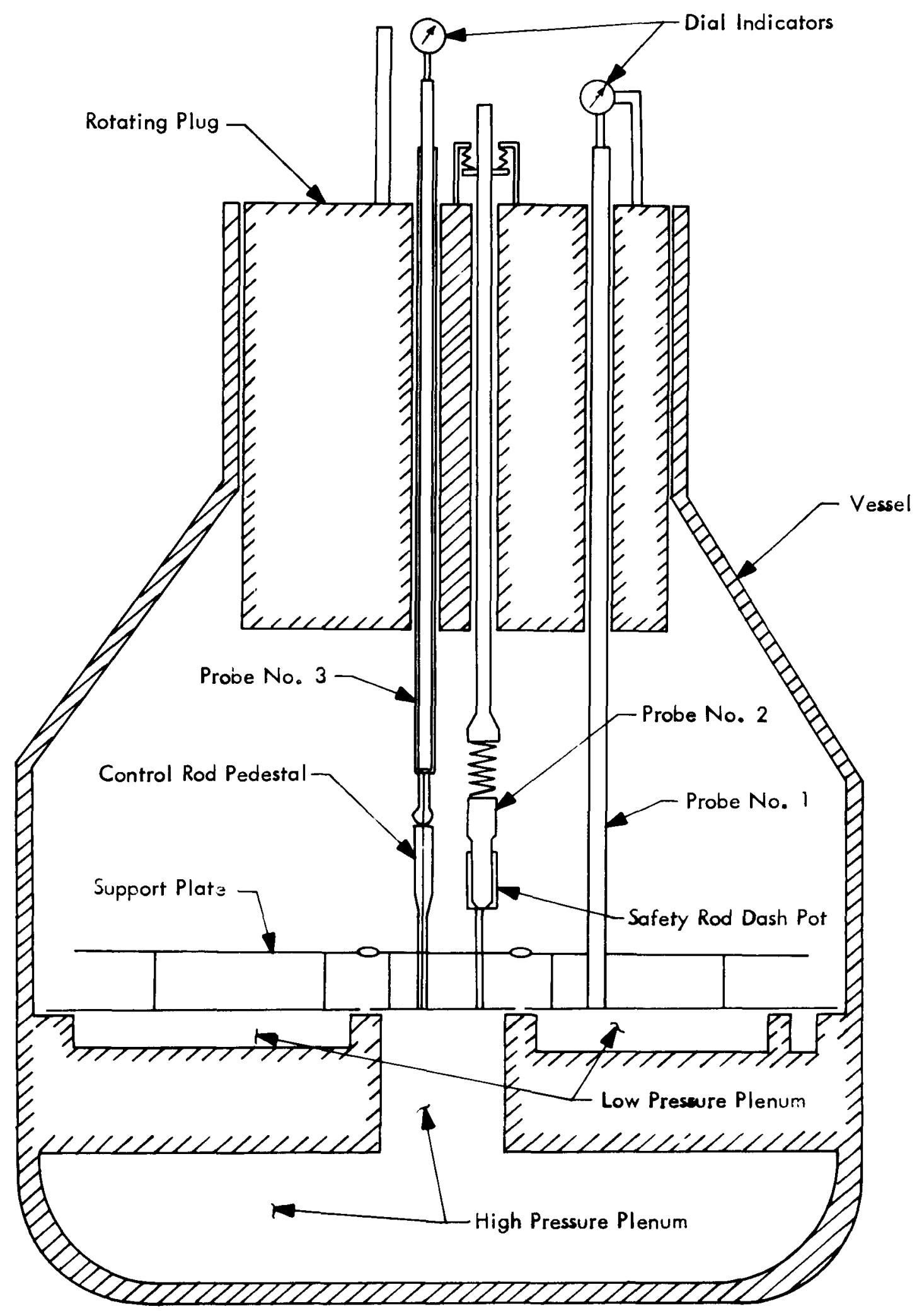

FIG. III-4 SCHEMATIC OF PROBE INSTALLATION FOR CHECKING SODIUM PRESSURE AND PRESSURE SURGES 
IV. FUEIS

\section{A. FUEL PROGRAMS}

During the past several years, APDA has been engaged in four separate fuel development programs: Core A, consisting of $U-10 \mathrm{w} / \mathrm{o}$ Mo pin-type elements with $U-3 \mathrm{w} / \mathrm{o}$ Mo axial blanket rods for the initial core loading of the Enrico Fermi reactor; a proposed Core B, consisting of $\mathrm{UO}_{2}$-SS cermet plate-type fuel elements with $\mathrm{UO}_{2}$ axial blanket rods for the Enrico Fermi reactor; plutonium fuel studies; and piped particulate development.

\section{Core A}

To establish the initial fuel system (Core A) for the Enrico Fermi reactor, APDA engineers met and solved many basic problems connected with the design and fabrication of high-power-density fuel elements for the fast breeder reactor. A major effort was devoted to the development of a suitable fuel alloy and to the investigation of structural and fuel-cladding materials for use in sodium, with the emphasis placed on determining the corrosion resistance of the fuel element cladding. A program was conducted dealing with the metallurgical problems in fuel fabrication to determine:

(a) the production fabrication procedures to be employed in preparing a homogeneous fuel alloy pin,

(b) the allowable impurity limits on the basis of fabrication, homogenization, and irradiation behavior, and

(c) the causes of cracking during fabrication of the fuel alloy selected for the Enrico Fermi reactor and methods of eliminating this cracking.

Following this fabrication development program, APDA wrote the fuel fabrication specifications, developed nondestructive testing techniques used for evaluating the production fuel and, in general, had prime responsibility for the successful fabrication of the core. Extensive design studies of the core were conducted, including methods for supporting the fuel in the core. In addition, core temperature distributions and the relationship of pressure drop and coolant flow were studied and predicted, and thermal and hydraulic stress were analyzed. To verify the analytical predictions, APDA engineers specified and carried out conventional pressure drop, hydraulic force, and thermal deflection tests and developed new techniques for measuring velocity profiles in unusually narrow channels. The results of the velocity profile work were made available to ANI, where the techniques developed by APDA were extended and applied to the EBR-II development program. 
Finally, APDA designed various types of subassemblies for obtaining data to be used in conducting and evaluating the nuclear tests for startup and initial low-power operation--one subassembly for fine reactivity adjustment, a second for mapping neutron flux over the core, one for determining the reactivity value of sodium in the reactor, and oscillator rods for studies of reactor dynamics under low-power and full-power operation. More recently, APDA developed the nonfissionable materials test subassembly (Figure IV -1) to aid in studying the effects of radiation on nonfissionable materials, and the standard fuel test subassembly (Figure IV-2) for fuel testing.

Prior to low-power testing of the reactor, APDA engineers designed and carried out an extensive radiation-testing program involving the testing of subsized specimens in the Materials Testing Reactor (MTR) and the testing of full-length fuel pins in the Argonne Rescarch Reactor (CP-5). In the case of the MTR tests, essentially all the work was carried out by Battelle Memorial Institute (BMI) under contract to APDA. In this case, BMT designed and fabricated the radiation capsules, followed the radiation exposures, and conducted the hot cel] cxamination of the specimens. In the case of the CP-5 ixradiations, APDA employees, working at Argonne, designed the air-cooled loop in which experiments were carried out, supexvised installation of the loop, and conducted the experiments in the reactor. The postirradiation examinations were carried out in the ANL hot cell under the supervision of APDA engineers.

\section{Core B}

The fabrication, development, and irradiation program for Corc $B$ was done at Oak Ridge National Iaboratory (ORNL) under the AEC-PRDC contract; the design and out-of-pile testing was sponsored and carricd out by APDA. In addition to the general design work, APDA's part of the program included determination of thermal conditions for both steady state and scram and a preliminary stress analys is of Core B. APDA also planned, designed, and carried out a test to determine flow distribution between plates and a test simulating thermal cycling conditions in sodium. An endurance test of the fuel bundles in sodium and a test subjecting the fuel bundle and the supporting mechanism within the wrapper can to loads simulating those that will occur during actual opcration were also planned and designed.

\section{Plutonium Fuel Studies}

APDA conducted a survey of potential fuel systems that could be used in the Fermi reactor. The object of the survey was to determine. whether a plutonium breeder fuel could be developed and fabricated into a full core loading by 1969. Early in the survey, the selection of a fuel was narrowed down to (1) the mixed oxide plutonium and uranium, and (2) plutonium oxide dispersed in a matrix of stainless steel (cermet). Conceptual designs, using fuel elements in the form of pins, were developed for each of these fuels. 
The results of the study indicated that the plutonium oxideuranium oxide $\left(\mathrm{PuO}_{2}-\mathrm{UO}_{2}\right)$ fuel would be the most suitable material for the Fermi reactor based on its long-range potential, the schedule desired, the technological background available, and the relevant programs underway in the United States and abroad to develop this material as a fuel. As a result of these conclusions, a detailed program to demonstrate the performance and operating characteristics of the mixed-oxide fuel in the Fermi reactor was outlined under the sponsorship of The Detroit Edison Company.

Started in 1965, the program involves a concentrated effort to develop a detailed core design and specification that can be scheduled for completion in four years at an estimated cost of approximately $\$ 5$ million. In this program the fabrication development effort will be carried out by BelgoNucleaire in cooperation with EURATOM and the Belgium CEN. Their responsibility will be to develop fabrication process specifications and to fabricale test pins to be uscd in the radiation test portion of the program.

The radiation tests will be conducted in the Fermi reactor, using a fuel test subasscmbly designed by APDA (Figure IV-2). The over-all test program will again be developed within APDA, and the actual radiations will be followed by APDA engineers. Postirradiation examination of the test pins will be carried out at an outsiclc hot cell.

This program was started at APDA in mid-1965, with an early objective of having fucl pins ready for radiation testing in Fermi by January 1, 1967. The radiation tests will be conducted over approximatcly a two-year period, with plans for a core to be ordered for use in the Fermi reactor by late 1968 .

\section{Fuel Cycle Studies}

In addition to working on design and materials problems, APDA has studied the other economic and engineering problems associated with fast reactor fuel cycles. Economic and engineering studies have been made of the fuel cycles of a wide variety of fuels, using as the fissionable material either U-235 or plutonium in the form of metallic alloys, cermets, and ceramics. The studies were made in connection with several APDA-directed design studies, including the $300-M w e$ and 150 -Mwe plutonium-fueled reactor studies reported in APDA-129, "A Plutonium-Fueled Fast Breeder Atomic Power Plant"; APDA-154, "Fast Reactor Fuel Cycle Costs and Temperature Coefficients of Reactivity for $\mathrm{PuO}_{2}{ }^{-\mathrm{SS}}$ and $\mathrm{PuO}_{2}-\mathrm{UO}_{2}{ }^{\prime \prime}$; and APDA-136, "150-Mwe Plutonium-Fueled Fast Breeder Atomic Power Plant", respectively, and in connection with the fucl cycle parameter study carried out by APDA under contract to the AEC and reported in APDA-133, "Fast Reactor Core Design Parameter Study." 
The significant parameters considered in the conomic studies have included reactor variables such as burnup, power density, and breeding ratio, as well as out-of-pile costs such as fuel fabrication, shipping, reprocessing, plutonium price, fuel use charges, and steam revenue. Problems considered under the engineering studies include materials accountability, reprocessing and transportation of irradiated and nonirradiated fuel, fuel cycle throughput rates and inventory requirements, and the handling and disassembling of irradiated fuel subassemblies.

APDA's work on materials accountability represents the first major effort in the industry to determine the basic requirements for fuel accountability. This effort required the establishing of detailed sampling procedures, chemical and isotopic analysis procedures, and a bias check program to provide the data for a statistical accountability analysis. Sta tistical methods were also used to establish the limits of uncertainty in fuel loading and in burnup calculations.

\section{B. FACIIITIES}

\section{Hydraulic-Water Systems}

a. Four-Inch Hydraulic Test Loop

At the present time, APDA has two high-capacity, closed loops which can be used for various hydraulic tests on fuel subassemblics. The work carried out by APDA in these loops includes the determina ion of pressure drops for multitube test sections and for rectangular channels, and the determination of lifting velocities for the EFAPP subassembly. The loop has also been used for cavitation tests.

As shown in Figure IV-3, both loops are supported on the same stand. One of these two loops is all stainless steel; the other, carbon steel. The stainless steel loop can accept either a verical or a horizontal test section. The vertical sections of both loops can accommodate a 110 inch-long test section without modifications, and a horizontal test section about 34. 5 inches long can be inserted in the stainless steel loop. A switching panel (Figure IV-4), used to connect the static pressure taps of the test section to the readout instruments, enables about 120 different pressure points per test section to be read. Both loops circulate water by means of centrifugal pumps whose capacities are $300 \mathrm{gpm}$ at $150 \mathrm{psi}$ discharge pressure. (Hot water, between $120 \mathrm{~F}$ and $220 \mathrm{~F}$, can be circulated.)

The permanent instrumentation used with these loops includes:

1. Three Cox turbine flowmeters covering the range 0 to 300 gpm.

2. One Leeds \& Northrup Pulse Converter

3. $C \& G$ Electromanometer covering the range -150 psi to +150 psi 
4. One CEC Servo-amplifier (pressure readout): $0.15 \mathrm{psi}$ least division

Miscellaneous equipment includes various thermocouples and a temperature recorder. A one-half-inch National Borescope and a onehalf-inch fiber optical device is available within APDA and can be used to conduct visual observations within the test section.

Cavitation testing done in the stainless steel water loop involved the use of a test chamber with three glass viewing ports to observe the formation of the vapor bubbles. The chamber is designed to simulate the Fermi support plates with a Core A nozzle installed but could be modified to mock up other geometries.

The loop can develop a pressure at the inlet of the test chamber of about 100 psig at a flow rate above $100 \mathrm{gpm}$. The pressure downstream of the test chamber is adjusted by varying the cover gas pressure. This control, plus control of the loop water temperature, permits the establishment of conditions under which the water will cavitate at the same flow rate as sodium.

Of special interest is the recent preliminary work that has been done in the development of a technique for visually observing the flow patterns in a multitube test section. Should this technique be fully developed, the existing equipment would be well suited for mixing investigations.

\section{b. Simulant Mobile Fuel Ioops}

In addition, to the high capacity loops, there are several smaller plastic loops, in use and presently being designed, for studies in support of the high-temperature test loop. These are to be used primarily for two-phase (solid-liquid) flow, such as copper-or lead-shot and water systems. Pressure drops, particle mobility, flow stability, and component characteristics are to be determined in these loops.

\section{High-Temperature Sodium Loop}

Used in connection with APDA's mobile fuel (paste) program, it is expected that the loop will be available for other work as of July 1 , 1966. A complete description of this facility and its capabilities can be found in Section V - Liquid Metals.

\section{Sodium Endurance Loop}

This sodium flow loop is used for endurance testing of fuel subassemblies at APDA. The facility and its capabilities are discussed in detail in Section V - Iiquid Metals. 
4. Fuel Pin Melidown Equipment

APDA has conducted melidown studies using a lead rod-water system to simulate the fuel rod-sodium system. Resistance heating of the rods was used. The power supply used was designed to deliver $60 \mathrm{kw}$. This equipment has been dismantled and the reusable equipment has been placed in storage.

\section{MAJOR CONTRIBUTIONS AND PUBIICATIONS}

The major contribution of APDA to fuel technology is felt to be the evaluation of fission rate effect on the stability of the gamma phase of the $\mathrm{U}-10 \mathrm{w} / \mathrm{o}$ Mo alloy. There have been numerous publications on the results of the APDA radiation program, the most significant of which was presented at the Vienna Symposium on "Radialion Damage in Solids and Reactor Materials, "May 1962. The title of this paper was "The Effect of Radiation Temperature and Fission Rate on the Radiation Stability of U-10 w/o Molybdenum Alloys."

The following is a list of APDA publications on fuels:

Effect of Heat Treatment and Burmup on the Radiation Stability of U-10 w/o Mo Fuel Alloys (ASTM)

The APDA Irradiation Test Program on Selected Fuel Alloys, June 1954-June 1957 (APDA-122)

Radiation Stability of Fuel Elements for the Fnrico Fermi Power Reactor (UN Paper-622) (OIC-1291)

Development of Core Elements for the Enrico Fermi Power Reactor (UN Paper-792) (OIC-128-1)

Effects of Irradiation on the Type 347 Stainless Steel Flow Separator in the EBR-I Core, ASTM Paper (Jointly with Argonne National I aboratory) to be published by ASTM

Report on Core and Blanket Designs and Technology

Model Studies of the Flow Characteristics of the Fuel Elements for the Enrico Fermi Reactor (AICHE)

Thermal Bowing of Core Subassemblies (APDA-128)

Fuel Enrichment for the Enrico Fermi Reactor (APDA-133)

Pu-U and U-233-Th Cermet Type Fast Breeders (ANI) 
Irradiation Testing of Enrico Fermi Prototype Fuel Pins in the CP-5 (APDA-130)

Cubic Expansion of Plutonium and Plutonium Iron Eutectic Between Room Temperature and 700 to $800 \mathrm{C}$ (Second International Conference on Plutonium Metallurgy, Grenoble, France, April 1960)

Radial Heat Transfer Analyfis of Finned Air-Cooled Irradiation Capsules (Second AEC-Sponsored Conference on Irradiated Capsule Experiments, May 1960)

Irradiation Testing of Enrico Fermi Prototype Fuel Pins in the CP-5 Reactor (ASTM, June 1960)

Summary of the APDA Fuel Development Programs (APDA-143)

The Effect of Irradiation Temperature and Fission Rate on the Radiation Stability of $\mathrm{U}-10 \mathrm{v} / \mathrm{O}$ Mo Alloy (IAEA, Venice)

Design and Economic Evaluation of Fixed Blankets for Fast Reactors (APDA-156)

Design and Economic Evaluation of Mobile Blankets for Fast Reactors (APDA-160) 


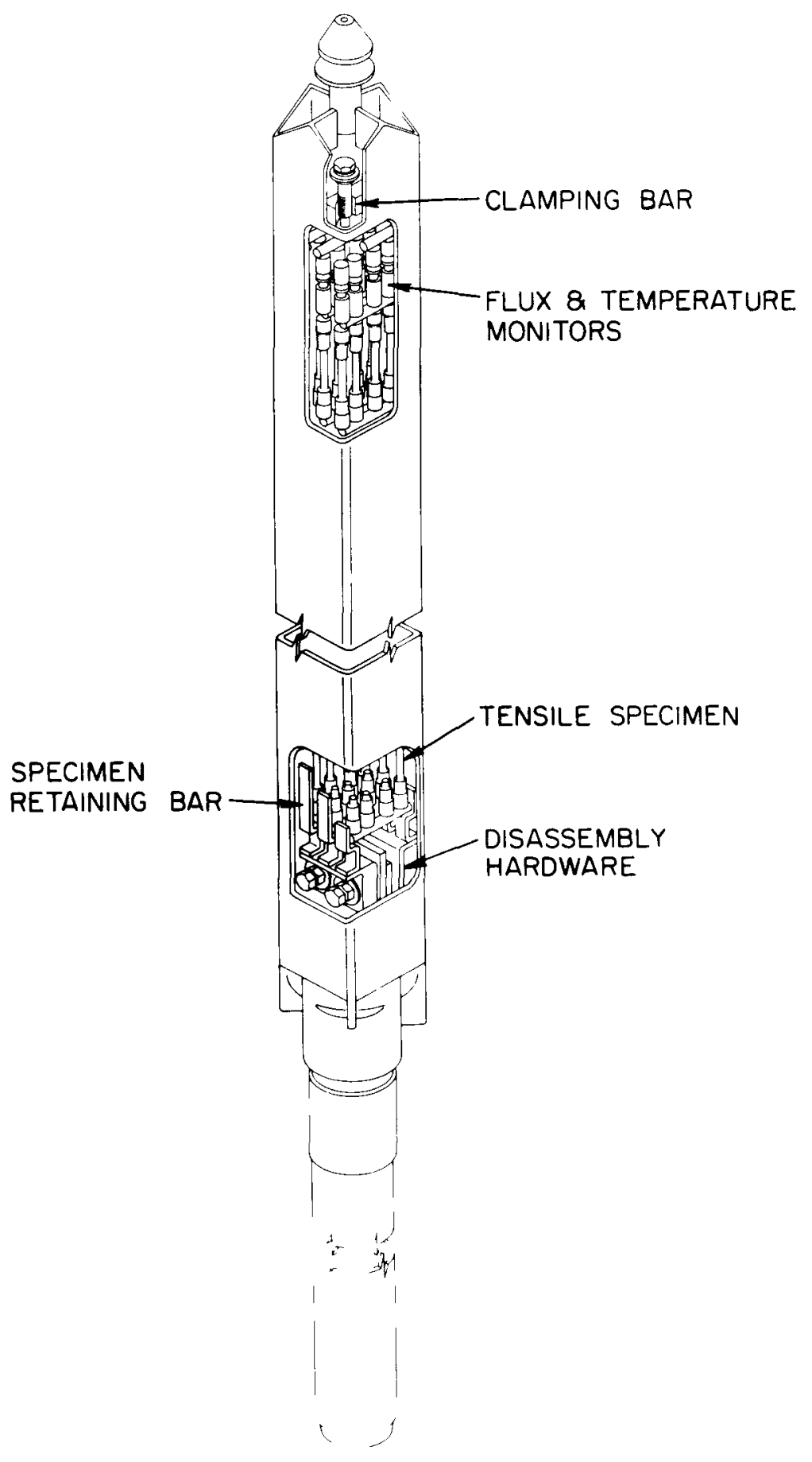

FIG. IV-1 NONFISSIONABLE MATERIALS SUBASSEMBLY 


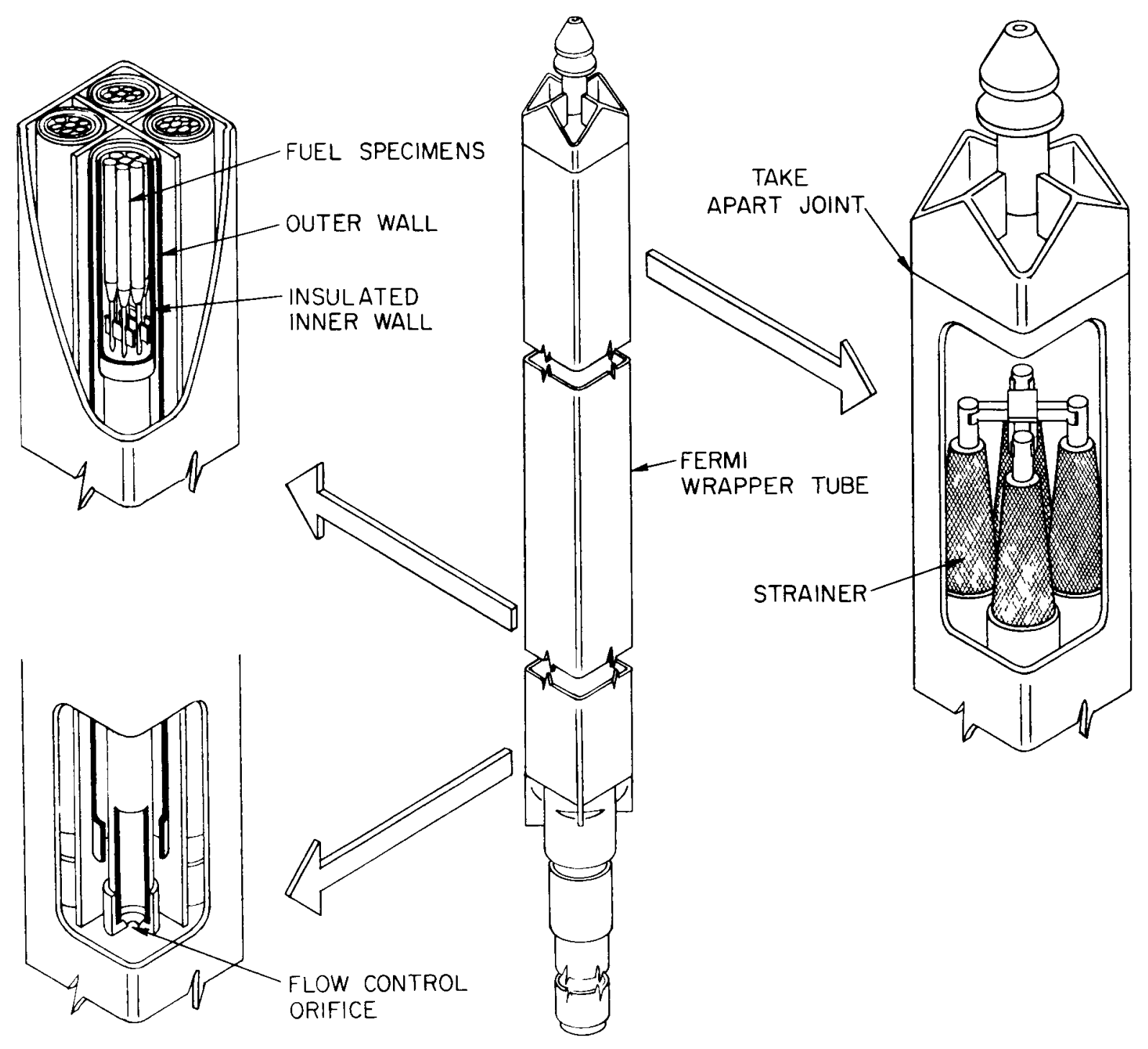

FIG. IV-2 STANDARD FUEL TEST SUBASSEMBLY 
I

I

1

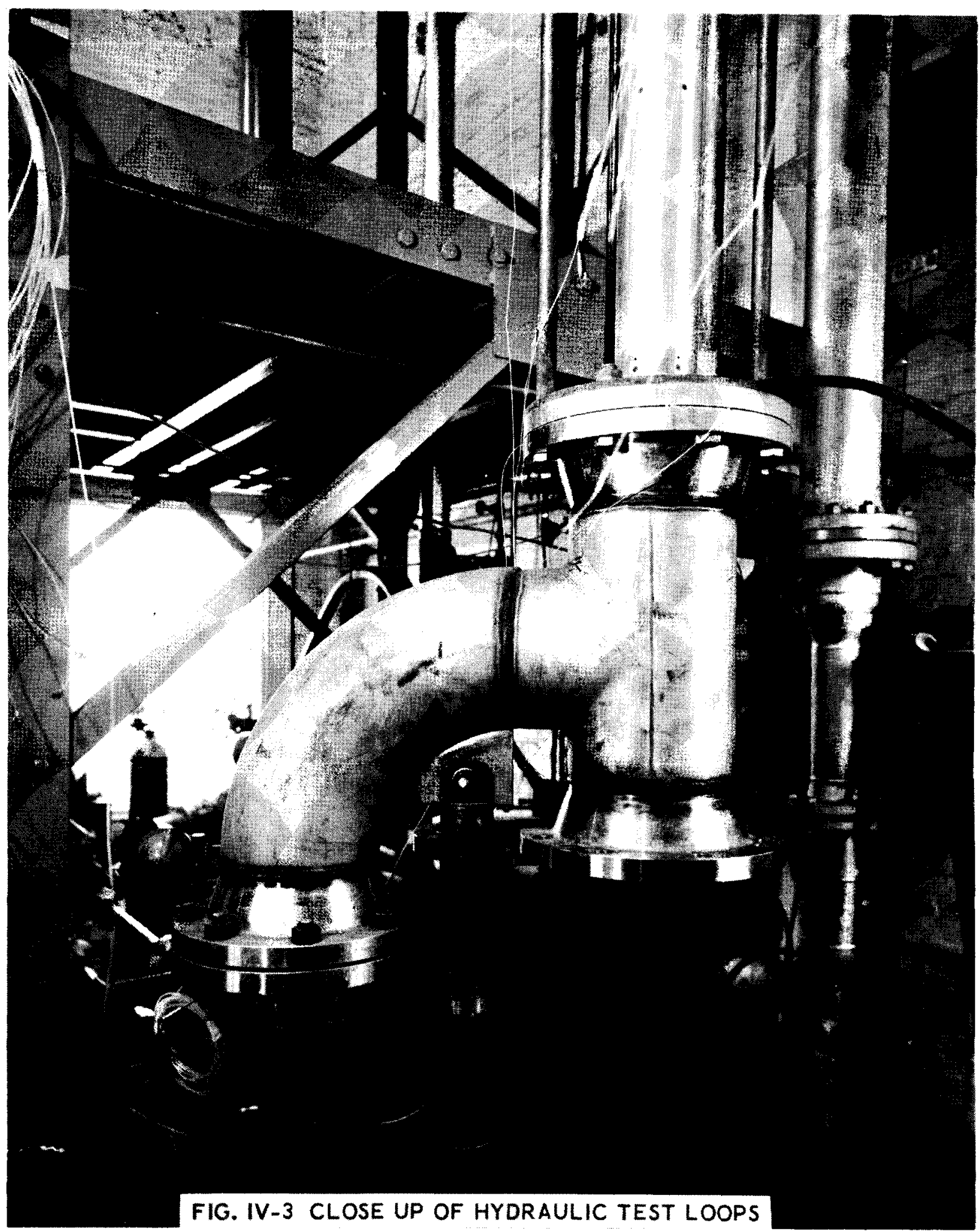




\section{LIQUID METALS}

\section{A. FACILITIES}

APDA has performed and continues to perform a wide variety of highly specialized tests concerned with the operation of liquid-metal systems. Almost all of these tests have been performed at the APDA Test Site, located at the Sibley Quarry in Trenton, Michigan. The buildings and structures located at this site are shown in Figures V-1 through V-4; specific test loops and equipment housed in these buildings and structures are discussed below.

\section{Hydraulic-Water Systems}

At present, APDA has two basic systems for studying hydraulic effects using water as the test fluid: (1) a four-inch, two-loop system for studying the hydraulic effects on fuel subassemblies, and (2) a series of small simulant loops for studying the hydraulic characteristics of piped particulate fuel systems. These loops are described in detail in Section IV.

\section{High-Temperature Sodium Loop}

Two-phase (solid-liquid) systems, such as uranium carbidesodium systems, have been studied in the high-temperature sodium loop shown in Figure V-5. A Mine Safety Appliance Company clectromagnetic pump with a $10 \mathrm{gpm}$ capacity at $40 \mathrm{psig}$ is used, and at present, a 2-inch-diameter, 58 inch-long test section is being used in the loop. Designed to test two-phase pressure drops, particle mobility and attrition, and component performance in connection with APDA's mobile fuel (paste) program, it is expected that the loop will be available for other work as of July 1, 1966.

Instrumentation used with this loop includes:

1. 2 Moore Model 50 Pressure Transducers; range 0 to 15 inches water

2. I Moore Model 50 Pressure Transducer; range 0 to 60 psi

3. 1 Minneapolis Honeywell temperature recorder, 24 point

4. I Minneapolis Honeywell temperature recorder, 16 point

5. 11 Magnetic flowmeters, gap-flux density, 4500 gauge, range 0 to $10 \mathrm{gpm}$, made at APDA

6. Level indicators (induction probes)

7. Rhometers

There are also carburization and erosion stations in the loop. 


\section{Sodium Endurance Loop}

APDA also has a sodium flow loop which is used for the endurance testing of fuel subassemblies (Figure V-6). The capacity of this loop is 300 gpm at a 200-foot head. The maximum operating temperature is $1150 \mathrm{~F}$. It can accommodate two complete Fermi-sized subassemblies, approximately 96 inches long, in an 8 -inch-diameter test section. The loop can be drained and can be used as a vacuum distillation cleaning apparatus for cleaning test specimens before their removal from the loop. As this is primarily an endurance loop, instrumentation is limited to flow rate, temperature, and pressure drop devices.

\section{Fuel Pin Meltdown Equipment}

APDA has conducted meltdown studies using a lead rod-water system to simulate the fuel rod-sodium system. Resistance heating of the rods was used. The power supply used was designed to deliver $60 \mathrm{kw}$. This equipment has been dismantled and the reusable equipment has been placed in storage.

\section{Sodium Technology Loop}

The loop (Figure $\mathrm{V}-7$ ) is designed for a maximum operating temperature of $900 \mathrm{~F}$ and a flow rate of $200 \mathrm{gpm}$. It consists of 1 -inch and 4 -inch interconnected stainless steel loops through which 100 gallons of liquid sodium are circulated. The loop is designed for the investigation of sodium systems, including the development and cvaluation of in-line instruments for the detection and determination of impurities in sodium and the development and evaluation of sodium purification techniques and devices. A schematic drawing of the loop is shown in Figure V-8.

\section{Sodium-Water Reaction Test, Rig-10}

Figure V-9 is a photograph of the support structure, which contains the loop and components. Some of the loop components are shown in Figure V-10. The instrumentation and control room is located in the concrete building on top of the cliff to the right side of the support structure.

The test stand and flow directions are shown schematically in Figure V-11. The test stand supports five main systems: (1) the sodium system, (2) the circulating water system, (3) the reaction water system, (4) the reaction products system, and (5) the nitrogen cover gas system.

During a small leak test, sodium will be circulated by a centrifugal pump from the bottom of the test unit through the filter tank and back to 
the test unit. Large particles will be removed from the sodium by a fine mesh filter screen, designed to be removed through the top of the filter tank for cleaning. The sodium system also contains a cold trap and dump tank.

The circulating water loop is made of Schedule 160 steel pipe and contains a pressurizer, air-cooled heat dump, and three quick-acting valves for emergency isolation. The system is pressurized from a 6000-psi nitrogen station. High purity boiler feedwater at 2650 psia and $600 \mathrm{~F}$ flows by natural circulation from the pressurizer down through the test coil where it is heated. The hot water passes through the air-cooled heat dump and returns to the pressurizer.

The reaction water supply is contained in a storage tank which is separate from the circulating water. The same high-purity water will be used as that used in the circulating system, and may be heated to $600 \mathrm{~F}$ with electrical heaters. The system is pressurized from the same 6000-psi nitrogen supply used to pressurize the circulating water system. The reaction water flows through a Schedule 160 steel pipe, which is flanged to the reaction water trigger tube. The line contains a quick-closing valve for emergency operation.

The reaction products can be vented through two paths during a reaction. During the tests the hydrogen, with entrained sodium, will be vented through the hydrogen cooling tank to the atmosphere. In the event of an uncontrolled reaction, the products will be discharged through the $24-$ inch rupture disc, located in a 30 -inch pipe, into a reaction products separator.

The test unit consists of a pressure vessel, 3 feet in diameter and 16 feet long, containing a removable bundle of tubes, one of which is a natural circulation water coil. The remaining tubes have nitrogen sealed inside. The bundle is approximately 2 feet high and is positioned at the bottom of the vessel under 10 feet of sodium.

The trigger tube assembly is installed and removed through the top flange of the test unit. This device is used to inject a controlled amount of water into the sodium for the reactions tests. The trigger tube is approximately 16 feet long with the flow control orifice for the reaction water located at the lower end and a set of valves and flange connections at the upper end that connect to the water and nitrogen supply vessels. The trigger tube or water injection device employs a hardened capillary with one end sealed shut and the other end brazed into the injection tube. The sodium-water reaction is triggered by mechanically breaking off the capillary tube.

7. Sodium-Water Reaction Test, Rig-33

A photograph and a schematic of the test rig are shown in Figures $\mathrm{V}-12$ and $\mathrm{V}-13$. The primary component of the rig is the reaction vessel which 
houses the injection device and test tube array. This calrod-heated vessel was fabricated from 10-inch, Schedule 40, carbon steel pipe and stands approximately 6 feet high. A bolted flange is provided at the top of the vessel for disassembly, and the vessel support is pivoted at its base so that the whole assembly can be lowered to a horizontal position to facilitate cleaning and disassembly.

A 6-inch, Schedule 40, mild steel pipe leads from the top of the vessel to a reaction products receiver tank. This line contains a hardened capillary with one end sealed shut and the other end brazed into the line, and also, a 2-inch by-pass line around the disc for relief of the reaction products for the low-leak-rate experiments. The reaction products receiver tank is filled with transformer oil which traps any particulate reaction products that are carried through the relief line.

The water injection system consists of a high-pressure 16,000 psig) nitrogen supply, a $1600 \mathrm{cu}$ in. surge tank connccted through a solenoid valve to a calrod-heated, 200-cu in. water reservoir and an injection nozzle (trigger tube).

\section{Under Sodium Scanner Test Apparatus}

The under sodium scanner, being developed to locate objects in high-temperature liquid sodium using ultrasonics, is described in Section III.

\section{Hydrogen Detector Test Loop}

Specifications for this loop are in the early stages of formulation. The loop will employ analytical instrumentation for continuous hydrogen detection and should be available for use in approximately two years.

\section{Oil-Fired Heater}

The oil-fired sodium-potassium (NaK) heater is a completely self-supported unit including steel casing, insulation, refractory, tubing, headers, burner, and related equipment. The heater unit consists of 40 banks of 1 -inch, Type 304 stainless steel tubes designed for 300 psi at $1000 \mathrm{~F}$. The tubes terminate at two 6-inch pipe headers, Type 304 stainless steel, each 5 feet 9 inches long. The rated heat input to the heater is $5.0 \times 10^{6} \mathrm{Btu} / \mathrm{hr}$ with an efficiency of 68.3 per cent. Based on a $\mathrm{NaK}$ flow of $30,200 \mathrm{lbs} / \mathrm{hr}$ at an inlet temperature of $450 \mathrm{~F}$, the temperature of the $\mathrm{NaK}$ leaving the heater is $900 \mathrm{~F}$. The unit is available as a heat source for a NaK system which is to be.used for purposes such as testing steam generators, heat exchangers, etc. 


\section{NaK Heater-Cooler Unit}

This unit may be used as a source of heat input into a sodiumpotassium ( $\mathrm{NaK}$ ) piping loop, or a heat sink in a $\mathrm{NaK}$ loop containing another source of heat input. It includes a heat exchanger, an oil-fired furnace for heating, and an air blower for cooling. When operating with either the oilfired furnace or the air blower, the unit is capable of exchanging 3,000,000 Btu/hr during either heating or cooling.

The unit will heat 117,000 pounds of $\mathrm{NaK}$ per hour from $810 \mathrm{~F}$ to $920 \mathrm{~F}$ using 10,000 pounds per hour of combustion gas cooled from $2130 \mathrm{~F}$ to $1060 \mathrm{~F}$; the $\mathrm{NaK}$ pressure drop is 1 psig. The design temperature of the heat exchanger is $1000 \mathrm{~F}$, and the design pressure is 150 psig on the tube side and atmospheric on the shell side.

The heat exchanger is a Griscom-Russel, Type RU, K-Fin section with $890 \mathrm{sq} f t$ of gross heating surface. It has twenty U-tubes, $1-1 / 2$ inches IPS, made of Schedule 40, Type 304 stainless steel; there are eight copper fins per inch of tube. The fins are 3.4 inches $O D$ and are clad with Type 304 stainless steel, 0.05 inch thick. The heat exchanger tubes terminate in two Type 316 stainless steel manifolds, 6-1/4 inches OD, 9/16 inch wall thickness.

The combustion chamber, manufactured by Alcorn Combustion Co., is 4 feet 6 inches in diameter and 12 feet long. The oil burner is at one end of the chamber, and the flue gas discharge at the other. These flue gases pass vertically through the heat exchanger to the stack.

The oil-fircd burner is a North American, Type 214 A-9, with a capacity of up to $45 \mathrm{gph}$ of No. 2 fuel oil delivered at 30 psig at $80 \mathrm{~F}$.

The cooling air blower is an American Blower Co., No. 360SISW, Series $81 \mathrm{HS}$, fan. It will deliver air at the rate of $104,000 \mathrm{lb} / \mathrm{hr}$ based on inlet air at $80 \mathrm{~F}$ and a 5 -inch water pressure.

\section{Chemistry Laboratory}

The chemistry laboratory is used both as a research group and as a service group for the liquid-metal programs. The laboratory is well equipped to handle the highly reactive sodium samples normally analyzed. Some of the more specialized equipment is listed below:

Dry Boxes - The laboratory presently contains two dry boxes, interconnected through vacuum ports, in which all sample manipulations are done in an inert argon atmosphere. Prior to entering the dry box, the argon is recirculated at the rate of $1500 \mathrm{cu} \mathrm{ft/hr}$ (an atmosphere change within the box every $3.4 \mathrm{~min}$ ) through a gas purifier which contains a bed of hot copper 
to remove oxygen and molecular sieves ( $5 \AA$ ) to remove carbon dioxide and moisture. The moisture level in the argon is maintained below $1 \mathrm{ppm}$ and is continuously monitored by a moisture monitor (Consolidated Electrodynamics Corp.). The oxygen level is measured periodically by gas chromatography and is maintained at less than $5 \mathrm{ppm}$. The atmospheric purity in the dry box is such that a freshly cut piece of sodium will remain for days without tarnishing.

\section{Gas Chromatographs - Two F\&M gas chromatographs, Models} 500 and 720 , are used to quantitatively measure the gases evolved from certain analytical procedures. The Model 500 is designed as a dual system. There are two separate cell systems in which helium and argon can be used as the carrier gas. This arrangement provides versatility in carrying out analytical measurements.

Atomic Absorption Spectrometer - The atomic absorption unit is being used in the development of methods for detecting trace metallic impurities in sodium, e.g., iron, nickel, chromium, and zirconium. 'The in. strument is capable of detecting some of these elements at concentrations as low as 0.1 ppm.

Mass Spectrometer - The mass spectrometer, Picker Corp., Model MS-10, has a mass range of 0 to 200 . It is being used to determine the gases evolved from the vacuum distillation of sodium and from the reactions of various compounds (e.g., water) with sodium.

Microscope - A light microscope equipped with lenses up to 1000 magnification is used in conjunction with particle size studies.

Spectrophotometer - A spectrophotometer is available for quantitative measurements in the range of visible light.

High-Vacuum Glass Systems - There are presently three specially designed high-vacuum glass systems in use in the laboratory. Each system is equipped with mercury diffusion pumps as well as the usual mechanical pumps, and each is capable of maintaining a vacuum at $10^{-8} \mathrm{~mm}$ of mercury.

One system is used for the vacuum-reflux method for determining hydrogen in sodium. This system is also equipped with a sensitive Cahn electrobalance. The second system is used to vacuum distill sodium away from the less volitile constituents present such as oxygen-containing and metallic impurities. The third system is being used to study the solubility of hydrogen in sodium. 

Control Rod Component, Drive Mechanisms, and Position Indicator Development and Testing

Large Component Model and Prototype Testing (Including Pumps and Heat Exchangers)

Valve, Seal, Pipe and Joint Development, and Testing (Including Thermal Shock)

Decontamination Process Development

Reactor Control and Data Display Instrumentation

Nuclear Instrumentation (Including Flux and Fuel Failure)

Nonnuclear Process Monitoring Instrumentation (Temperature, Pressure, and Sodium and Cover Gas Purity, Flow, Leak, and Level)

Radiation Effects

In-Line Instrument Development for the Detection of Sodium Impurities

\section{PROGRAMS AND ACCOMPLISHMENTS}

\section{Endurance and Hydraulic Testing}

APDA has conducted numerous endurance and hydraulic tests of the fuel components for the Fermi reactor using, among other facilities, the hydraulic water systems, and the sodium endurance loop. Extensive testing of Core A subassemblies was carried out, both in water and in sodium, including (1) a flow endurance test establishing the mechanical reliability of core and blanket subassemblies, (2) dimensional stability tests of core subassemblies to determine whether reactor temperatures could cause a permanent set in the subassemblies, (3) flow velocity measurements, (4) and the rmal cycling phase change tests. In addition, a similar effort was expended on actual and simulated Core B elements which were also tested in both water and sodium. This work included (1) hydraulic testing of the actual flat-plate elements to determine pressure drop as a function of water flow under various misalignment settings of the core seal strips, and (2) endurance and annulus flow tests on the simulated Core $B$ elements. A description of these programs can be found in APDA-143, "Summary of the APDA Fuel Development Programs."

Currently, APDA is preparing the final report on Fuel Element Flow Stability Studies, AEC Contract No. AT(11-1)-865, Project Agreement No. 12. The fuel element flow stability project, an isothermal hydraulic study, was designed to determine the hydraulically induced forces acting on the fuel rods of a fuel rod assembly. The testing effort of the study comprised a series of tests conducted on simulated, spiral-wire-spaced fuel rod configurations, using hot water as the test fluid. The associated analytical effort was directed at trying to establish the force distribution arising from combined thermal, mechanical, and hydraulic effects acting on fuel assemblies in liquid metal systems. 
2. Paste Concept for Fast Reactor Blanket Application, AEC Contract No. AT(11-1)-865, Project Agreement No. 8

The purpose of the project is to investigate the application of the APDA paste fuel concept to future fast breeder reactor blankets. This is a concept of a mobile-fueled system which is operated in the reactor as a settled bed of particles and handled externally as a slurry in a sodium carrier. The first phase of the project included a comparison of a paste blanket with other blanket concepts, and a conceptual design of a paste blanket for a large fast breeder reactor of an advanced design. The current objective of the project is a proof-of-principle demonstration of the conceptual paste blanket utilizing an in-pile irradiation loop.

3. Fast Reactor Fuel Meltdown Studies, AEC Contract No. AT (11-1) -865 , Project Agreement No. 5, Task 1

This program was an experimental and an analytical effort designed to produce a better understanding of meltdown accidents in a sodium-cooled fast reactor fueled with uranium-alloy pin-type elements. The approach was to perform dynamic mockup tests using lead and water in substitution for uranium alloy and sodium, respectively, and electrical resistance heating to simulate fission heating (Fuel Pin Meltdown Equipment). This work is reported in APDA-155, "Study of Fast Reactor Meltdown Accidents Using Simulant Materials."

4. Sodium Technology Loop Program, AEC Contract No. AT(11-1)865, Project Agreement No. 11

A continuing Commission-sponsored program has involved the use of APDA's sodium technology loop. This program covers the evaluation of inline instruments for the qualitative and quantitative detection of the more common liquid-sodium impurities such as carbon, hydrogen, and oxygen. More recently, APDA has added experimental purification devices to the loop to study their effectiveness as clean-up devices. Two types of impurity monitoring devices are being evaluated at present: the Rhometer and the oxygen meter. In addition to the Rhometer and oxygen meter, a detector is being developed for the monitoring of hydrogen in sodium. The principle of operation is the diffusion of hydrogen through a metallic barrier, the catalytic oxidation of the hydrogen as it emerges from the metallic surface, and detection of the water produced with a precision moisture monitor.

Three Rhometers and four of the United Nuclear Corporation oxygen meters are being evaluated for their response to conditions of steadystate impurity level and of increasing and decreasing impurity level. In addition the Rhometer's response to various types of impurities is being evaluated. Also, a temperature compensator is being developed for the 
Rhometers and will automatically correct for temperature variations, and the oxygen meters are being evaluated for their response to conditions of increasing and dccreasing temperature level. Concurrent with the evaluation of these two monitoring devices, purification devices being evaluated include a supercentrifuge, hot trap, cold trap, filters, and hydroclones.

\section{Small Leak Sodium-Water Reaction, AEC Contract No. AT (11-1)-865, Project Agreement No. 10}

In support of the AEC's sodium-heated steam generator development program, APDA was awarded a contract to conduct a series of sodiumwater reaction tests. A program was established to investigate the effect on tube wastage of a small leak of water into sodium. The variables controlling the factors that affect tube wastage were reviewed and a statistical program outlined for the study of the four most important variables at two levels. This work will be done in Rig-10, a relatively large installation. The rig size was based on simulating the dynamics of a steam generator and the necessity of accommodating the reaction products resulting from water leaks lasting approximately 5 to 15 minutes.

In order to attempt to control wastage, a better understanding of the cause or mechanisms of wastage must be acquired. Review of existing information on experimental programs and the Fcrmi incident suggest that tube wastage is the result of a complex combination of mechanisms rather than merely rapid corrosion. Tests in both bench-scale apparatus and in Rig-33 will be made to establish the cause of wastage and to obtain some feeling for the significance of the variables in the Rig-10 tests. The bench tests $w i l l$ be directed more towards establishing the mechanisms of wastage while Rig33 will serve as a shakedown facility for unproven components and equipment which will be used in Rig-10 and to investigate some of the Rig-10 variables.

\section{Under Sodium Scanner, AEC Contract No. AT(11-1)-865, Project Agreement No. 14}

APDA is engaged in a research program to develop an ultrasonic scanning device which will locate objects in high-temperature liquid sodium and transform the reflected sound waves into an image. In this connection, the successful development of an ultrasonic beam orientation has been made possible by work done by APDA in determining the attenuation of sound waves in liquid sodium and in developing a transducer which operates at the high temperatures. of interest. This work is reported in APDA-180, "Attenuation Measurements of Sound and Performance of Ultrasonic Transducers in $600 \mathrm{~F}$ Liquid Sodium."

Conceptual designs of two practical methols for viewing objects immersed in liquid sodium have been advanced by APDA: the single transducer 
scanner and the electronic acoustic image conversion system. APDA-179, "Concepts for General Purpose of Under Sodium Scanning Systems" is a presentation and discussion of the conceptual designs proposed by APDA.

\section{Sodium-Heated Steam Generator Development}

Another aspect of liquid-metal technology in which APDA has pioneered is the development of once-through, single-walled, sodium-heated steam generators. For this reason, APDA's Steam Generator Test, a completely intergrated facility for testing liquid-metal-fired steam generators, was constructed. Before it was dismantled, a prototype of a horizontal Ushaped steam generator was evaluated in this facility as well as a vetical, bayonet-type, once-through unit.

AEC-sponsored steam generator development projects undertaken by APDA have included a compilation of design information on steam generators, published as TID Report 18072, and a brief study of economically optimum steam conditions and cycles for large sodium-cooled nuclear power plants. Currently APDA is serving as a consultant to Babcock \& Wilcox Compnay on an AEC contract to design a 1000-Mwt steam generator and to design and build a 30-Mwt prototype. A report on this work, AEC Contract No. AT(11-1)-1280, Subcontract No. 1, can be found in APDA-176, "Analysis of the Babcock \& Wilcox Full Size Steam Generator for a Sodium-Water Reaction."

\section{APDA Reactor Components Test}

APDA's responsibilities with respect to the Fermi plant have included the research, development, and conceptual design of the reactor-steam portion of the plant, as well as the conceptual design of the entire plant. In this regard, APDA's largest single undertaking was the development, construction, and testing of the world's largest sodium system for nuclear purposes..the APDA Reactor Components Test, now an integral part of the Enrico Fermi plant. To carry out this task, APDA evolved the conceptual design, wrote the procurement specifications, and purchased and supervised the fabrication and installation of the reactor vessel, primary shield tank, rotating shield plug, hold-down mechanism, fuel-handling mechanisms, safety rod drive, primary sodium pump, piping, and instrumentation. These components, together with sodium purification equipment and temporary heater-cooler facilities, were assembled into a full-sized mechanical and hydraulic test of the reactor and one primary coolant loop. APDA-147, "APDA Reactor Components Test," is a review of this work.

\section{Sodium Loss Test}

The sodium loss test considers a malfunction in the fuel transport cask car of the Fermi plant, wherein (1) failure of blowers reduces cooling so that the sodium temperature within a finned pot containing a heat-generating 
subassembly reaches an equilibrium temperature in the range of $700 \mathrm{~F}$ to $1000 \mathrm{~F}$, and where (2) the cooling malfunction may also cause seal leakage and resulting contamination of the cask car argon atmosphere by air. Assuming these conditions, the test attempts to ascertain whether the time rate of loss of sodium from the pot due to evaporation, chemical reaction, etc., could be high enough so that the sodium level could drop enough to uncover any portion of the fuel pins. Still in process, the full requirements of this test, which began in January 1964, are to measure the rate of sodium loss as a function of ranges of the following variables:

1. Sodium surface temperature, $750 \mathrm{~F}$ to $900 \mathrm{~F}$

2. Argon purity, 20 to 100 ppm of oxygen (Other reactive impurities will be neglected because of their low quantity ratio to oxygen.)

3. Enclosure (condenser) inside wall temperature, $200 \mathrm{~F}$ to $300 \mathrm{~F}$

4. Ratio of sodium surface area to enclosure (condenser) surface area, $1: 800$ to $1: 3000$.

5. Effect of pot lip height above surface

10. Safety Analysis Capability and Fxperience

Many of APDA's programs, particularly in respect to the Enrico Fermi plant have involved liquid-metals safety analysis. A summary of APDA's Fermi work can be found in "Technical Information and Hazards Summary Report." Also, discussions of APDA's work in accident containment can be found in "Design Considerations for an Atomic Power Reactor Containment Structure," ASME 57-NESC-116, and "Sodium-Air Accident Study for a Sodium Cooled Reactor," TM-20. In addition, APDA-303, "Development of the Machinery Dome for the Enrico Fermi Fast Breeder Reactor, "is cur rently in preparation and presents a further review of APDA's experience in containment analyses. APDA's Sodium Loss Test Program, and the Small Leak Sodium-Water Reaction Program are discussed in previous sections.

\section{PUBLICATIONS}

In addition to those publications mentioned in the text, APDA publications on liquid-metal technology include the following:

Sodium Components Test Facility (APDA-134)

Sodium Water Reaction Test (APDA Test Memo No. 29)

Evaluation of the Blake Sodium Resistivity Meter (APDA-149)

Liquid Metal Heat Transfer in Nuclear Power Reactors (1962 Nuclear Congress) 
Carbon in the Primary Sodium System of the Enrico Fermi Power Plant (TM-35)

Application of Gas Chromatography to the Determination of Carbon in Sodium

Operation of the Sodium Technology Loop for Contamination Meter Evaluation (APDA-163)

Determination of Carbon in Sodium by a High-Temperature Combustion Method Utilizing Gas Chromatography (APDA-164)

Determination of Carbonate Carbon in Sodium Metal (APDA-166)

Literature Review of Sodium - Water Reaction (APDA-167)

The Determination of Oxygen in Sodium (APDA-168)

The Determination of Hydrogen in Sodium Metal (APDA-183) 


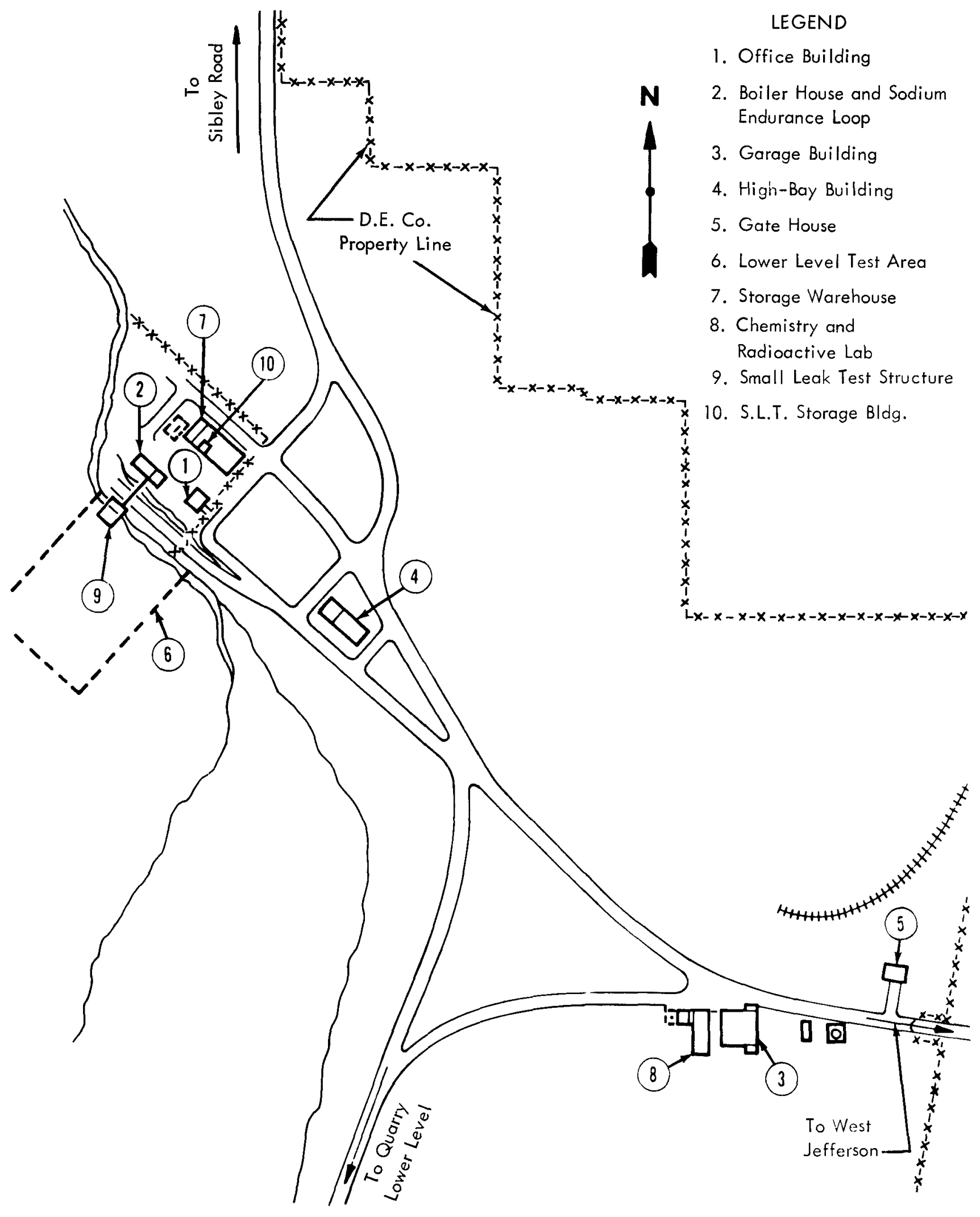

FIG. V-1. PLOT PLAN OF FACILITIES AT APDA TEST SITE 


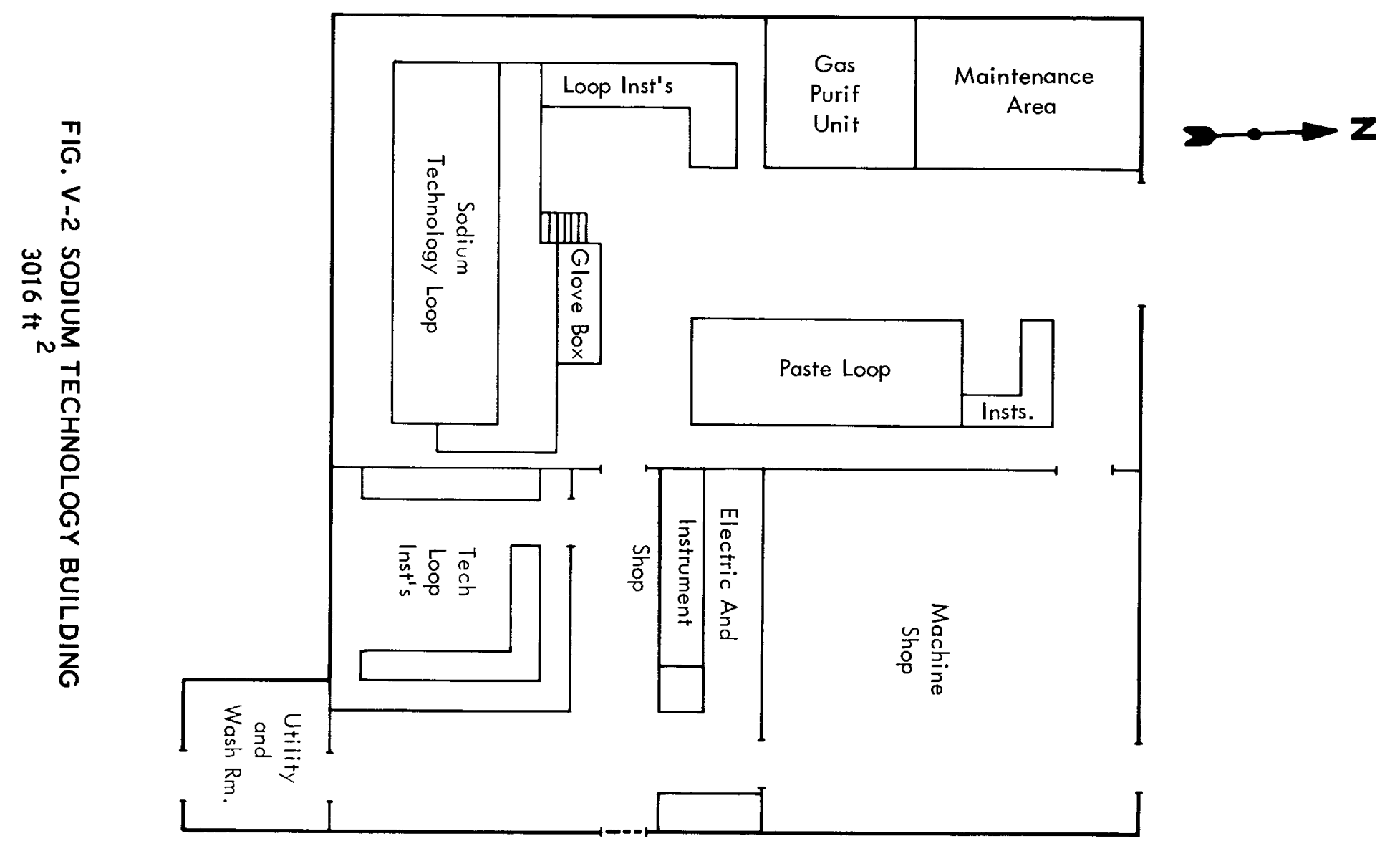



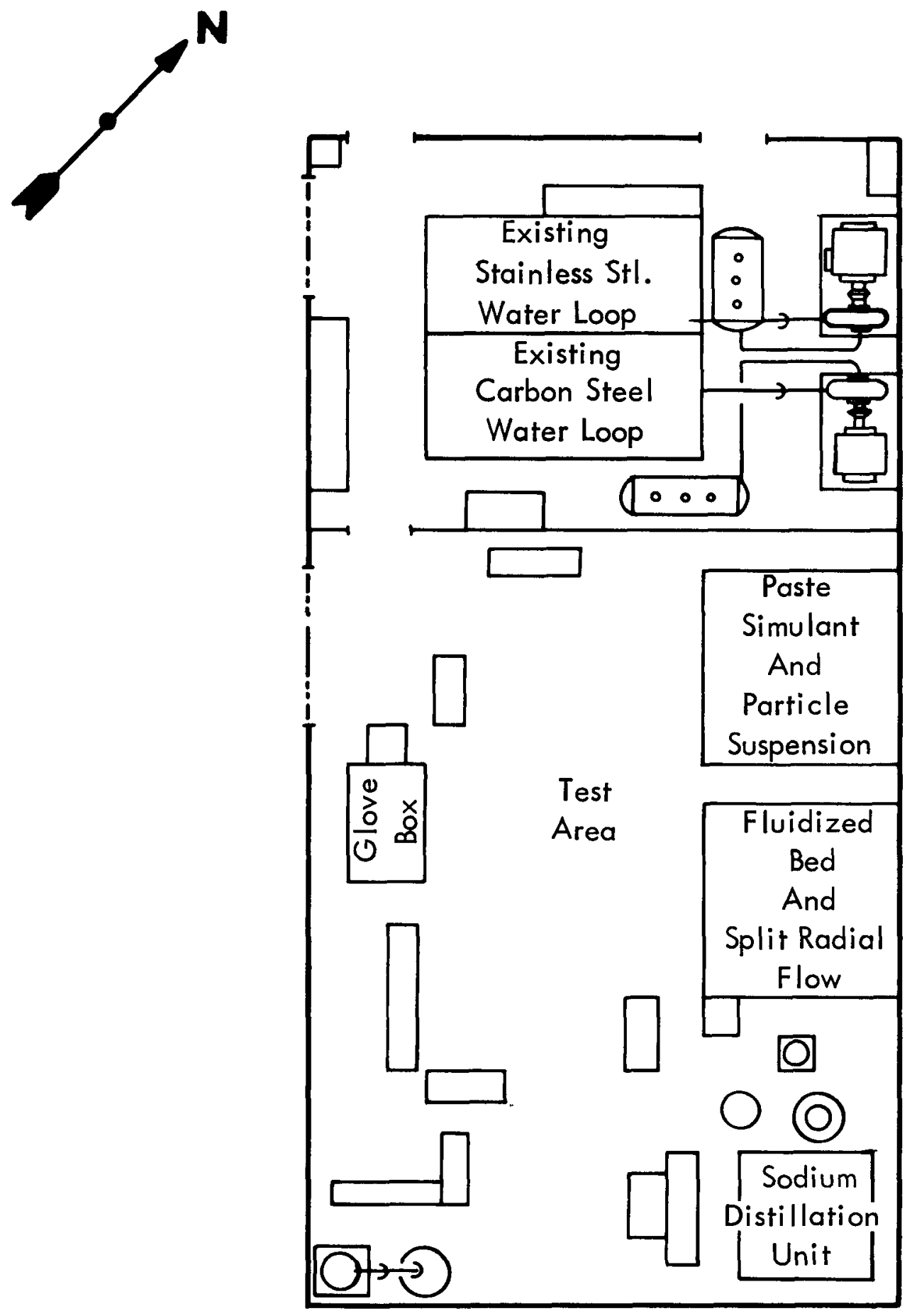

FIG. V-3 HIGH - BAY BUILDING $1800 \mathrm{ft}^{2}$ 


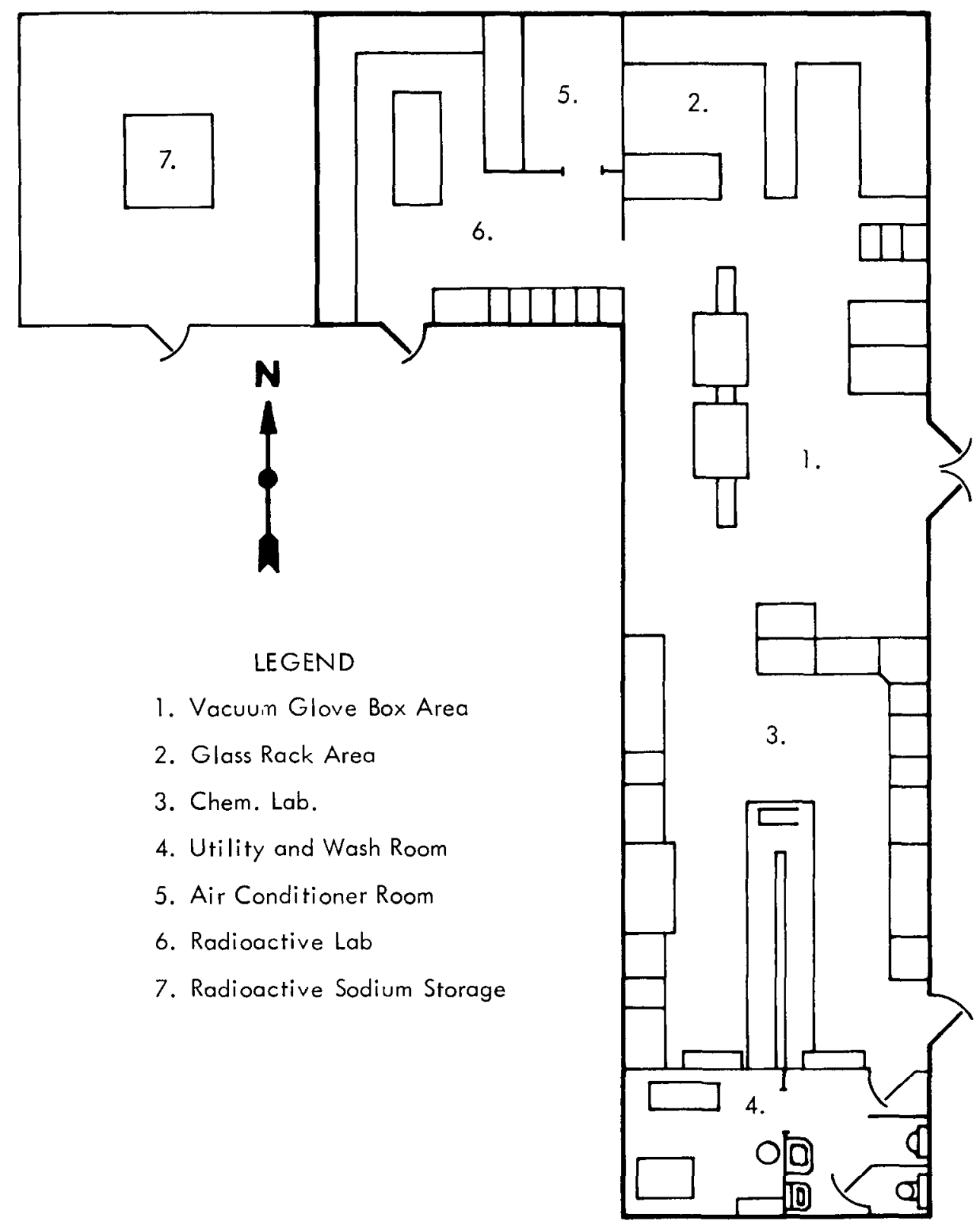

FIG. V-4. CHEMISTRY AND RADIOACTIVE LABORATORY

1730 it.? 


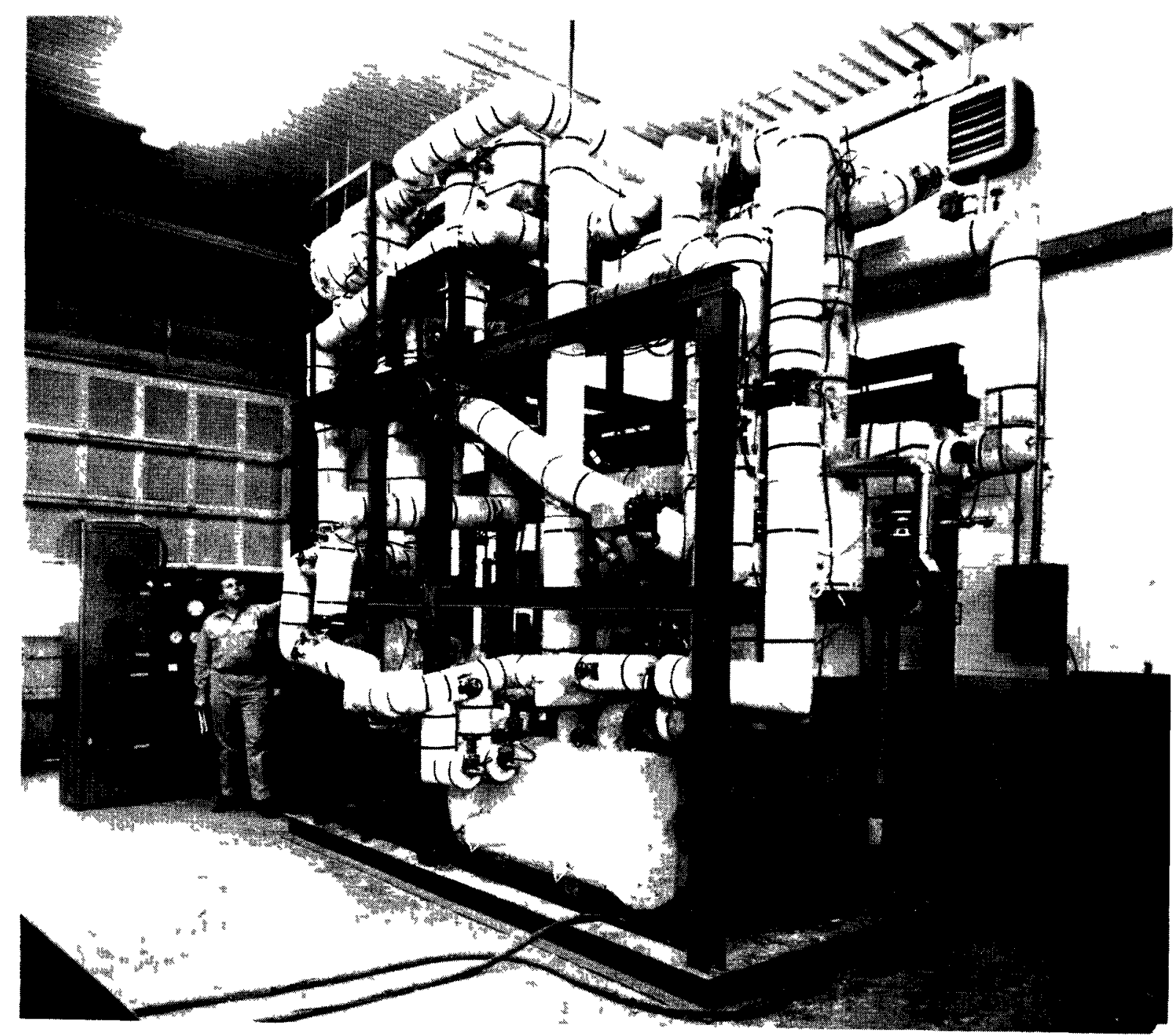

FIG. V-5 HIGH-TEMPERATURE SODIUM LOOP 


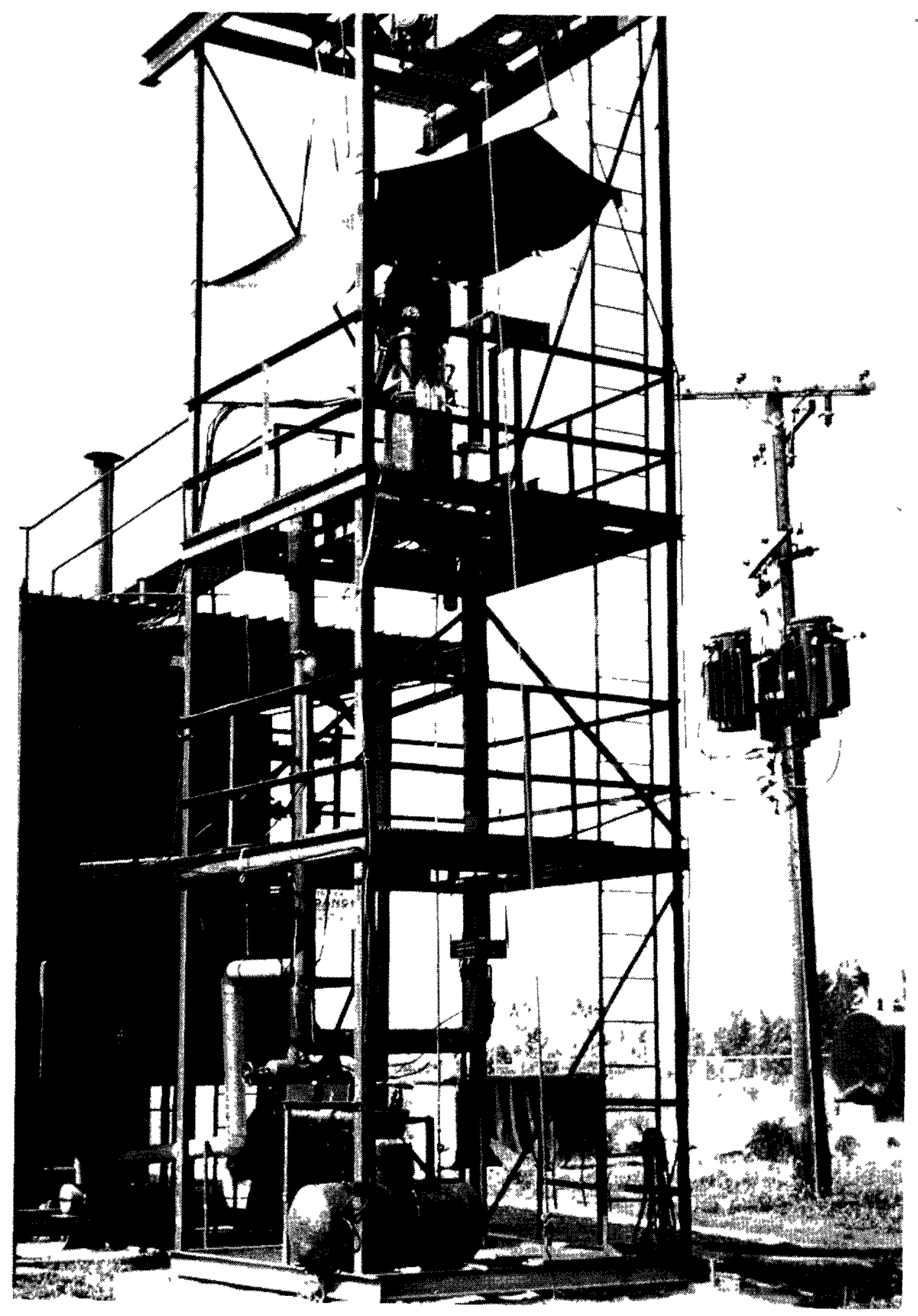

FIG. V-6 SODIUM ENDURANCE LOOP 


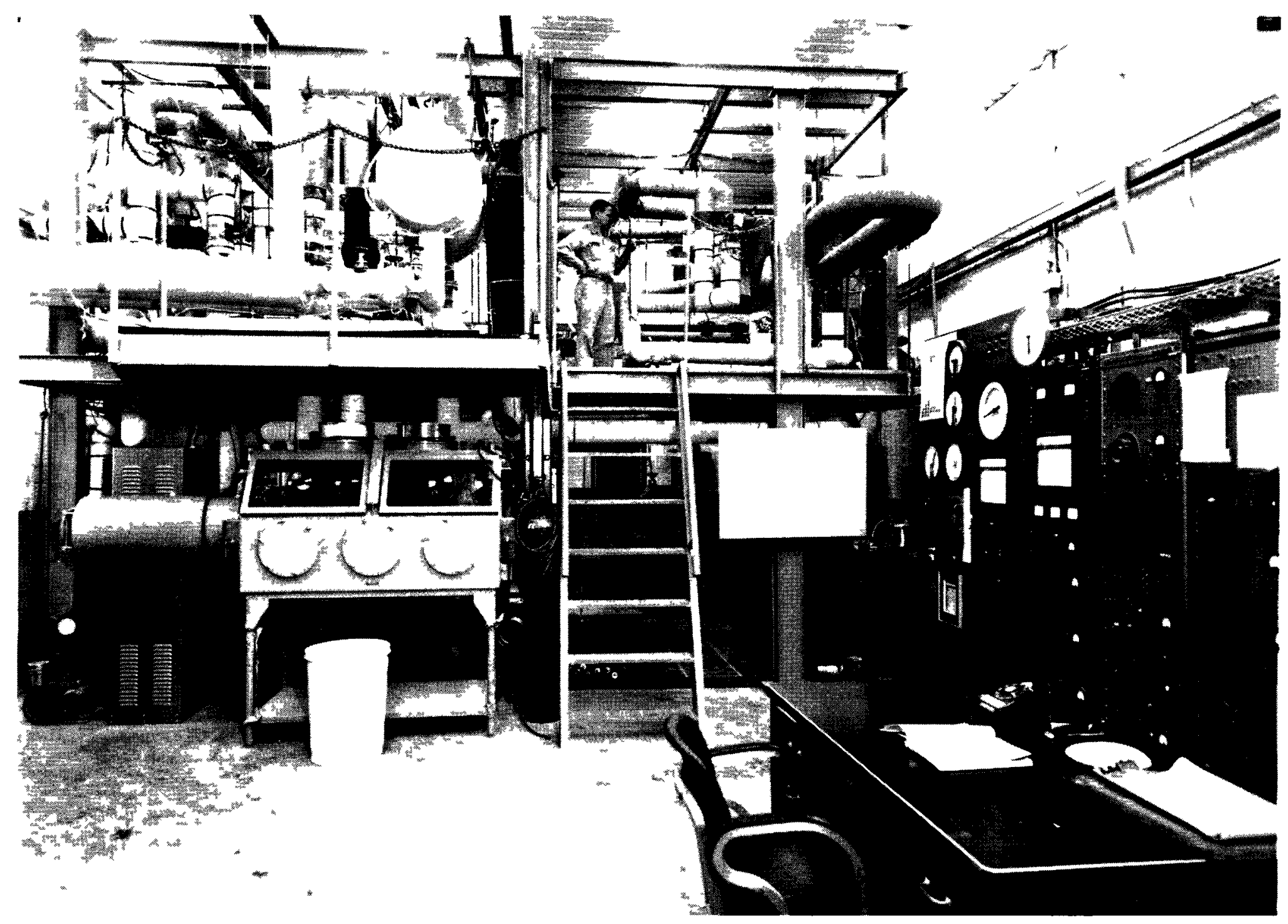

FIG. V-7 SODIUM TECHNOLOGY LOOP 


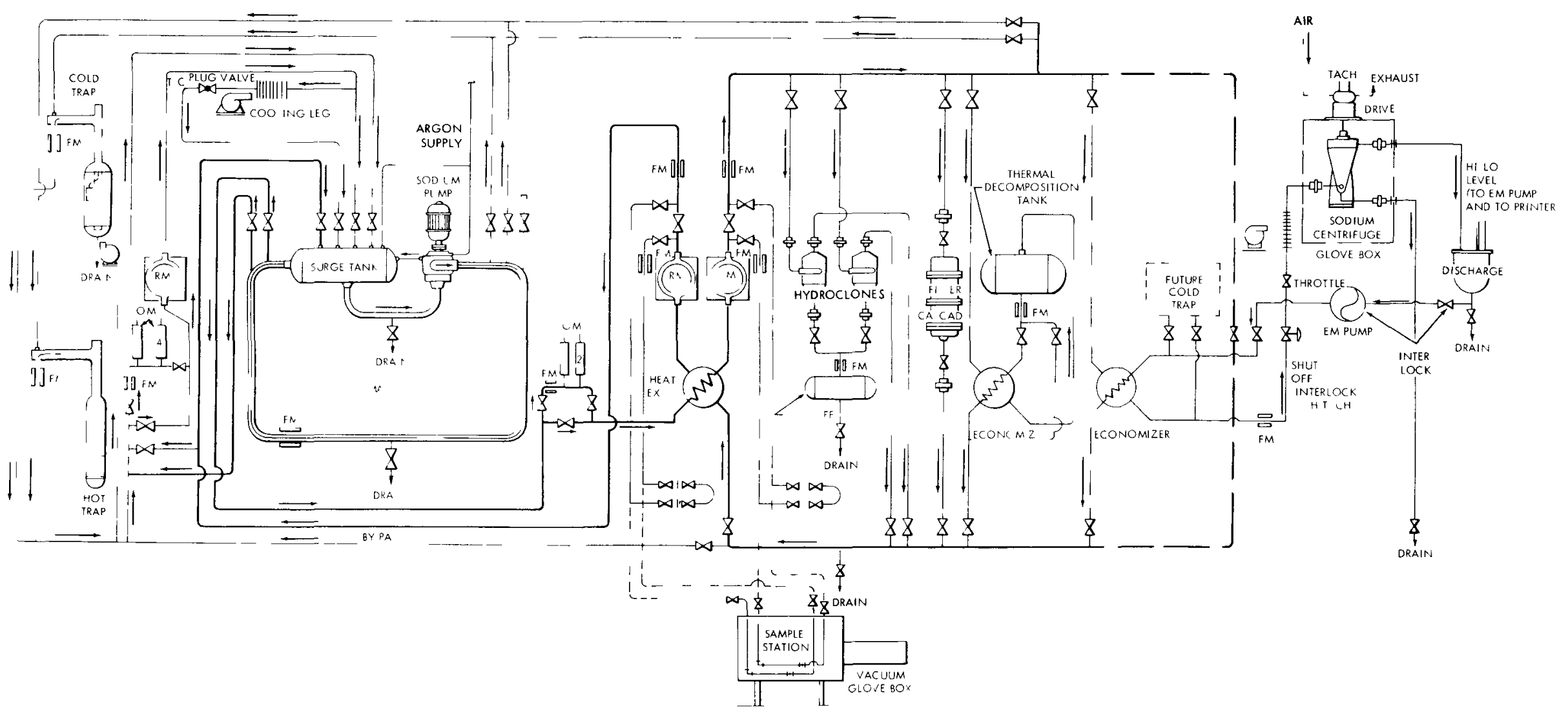

FIG. V.8 SCHEMATIC OF SODIUM TECHNOLOGY LOOP 


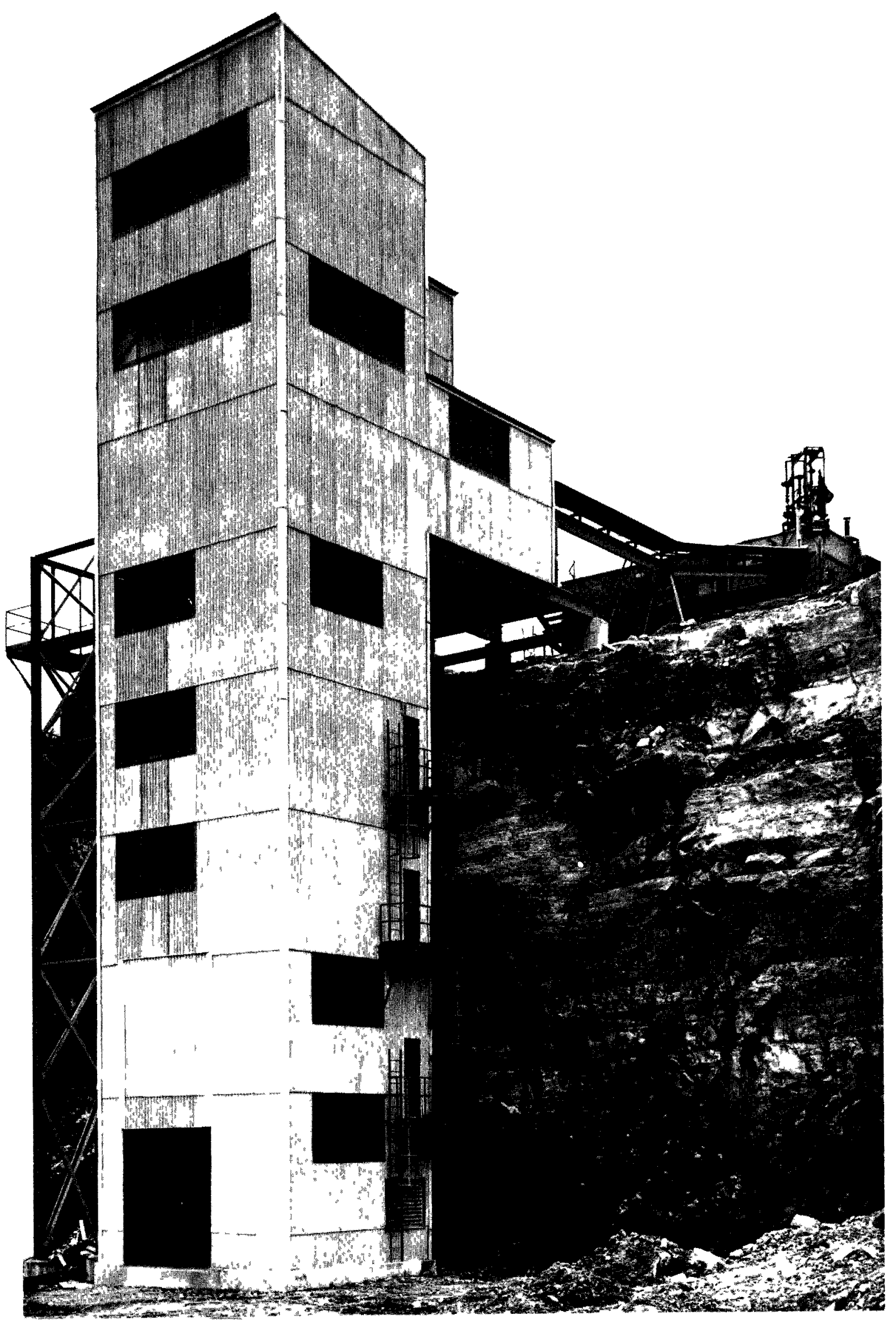

FIG. V-9 101-FOOT SUPPORT STRUCTURE FOR SODIUM WATER REACTION TEST, REG 10 


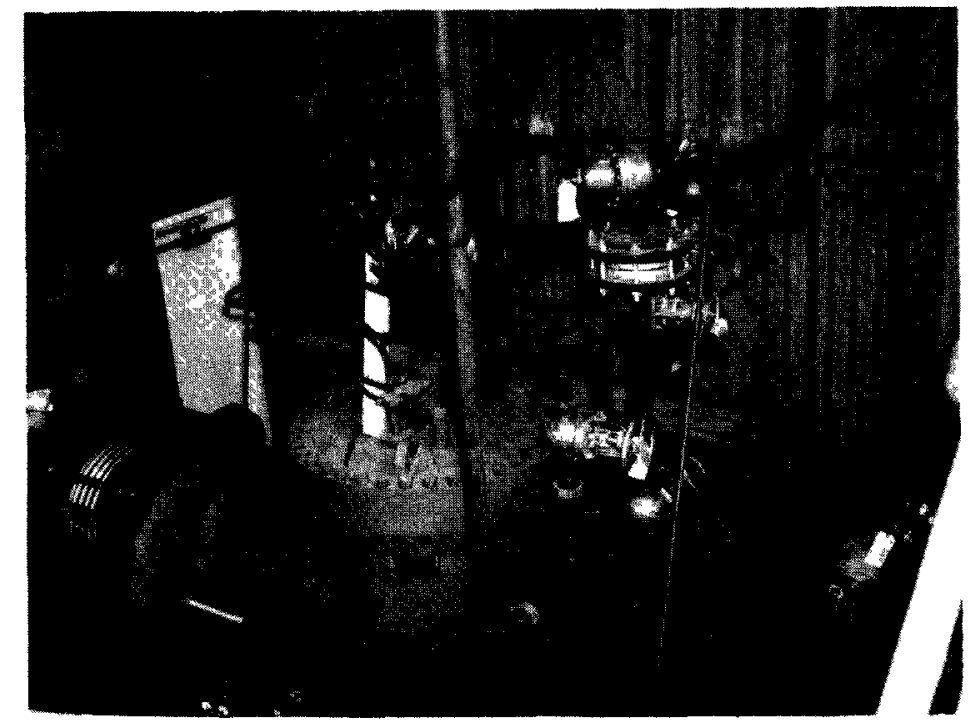

TOP OF REACTOR VESSEL SHOWING

24 -INCH PIPE LEADING TO THE SEPARATOR

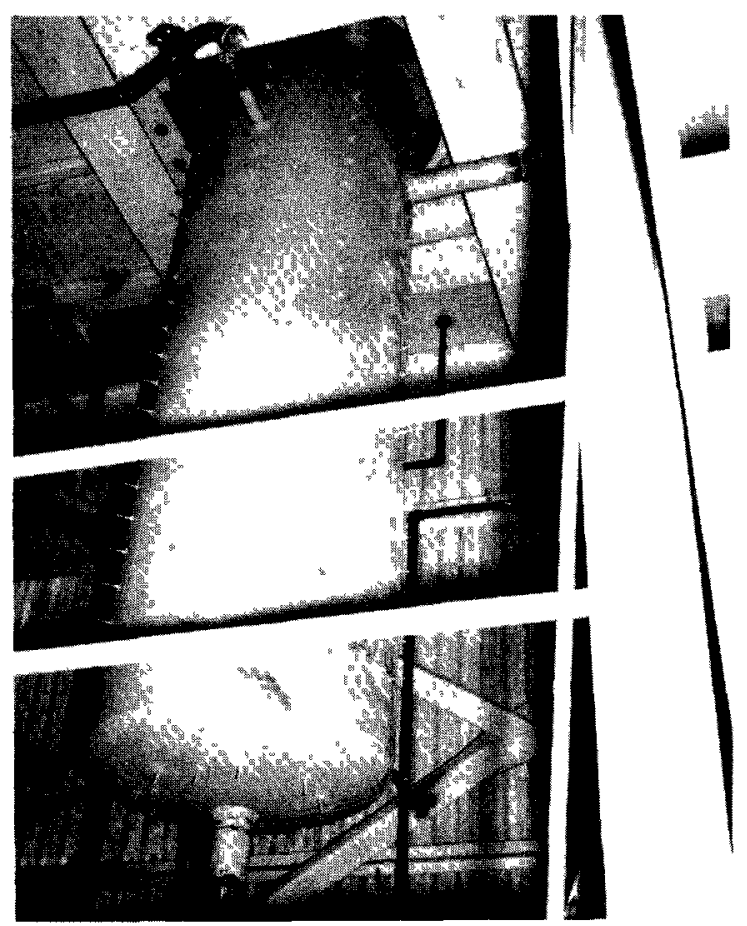

BOTTOM OF REACTOR VESSEL

FIG. V-10 REACTOR VESSEL, RIG 10 


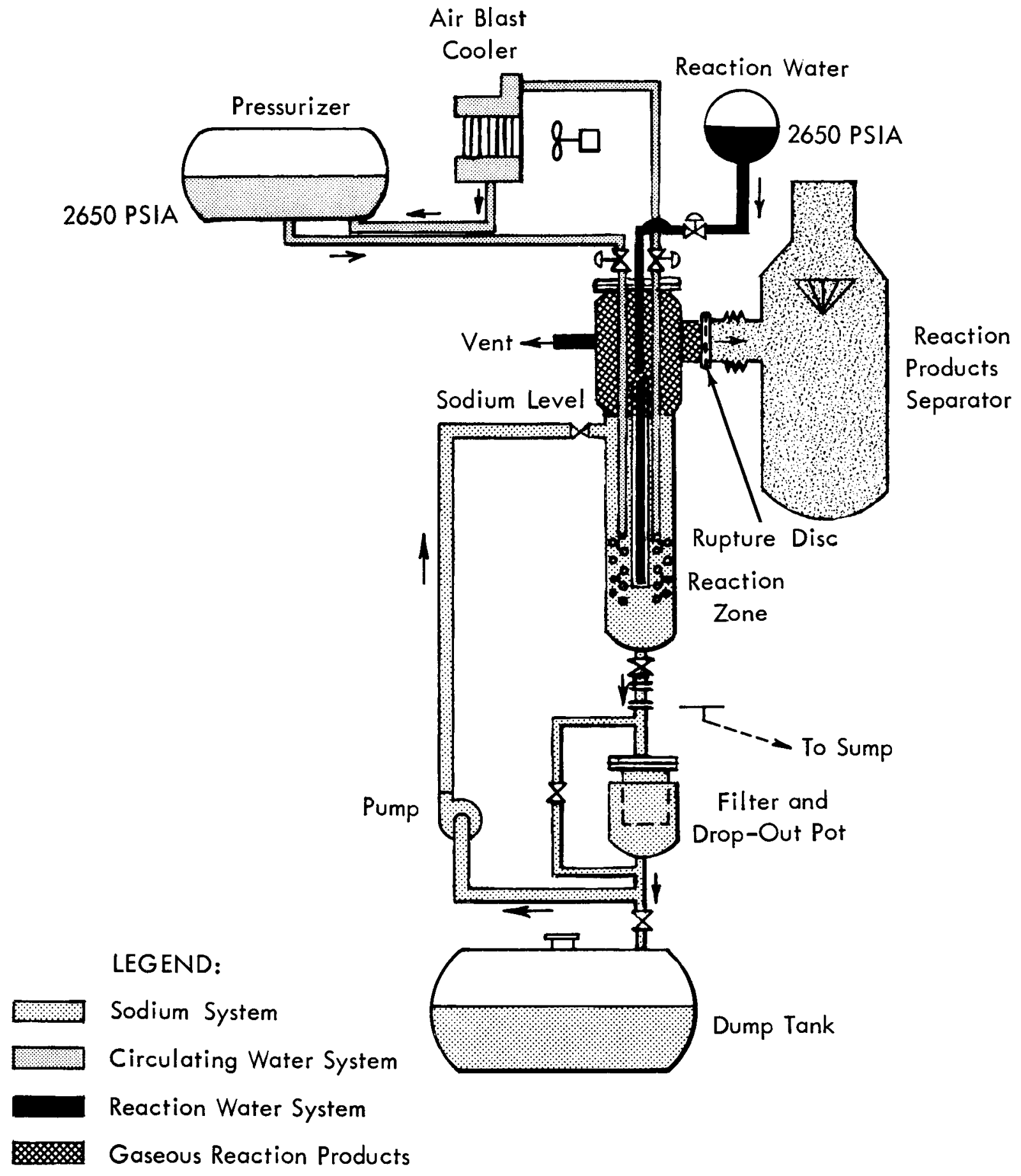

FIG. V-11 SCHEMATIC OF SODIUM - WATER REACTION TEST, RIG 10 


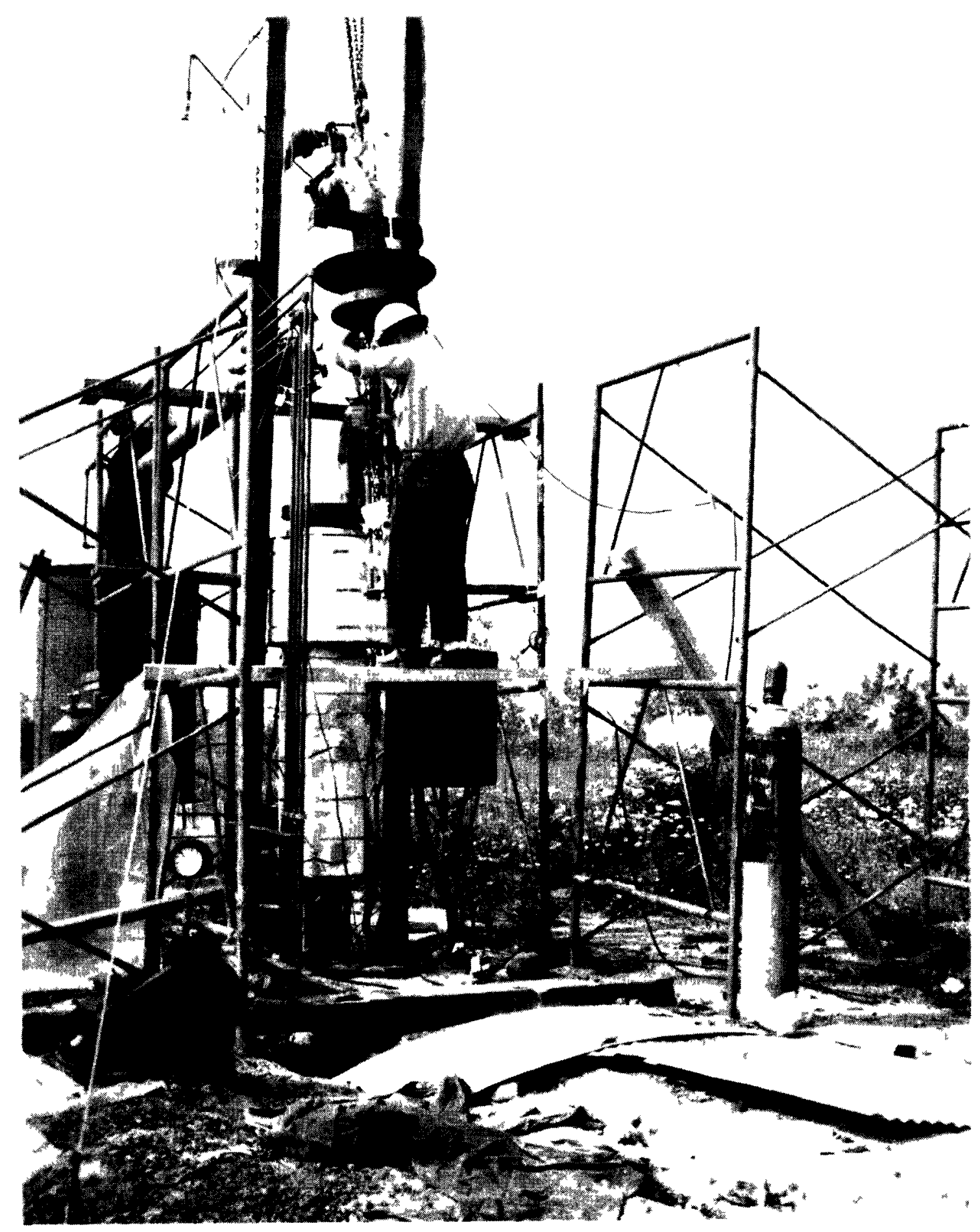

FIG. V-12 SODIUM - WATER REACTION TEST, RIG 33 


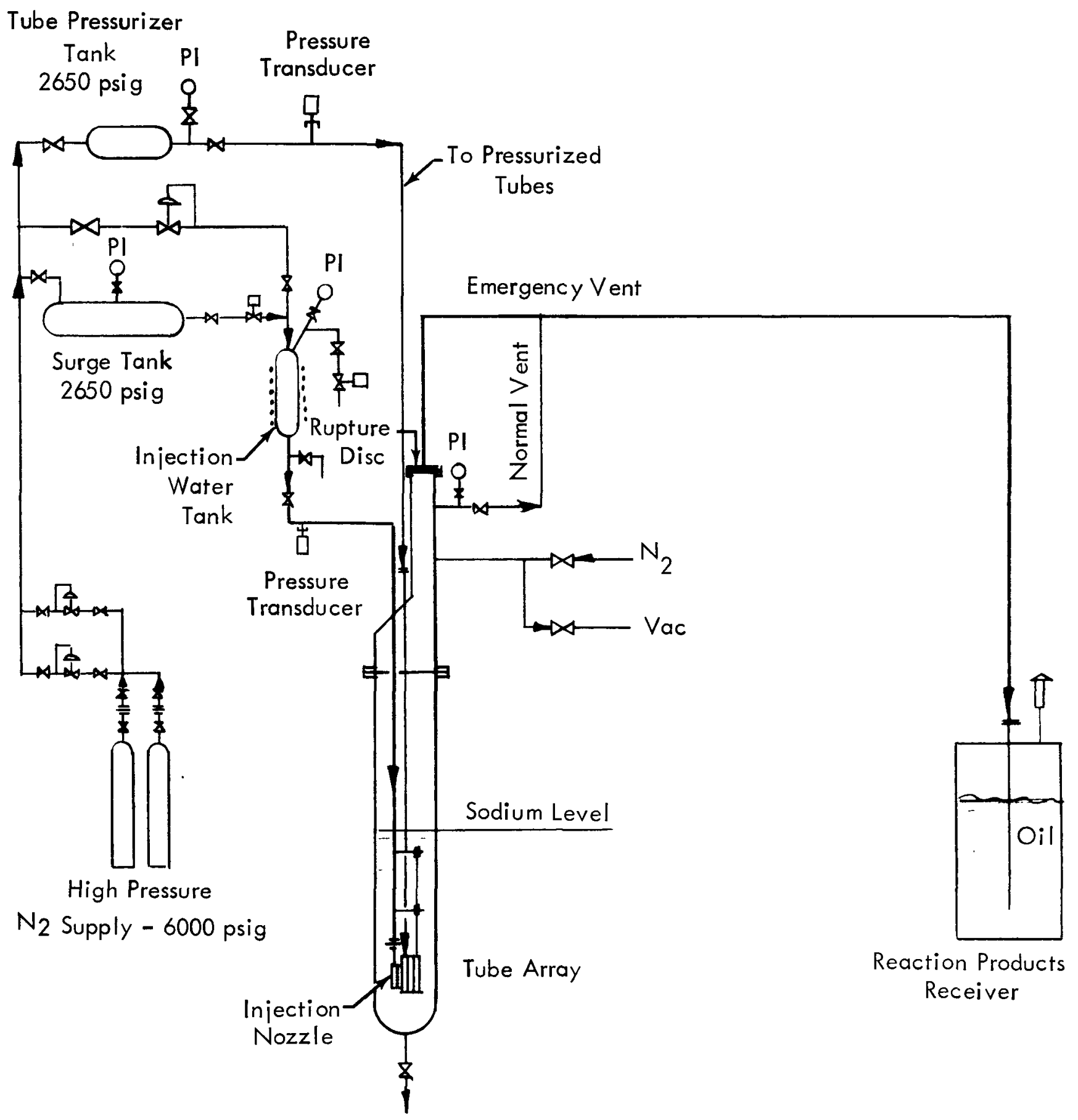

FIG. V-13 SCHEMATIC OF SODIUM WATER REACTION TEST, RIG 33 